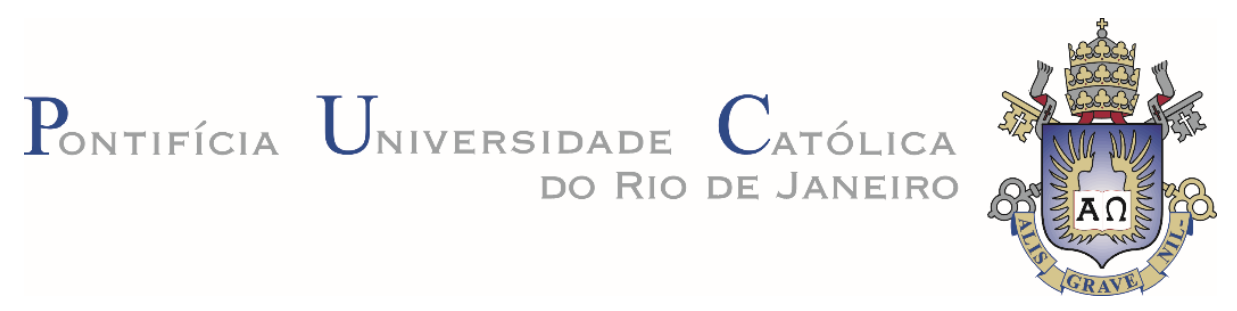

Rodrigo Villela de Faria

Teoria e Aplicação de Equivalentes Dinâmicos na Rede Elétrica

Brasileira

Dissertação de Mestrado

Dissertação apresentada como requisito parcial para obtenção do grau de Mestre pelo Programa de PósGraduação em Engenharia Elétrica da PUC-Rio.

Orientador: Prof. Armando Martins Leite da Silva Coorientador: Prof. Jorge L. A. Jardim

Rio de Janeiro

Março de 2019 


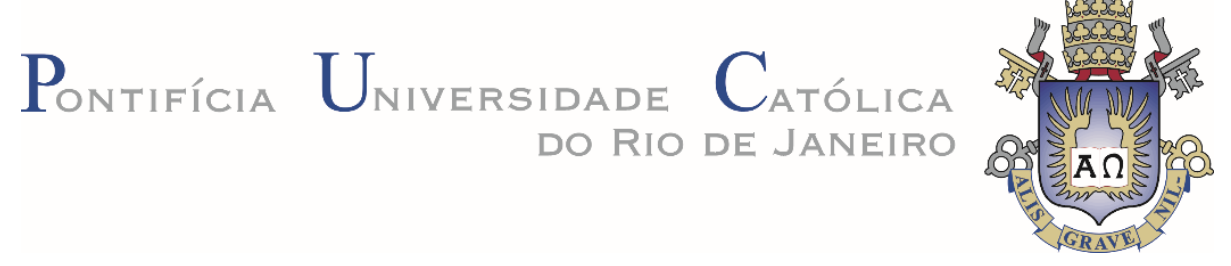

Rodrigo Villela de Faria

\title{
Teoria e Aplicação de Equivalentes Dinâmicos na Rede Elétrica \\ Brasileira
}

Dissertação apresentada como requisito parcial para obtenção do grau de Mestre pelo Programa de Pós-Graduação em Engenharia Elétrica da PUC-Rio. Aprovada pela Comissão Examinadora.

\author{
Prof. Armando Martins Leite da Silva \\ Orientador \\ Departamento de Engenharia Elétrica - PUC-Rio \\ Prof. Jorge L. A. Jardim \\ Coorientador - HPPA
}

Prof. Zulmar Soares Machado Júnior

UNIFEI

Dr. Carlos Alberto da Silva Neto

ONS

Rio de Janeiro, 27 de Março de 2019 
Todos os direitos reservados. É proibida a reprodução total ou parcial do trabalho sem autorização da universidade, do autor e do orientador.

\section{Rodrigo Villela de Faria}

Graduou-se em Engenharia Elétrica pela Universidade Estadual do Rio de Janeiro em 2008. Trabalha como engenheiro de planejamento da operação do sistema elétrico no Operador Nacional do Sistema - ONS.

Ficha Catalográfica

Faria, Rodrigo Villela de
Teoria e aplicação de equivalentes dinâmicos na rede
elétrica brasileira / Rodrigo Villela de Faria; orientador: Armando
Martins Leite da Silva; co-orientador: Jorge L. A. Jardim. - 2019.
101 f. : il. ; $30 \mathrm{~cm}$
Dissertação (mestrado)-Pontifícia Universidade Católica
Inclui bibliografia
1. Engenharia Elétrica - Teses. 2. Equivalentes estáticos.
3. Equivalentes dinâmicos. 4. Avaliação de segurança online. 5.
Planejamento da operação de grandes sistemas. 6. Simulação em
tempo real. I. Silva, Armando M. Leite da. II. Jardim, Jorge Luiz de
Araújo. III. Pontifícia Universidade Católica do Rio de Janeiro.
Departamento de Engenharia Elétrica. IV. Título.

CDD: 621.3 


\section{Agradecimentos}

Aos meus pais, pelo apoio e a paciência.

À minha esposa, pelo seu amor incondicional e apoio.

Ao orientador, professor Armando Martins Leite da Silva, pela dedicação, apoio, disposição, e paciência, permitindo meu crescimento acadêmico e profissional.

Ao coorientador, professor Jorge Jardim, pelo acolhimento, incentivo, suporte e acompanhamento deste trabalho.

Aos colegas, Agílio Coutinho e Carlos Neto, pelo auxílio ininterrupto e eficaz.

Finalmente, agradeço à PUC-Rio pelos auxílios concedidos, sem os quais este trabalho não poderia ter sido realizado.

O presente trabalho foi realizado com o apoio da Coordenação de Aperfeiçoamento de Pessoal de Nível Superior - Brasil (CAPES) - Código de Financiamento 001. 


\section{Resumo}

Faria, Rodrigo Villela de; Leite da Silva, Armando Martins; Jardim, Jorge Luis de Araújo. Teoria e Aplicação de Equivalentes Dinâmicos na Rede Elétrica Brasileira. Rio de Janeiro, 2019. 101p. Dissertação de Mestrado Departamento de Engenharia Elétrica, Pontifícia Universidade Católica do Rio de Janeiro.

Modelos equivalentes de rede podem ser usados na avaliação de segurança online, no planejamento da operação de grandes sistemas e na simulação em tempo real. A representação de partes não observadas do sistema por equivalentes melhora significativamente o desempenho computacional, que é um requisito importante na avaliação de segurança on-line, e necessário quando não estão disponíveis informações sobre áreas não observadas. Em simuladores em tempo real, devido a limitações de hardware, é obrigatório o uso de equivalentes. Para estudos de planejamento, as reduções de rede fazem sentido se o sistema for muito grande e o foco da análise restrito a uma parte relativamente pequena do sistema, para os quais o uso de equivalentes de rede pode poupar uma enorme quantidade de tempo. O tema dos equivalentes de rede recebeu atenção significativa nos anos 70 e 80, principalmente na avaliação da segurança estática. Entretanto, para aquelas perturbações que envolvem respostas de potência pelo sistema externo, simples modelos estáticos podem não ser suficientes. Para isso, utiliza-se a representação dinâmica nesses equivalentes. $\mathrm{O}$ sistema externo deve manter uma resposta semelhante às oscilações eletromecânicas do sistema original. Tendo em vista a expansão do Sistema Interligado Nacional (SIN), a crescente inserção de elos de corrente contínua e a elevada da participação de fontes de geração distribuída, especialmente a eólica, é esperado um aumento significativo do número e complexidade dos modelos para simulações dinâmicas. Assim, é de extrema relevância o aperfeiçoamento dos equivalentes dinâmicos, tanto para utilização on-line como para o planejamento da operação. Portanto, esta dissertação visa explorar os limites das técnicas de equivalentes dinâmicos de rede mais recentes, bem como possíveis caminhos para o aperfeiçoamento de sua 
aplicação, inclusive com a consideração do seu uso para acelerar o cálculo de regiões de segurança. Além de uma revisão da teoria recente de equivalentes estáticos e dinâmicos, serão apresentadas aplicações de equivalentes dinâmicos em diferentes regiões do SIN. A primeira região, mais restrita, representa a rede de atendimento aos estados do Acre e Rondônia, com o restante do SIN reduzido. A segunda região, mais geral, reduz partes do SIN considerando o bloqueio total do Bipolo Xingu-Estreito e seu impacto na rede. Os resultados obtidos são amplamente discutidos.

\section{Palavras-chave}

Equivalentes estáticos; equivalentes dinâmicos; avaliação de segurança online; planejamento da operação de grandes sistemas; simulação em tempo real. 


\section{Abstract}

Faria, Rodrigo Villela de; Leite da Silva, Armando Martins (Advisor); Jardim, Jorge Luis de Araújo (Co-Advisor). Theory and Application of Dynamic Equivalents to the Brazilian Power Grid. Rio de Janeiro, 2019. 101p. Dissertação de Mestrado - Departamento de Engenharia Elétrica, Pontifícia Universi-dade Católica do Rio de Janeiro.

Equivalent network models can be used for online security assessment, operation planning of large systems, and real-time simulation. Representing unobserved parts of large networks by equivalents significantly improves computational performance, which is an important requirement in online security assessment and required when no information on unobserved areas is available. In real-time simulators, due to hardware limitations, the use of equivalents is mandatory. For planning studies, network reductions make sense if the system is too large and the focus of analysis is restricted to a relatively small part of the system, for which the use of network equivalents can save a huge amount of time. The topic of network equivalents received significant attention in the 1970s and 1980s, especially in static security assessments. However, for those perturbations involving power responses by the external system, simple static models may not be sufficient. For this, the dynamic representation in these equivalents is used. The external system must preserve a response similar to the electromechanical oscillations of the original system. Considering the expansion of the Brazilian Interconnected System (BIS), the increasing insertion of DC links and the high contribution of distributed generation sources, especially wind, a significant increase in the number and complexity of the models for dynamic simulations is expected. Thus, it is extremely important to improve the dynamic equivalents, for both online use and for operation planning. Therefore, this dissertation aims to explore the limits of the latest dynamic network equivalent techniques as well as possible ways to improve its application, including its use to speed up the assessment of security regions. In addition to a review of the recent theory of static and dynamic equivalents, applications of dynamic equivalents will be 
presented in different regions of the BIS. The first region, more restricted, represents the network transmission services to the states of Acre and Rondônia, with the rest of the BIS reduced. The second region, more general, reduces parts of the BIS considering the total block of the Xingu-Estreito bipole and its impact on the network. The results obtained are widely discussed.

\section{Keywords}

Static equivalents; dynamic equivalents; online security assessment; operation planning of large systems; real-time simulation. 


\section{Sumário}

1 Introdução 17

1.1. Considerações Gerais 17

1.2. Objetivos 20

1.3. Estrutura da Dissertação 21

2 Detalhamento do Método de Equivalentes Estáticos 22

2.1. Introdução 22

2.2. Equivalente Ward 22

2.3. Eliminação de Gauss 25

2.4. Equivalente Ward - PV 26

2.5. Equivalente Ward Estendido 26

2.6. Zona Intermediária 28

2.7. Metodologia para Redução da Rede parte Estática 29

2.7.1. Método de Ward 29

2.7.2. Método de Ward - PV 30

2.7.3. Zona Intermediária 30

2.7.4. Retenção Forçada 31

2.7.5. Outras Considerações Práticas 31

2.7.6. Definição do Sistema Interno 32

2.7.7. Remoção (Corte) de Elementos 33

2.7.8. Análise de Precisão Estática 33

2.8. Comentários Finais $\quad 34$

3 Detalhamento do Método de Equivalentes Dinâmicos 35

3.1. Introdução

3.2. Conceito Geral dos Métodos de Equivalentes Dinâmicos 35

3.3. Detalhamento dos Métodos com Representação Padrão 36

3.3.1. Método da coerência 38 
3.3.2. Método da Coerência Modal 39

3.3.3. Métodos da Coerência Lenta, Vínculos Fracos e Sincronismo 42

3.3.4. Método dos Agrupamentos por Distância Elétrica (Organon) 42

3.4. Métodos de Agregação de Geradores no Modelo Clássico 44

3.4.1. Método de Agregação de Podmore 45

3.4.2. Modelo de Agregação Inercial 46

3.4.3. Método de Agregação de Zhukov 47

3.4.4. Método de Agregação de Geradores: Modelo de 2a. Ordem 50

3.5. Análise de Precisão Dinâmica 54

3.6. Comentários Finais $\quad 55$

4 Aplicação do Equivalente Dinâmico no Sistema Elétrico Brasileiro 56

4.1. Introdução 56

4.2. Sistema do Acre e Rondônia (Cenário 1) 57

4.2.1. Definição das Regiões Internas, Externas e da Zona Intermediária 58

4.2.2. Lista de Contingências 58

4.2.3. Definição dos Valores de Sensibilidades $\quad 59$

4.2.4. Resultados do Teste T1_1 60

4.2.5. Resultados dos Testes T1_2 64

4.2.6. Conclusões dos Testes T1_1 e T1_2 66

4.2.7. Resultados da Região de Segurança do Acre e Rondônia 67

4.3. Interligação Norte Sudeste e Bipolo de Belo Monte no Sentido de

Estreito para Xingu (Cenário 2) $\quad 69$

4.3.1. Definição das Regiões Internas, Externas e da Zona Intermediária 71

4.3.2. Lista de Contingências 72

4.3.3. Definição dos Valores Limites para as Sensibilidades de Retenção de Circuitos e Agrupamento de Geradores $\quad 72$

4.3.4. Resultados do Teste T2_1 73

4.3.5. Resultados do Teste T2_2 77

4.3.6. Resultados do Teste T2_3 81

4.3.7. Resultados do Teste T2_4 87

4.3.8. Conclusões dos Testes T2_1, T2_2, T2_3 e T2_4 91

5 Conclusões 95 
6 Referências bibliográficas

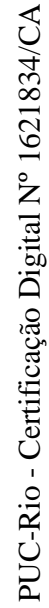




\section{Lista de figuras}

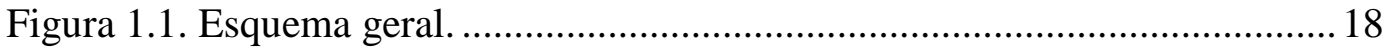

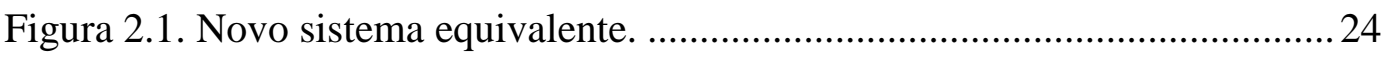

Figura 2.2. Ligações entre barras de fronteira e barras PV fictícias.......................227

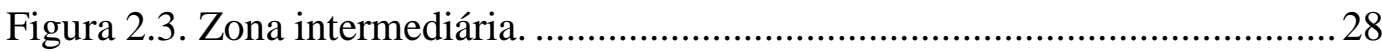

Figura 3.1. Modos de oscilação [7] .................................................................. 40

Figura 3.2. Árvore modal - modos eletromecânicos [7]...................................... 41

Figura 3.3. Esquema de agregação "Podmore" [15] ............................................ 46

Figura 3.4. Esquema de agregação inercial [15]. .................................................. 47

Figura 4.1. Diagrama unifilar do sistema Acre e Rondônia.................................57

Figura 4.2. Síntese da redução da rede e do teste de precisão no T1_1. ................61

Figura 4.3. Comparação da tensão na barra de Vilhena 230 kV na

contingência ${ }^{\circ} 13$, LT 230 kV Jauru - Vilhena C1 e C2, no T1_1..................... 63

Figura 4.4. Comparação da tensão na barra de P. Bueno 230 kV na

contingência $\mathrm{n}^{\circ} 13$, LT 230 kV Jauru - Vilhena C1 e C2, no T1_1. ..................... 63

Figura 4.5. Síntese da redução da rede e do teste de precisão no T1_2 ................6 64

Figura 4.6. Comparação da tensão na barra de Vilhena 230 kV na

contingência $\mathrm{n}^{\circ} 13$, LT 230 kV Jauru - Vilhena C1 e C2, no T1_2. .....................65

Figura 4.7. Comparação da tensão na barra de P. Bueno $230 \mathrm{kV}$ na

contingência ${ }^{\circ} 13$, LT 230 kV Jauru - Vilhena C1 e C2, no T1_2. ......................65

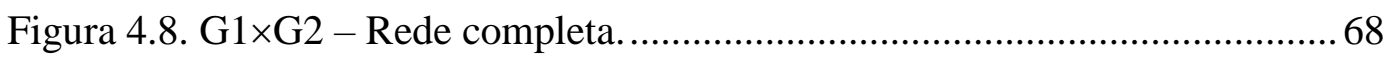

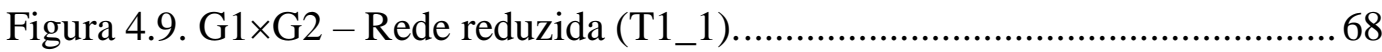

Figura 4.10. Localização Geográfica das Interligações Norte/Nordeste,

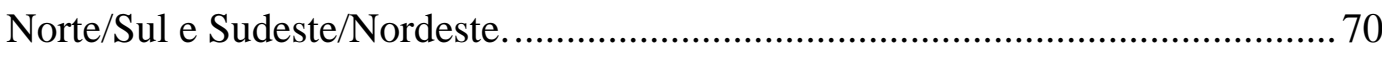

Figura 4.11. Diagrama unifilar dos sistemas Norte e Nordeste e sua

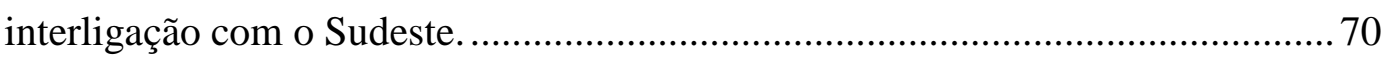

Figura 4.12. Síntese da redução da rede e do teste de precisão para o

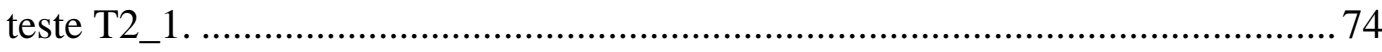

Figura 4.13. Comparação da tensão na barra de Rio das Éguas 500 kV ............... 75

Figura 4.14. Comparação da tensão na barra de Serra da Mesa 500 kV............... 75

Figura 4.15. Comparação da tensão na barra de R. Gonçalves 500 kV . ............... 75 
Figura 4.16. Comparação da corrente na LT 500 kV Miracema - Colinas. .76

Figura 4.17. Comparação da resistência aparente na LT 500 kV

R. Gonçalves - Colinas. .76

Figura 4.18. Comparação da resistência aparente na LT 500 kV

S. Mesa - Peixe 2 76

Figura 4.19. Comparação da tensão na barra de R. Gonçalves 500 kV. 77

Figura 4.20. Comparação da resistência aparente na LT 500 kV

R. Gonçalves - Colinas. 77

Figura 4.21. Síntese da redução da rede e do teste de precisão para o teste $\mathrm{T} 2 \_2$ .78

Figura 4.22. Comparação da tensão na barra de Rio das Éguas 500 kV............... 79

Figura 4.23. Comparação da tensão na barra de Serra da Mesa 500 kV ............... 79

Figura 4.24. Comparação da tensão na barra de R. Gonçalves 500 kV. ................ 79

Figura 4.25. Comparação da corrente na LT 500 kV Miracema - Colinas. ........... 80

Figura 4.26. Comparação da resistência aparente medida pela PPS

instalada na LT 500 kV R. Gonçalves - Colinas 80

Figura 4.27. Comparação da resistência aparente medida pela PPS instalada na LT 500 kV S. Mesa - Peixe 2 80

Figura 4.28. Síntese da redução da rede e do teste de precisão para o teste T2_10 .81

Figura 4.29. Comparação da tensão na barra de Rio das Éguas 500 kV 82

Figura 4.30. Comparação da tensão na barra de Serra da Mesa 500 kV. 82

Figura 4.31. Comparação da tensão na barra de R. Gonçalves 500 kV. 83

Figura 4.32. Comparação da corrente na LT 500 kV Miracema - Colinas 83

Figura 4.33. Comparação da resistência aparente medida pela PPS

instalada na LT 500 kV R. Gonçalves - Colinas

Figura 4.34. Comparação da resistência aparente medida pela PPS instalada na LT 500 kV S. Mesa - Peixe 2 84

Figura 4.35. Síntese da redução da rede e do teste de acurácia para o teste $\mathrm{T} 23 \mathrm{~b}$ .84

Figura 4.36. Comparação da tensão na barra de Rio das Éguas 500 kV............... 85

Figura 4.37. Comparação da tensão na barra de Serra da Mesa 500 kV............... 85

Figura 4.38. Comparação da tensão na barra de R. Gonçalves 500 kV. ................ 86 
Figura 4.39. Comparação da corrente na LT 500 kV Miracema - Colinas.

86

Figura 4.40. Comparação da resistência aparente na LT 500 kV

R. Gonçalves - Colinas. 86

Figura 4.41. Comparação da resistência aparente na LT 500 kV

S. Mesa - Peixe 2 .

Figura 4.42. Síntese da redução da rede e do teste de precisão para o

teste $\mathrm{T} 2 \_4 \mathrm{~b}$ .88

Figura 4.43. Comparação da tensão na barra de Rio das Éguas $500 \mathrm{kV}$ 89

Figura 4.44. Comparação da tensão na barra de Serra da Mesa 500 kV 89

Figura 4.45. Comparação da tensão na barra de R. Gonçalves 500 kV. .89

Figura 4.46. Comparação da corrente na LT 500 kV Miracema - Colinas. .90

Figura 4.47. Comparação da resistência aparente na LT 500 kV

R. Gonçalves - Colinas. 90

Figura 4.48. Comparação da resistência aparente na LT 500 kV

S. Mesa - Peixe 2 . .90 


\section{Lista de tabelas}

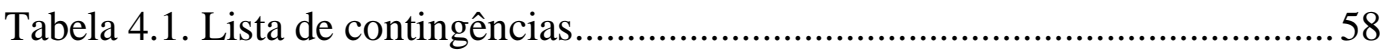

Tabela 4.2. Lista dos valores de parâmetros para redução da rede ........................ 72

Tabela 4.3. Lista dos valores de parâmetros para redução de geradores ............... 73

Tabela 4.4. Síntese dos resultados de redução do sistema.................................... 94 


\section{Lista de abreviaturas e símbolos*}

$\begin{array}{ll}\text { SIN } & \text { Sistema Interligado Nacional } \\ \text { TD } & \text { Diferença de Trajetórias } \\ \text { TS } & \text { Estabilidade Transitória } \\ \text { I.O. } & \text { Instruções de Operação } \\ \text { PPS } & \text { Proteção de Perda de Sincronismo } \\ \text { CE } & \text { Compensador Estático }\end{array}$




\section{1 \\ Introdução}

\section{1.}

\section{Considerações Gerais}

Modelos equivalentes para sistemas de energia são normalmente usados para avaliação de segurança online, planejamento da operação de sistemas interligados de grande porte e simulação em tempo real. Para a avaliação de segurança on-line, a representação de partes do sistema não observadas por modelos equivalentes, melhora o desempenho computacional, o que é um requisito importante para tais aplicações. Tal representação se torna ainda mais necessária quando informações sobre o status e estados das áreas não observadas estão indisponíveis. Grandes redes não podem ser representadas em simuladores em tempo real devido a limitações de hardware sendo, portanto, a redução de rede obrigatória. Para estudos de planejamento, as reduções de rede fazem sentido se o sistema for muito grande e o foco da análise for restrito a uma parte relativamente pequena do sistema. Em particular, para estudos que exigem grandes números de simulações (por exemplo, repetidas e extensas análises de contingência) o uso de equivalentes de rede pode economizar uma considerável quantidade de tempo.

O tema dos equivalentes de rede recebeu atenção significativa nos anos 70 e 80, principalmente com o propósito de ser utilizado na avaliação de segurança estática online. As referências [1-4] representam, em parte, as principais contribuições para o campo nesse período.

Vários métodos são propostos na literatura, no entanto, o método Ward e algumas de suas variantes serão o foco desta dissertação. Suas vantagens e desvantagens foram detalhadas nos estudos [2,3]. A seguir, é feito um resumo das justificativas para a sua utilização: 
- Foi demonstrado que com variantes do método Ward se pode obter resultados muito precisos;

- O método confirma um desempenho muito consistente para diferentes sistemas e configurações;

- Ao se adotar as melhores práticas, não se geram redes mal condicionadas;

- O método Ward-PV também é adequado para a computação de equivalentes dinâmicos;

- O método pode reter circuitos de baixa impedância entre as áreas, em vez de criar circuitos fictícios, sendo por esses caminhos retidos que os modos eletromecânicos se propagam;

- O método Ward-PV retém geradores que podem ser agregados em um segundo passo.

O problema, como apresentado em [5], é formulado pela definição de um subsistema de interesse, geralmente denominado sistema interno, e o resto do sistema é definido como externo. O sistema interno é totalmente preservado e um modelo equivalente reduzido é calculado para o sistema externo. A Figura 1.1, a seguir, mostra o esquema geral. As barras de fronteira são os únicos pontos de interconexão do sistema interno com o sistema externo.

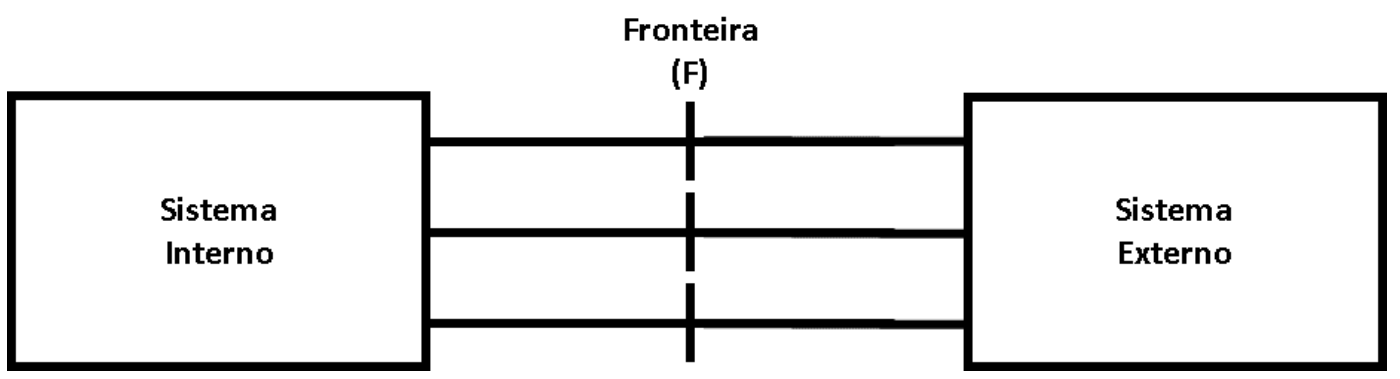

Figura 1.1. Esquema geral.

Verificou-se também que pode ser necessária a manutenção de partes do sistema externo para melhorar a precisão do equivalente sempre que esta rede afetar o desempenho da rede interna [4]. Essas partes retidas, geralmente são chamadas de zona intermediária, ou seja, entre o sistema interno e externo. 
Alguns requisitos importantes se aplicam ao equivalente externo, ou seja, este deve:

1. Ser compatível com programas regulares de fluxo de potência, i.e., não pode ser apenas um modelo matemático;

2. Estar matematicamente bem condicionado para evitar problemas de convergência;

3. Preservar no equivalente externo, com uma precisão relativamente boa, as sensibilidades do sistema interno, para mudanças no sistema interno.

O segundo e terceiro itens estão fortemente correlacionados e, em termos práticos, implicam que, para análises de regime permanente, as variações de fluxo nos circuitos equivalentes da rede externa devem ser próximas às do sistema original, e que as respostas MW e MVAr do sistema externo, para mudanças no sistema interno, também devem ser semelhantes ao do sistema original.

Obviamente, a medida que o tamanho do sistema externo diminui, parte de seus efeitos é removida e a resposta global não é a mesma do sistema original. Em geral, é possível encontrar modelos reduzidos para os quais, vistos a partir do sistema interno, as diferenças de resposta em relação ao sistema original são mínimas e aceitáveis. Na prática, o processo de determinação dos elementos a serem retidos na zona intermediária geralmente exige repetidas tentativas e ajustes baseados em heurísticas, até se obter um modelo aceitável e preciso.

Nos estudos dinâmicos, também é necessário ter uma representação dinâmica reduzida dos sistemas presentes no sistema externo. Neste caso, o desempenho dinâmico do modelo equivalente também deve manter uma resposta dinâmica semelhante à do sistema original. As referências [6-10] representam, em parte, as principais contribuições para a área nesse aspecto.

Cabe destacar que, assim como no problema de redução estática da rede, não existe um cálculo exato para os equivalentes dinâmicos, mas sim, uma aproximação do comportamento dinâmico original da rede, segundo os critérios adotados pelo analista. Ou seja, sempre haverá um compromisso entre o nível de redução e a precisão exigida. 
Em geral, a redução dinâmica implica no agrupamento ou agregação de geradores do sistema externo. O agregado é então representado por um modelo equivalente. No decorrer desta dissertação serão apresentadas as bases teóricas nas quais se fundamentam os métodos de Análise Modal $[8,11,12]$, o método de Máquinas Coerentes, e suas variantes, [6,7,13-16] e a metodologia de agrupamentos por Distância Elétrica [10].

\section{2.}

\section{Objetivos}

Tendo em vista o aumento significativo do sistema brasileiro, da crescente inserção de elos de corrente contínua e da elevação da participação na matriz energética de fontes de geração distribuída, notadamente a geração eólica, é esperado um aumento significativo do número e complexidade dos modelos para simulações dinâmicas. Portanto, é de extrema relevância tanto a obtenção de soluções precisas e eficientes do ponto de vista computacional quanto a utilização de métodos eficientes e acurados de equivalentes dinâmicos e de rede, para simulações on-line e off-line.

Sabendo que um bom equivalente, quando acoplado ao modelo detalhado da área interna, deve replicar consistentemente a amplitude e frequência das oscilações de potência e tensão nas barras de fronteira (extensível a todas as barras do sistema de interesse) assegurando dessa forma um comportamento dinâmico comparável ao do sistema original.

Esta dissertação investiga alguns dos recursos computacionais existentes no programa Organon [17,18] para a obtenção de modelos equivalentes. Inicialmente, se faz uma revisão da teoria adotada no cálculo de equivalentes dinâmicos. Então, são apresentados resultados de testes destes cálculos em diferentes regiões do Sistema Interligado Nacional (SIN).

O objetivo é buscar os limites dos métodos de equivalentes dinâmicos e de rede deste programa, bem como possíveis caminhos para o aperfeiçoamento de sua aplicação. 


\section{3. \\ Estrutura da Dissertação}

Esta dissertação encontra-se organizada da seguinte forma:

O presente capítulo apresenta uma descrição geral das aplicações usuais de equivalentes estáticos e dinâmicos, destacando algumas das referências mais importantes e analisando, de forma breve, os impactos que o crescimento das fontes renováveis, notadamente a eólica, terão no número e complexidade dos modelos para simulações dinâmicas.

Capítulo 2 aborda os principais conceitos, técnicas e métodos, existentes na literatura, para a determinação de equivalentes estáticos. Em especial, o método Ward-PV, que por suas características é utilizado, posteriormente, como base para o cálculo de equivalentes dinâmicos.

Capítulo 3 apresenta os principais conceitos, técnicas e métodos, existentes na literatura, para a determinação de equivalentes dinâmicos. Será abordado, em especial, o método baseado em distâncias elétricas, implementado no programa Organon, o qual foi utilizado nos testes de equivalentes dinâmicos no SIN.

Capítulo 4 apresenta os resultados obtidos em dois testes no SIN, sendo o primeiro deles um exemplo onde o sistema de atendimento aos estados do Acre e Rondônia é mantido, com o restante do SIN sendo reduzido. Já o segundo, faz a redução do SIN, mantendo, através da escolha de valores de sensibilidade de fluxo e tensão, a rede necessária para a correta representação do evento de bloqueio do elo de corrente contínua entre Estreito e Xingu.

Capítulo 5 apresenta as principais contribuições deste trabalho, bem como sugestões para a continuação do tema em trabalhos futuros. 


\section{2 \\ Detalhamento do Método de Equivalentes Estáticos}

\section{1.}

Introdução

Neste capítulo serão apresentadas as bases teóricas do método de equivalente estático, com ênfase no método de Ward e suas variantes, em especial, o Ward-PV. Também será abordado o conceito de zona intermediária.

\section{2.}

\section{Equivalente Ward}

Considerando a definição de subsistemas internos e externos, como apresentado na Figura 1.1, a matriz de admitância da rede pode ser particionada da seguinte forma:

$$
\left[\begin{array}{ccc}
Y_{e e} & Y_{e f} & 0 \\
Y_{f e} & Y_{f f} & Y_{f i} \\
0 & Y_{i f} & Y_{i i}
\end{array}\right] \times\left[\begin{array}{c}
V_{e} \\
V_{f} \\
V_{i}
\end{array}\right]=\left[\begin{array}{c}
I_{e} \\
I_{f} \\
I_{i}
\end{array}\right]
$$

onde os índices " $f$ ", “ $e$ " e " $i$ " são relacionados com as barras de fronteira, externas e internas, respectivamente. Ao se evidenciar $V_{e}$ na primeira equação do sistema de equações (2.1), tem-se:

$$
V_{e}=Y_{e e}^{-1}\left(I_{e}-Y_{e f} V_{f}\right)
$$

Substituindo a equação (2.2) em (2.1), temos:

$$
\left[\begin{array}{cc}
Y_{f f}^{e q} & Y_{f i} \\
Y_{i f} & Y_{i i}
\end{array}\right] \times\left[\begin{array}{l}
V_{f} \\
V_{i}
\end{array}\right]=\left[\begin{array}{c}
I_{f}^{e q} \\
I_{i}
\end{array}\right]
$$


onde:

$$
\begin{gathered}
Y_{f f}^{e q}=Y_{f f}-Y_{f e} Y_{e e}^{-1} Y_{e f} \\
I_{f}^{e q}=I_{f}-Y_{f e} Y_{e e}^{-1} I_{e}
\end{gathered}
$$

Assim, o novo sistema de equações dado em (2.3) é formado pelos seguintes elementos modificados:

- A matriz $Y_{f f}^{e q}$ contém as admitâncias shunts das barras de fronteira e as admitâncias associadas às suas ligações;

- A matriz $-Y_{f e} Y_{e e}^{-1} Y_{e f}$ contém os elementos criados no processo de redução;

- $\mathrm{O}$ vetor $I_{f}^{e q}$ contém as injeções de corrente equivalentes, formada por uma componente de injeções já existentes, $I_{f}$, e outra relativa à distribuição das injeções externas sobre as barras da fronteira, $-Y_{f e} Y_{e e}^{-1} I_{e}$.

Uma forma alternativa que pode ser derivada de (2.3), para calcular as correntes injetadas em (2.5), por exemplo, quando as injeções nas barras externas originais não são conhecidas, é a que segue:

$$
I_{f}^{e q}=Y_{f f}^{e q} V_{f}+Y_{f i} V_{i}
$$

Na equação (2.6), $V_{f}$ e $V_{i}$ pertencem apenas ao sistema interno.

Após o cálculo da rede externa equivalente, devem-se calcular as injeções equivalentes de potência ativa e reativa nas barras de fronteira de forma a acoplar a rede externa equivalente à rede interna, de interesse, garantindo que os estados (módulo e ângulo da tensão) se mantenham idênticos ao do caso original. Essas injeções são as seguintes:

$$
\begin{aligned}
& P_{k}^{e q}=V_{k}^{0} \sum_{m \in k} V_{m}^{0}\left(G_{k m}^{e q} \operatorname{Cos} \theta_{k m}^{0}+B_{k m}^{e q} \operatorname{Sen} \theta_{k m}^{0}\right) \\
& Q_{k}^{e q}=V_{k}^{0} \sum_{m \in k} V_{m}^{0}\left(G_{k m}^{e q} \operatorname{Sen} \theta_{k m}^{0}-B_{k m}^{e q} \operatorname{Cos} \theta_{k m}^{0}\right)
\end{aligned}
$$


onde:

$V_{k}^{0}$ e $\theta_{k m}^{0}$ são variáveis de estado referentes ao caso original;

$k$ é o conjunto das barras de fronteira;

$m$ é o conjunto das barras vizinhas às barras de fronteira, incluída a própria barra k;

$G_{k m}^{e q}+B_{k m}^{e q}$ são elementos da matriz $Y^{e q}$ de admitância nodal da rede reduzida:

$$
Y^{e q}=\left[\begin{array}{cc}
Y_{f f}^{e q} & Y_{f i} \\
Y_{i f} & Y_{i i}
\end{array}\right]
$$

Por fim, temos um novo sistema à semelhança da Figura 2.1, a seguir.

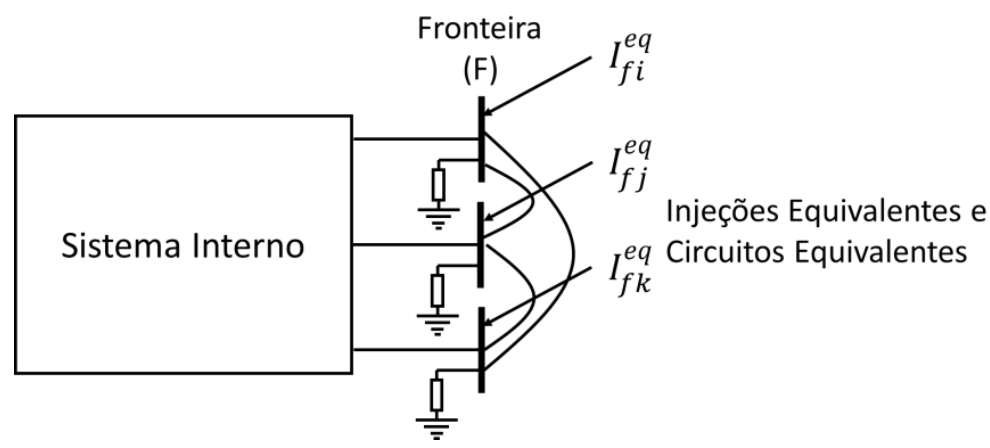

Figura 2.1. Novo sistema equivalente.

O ponto de operação do sistema reduzido é rigorosamente o mesmo que no sistema original. Idealmente, o sistema reduzido deve responder às mudanças como o original.

Um aspecto crítico deste método é a forma de levar em conta cargas e shunts. Eles podem ser convertidos em admitâncias constantes e adicionados à matriz de admitâncias em (2.1), que levam à variante Ward-Admitância, ou convertidos em injeções de corrente e adicionados às injeções de corrente de barra, ou simplesmente ignorados (não incluídos em (2.1)). De fato, as duas últimas alternativas conduzem à mesma matriz de admitância equivalente, e uma 
vez que as tensões de fronteira são conhecidas, as injeções de corrente de fronteira podem ser calculadas por (2.6).

Por outro lado, foi demonstrado em [2] que incluir cargas e shunts em (2.1), pode resultar em modelos matemáticos muito mal condicionados, uma vez que tal escolha pode resultar em ramos equivalentes com impedâncias negativas significativamente maiores e shunts muito grandes nas barras de fronteira. Isto deteriora a convergência, não só para a análise de contingência, mas também para o caso base em si. Por exemplo, shunts muito grandes aumentam significativamente a resposta MVAr para mudanças de tensão, ou seja, uma mudança de tensão muito pequena causa grandes desequilíbrios MVAr.

Isso ocorre devido às admitâncias entre barras serem comparativamente maiores do que as admitâncias dos elementos shunts. O que nos aproxima da condição onde as barras estariam em curto circuito, através dos elementos série, e os elementos shunts ligados em paralelo. Como durante o processo de redução ocorre aproximadamente a soma dos elementos shunts, estes acabam representados nas barras de fronteira com valores elevados.

Tais valores elevados de elementos shunts nas barras de fronteira podem levar à perda de precisão do equivalente e a dificuldades de convergência do equivalente nos programas de fluxo de potência.

Como resultado geral, o modelo Ward obtém boa precisão nas respostas de potência ativa para estudos de contingências de elementos da rede interna, porém as respostas de potência reativa muitas vezes não atingem o nível de precisão desejado. Isto ocorre devido ao tratamento igualitário dado às barras PV e PQ durante o processo, ou seja, na rede equivalente não são consideradas as eventuais contribuições das barras PV do sistema externo.

\section{3. \\ Eliminação de Gauss}

Como comentado em [5], devido às operações necessárias para construção da matriz (2.9) serem computacionalmente custosas ou mesmo impraticáveis, é comum que para sistemas de maior porte opte-se pela obtenção da submatriz $Y_{f f}^{e q}$ através do processo da eliminação de Gauss. 


\section{4. \\ Equivalente Ward - PV}

Para adereçar as limitações expostas anteriormente pode-se utilizar o método Ward com a retenção das barras PV. Essa retenção deve ocorrer naquelas barras PV que tenham respostas significativas para contingências na rede interna.

Para tal, de forma similar ao apresentado anteriormente, é feito o equivalente de rede, com a consideração adicional de se tratar como barras de fronteira as barras PV de interesse.

Em seguida, deve-se fazer o cálculo das injeções equivalentes nas barras de fronteira da seguinte forma:

i. Executa-se um fluxo de potência para calcular os ângulos das tensões das barras PV da rede externa retidas, com as seguintes considerações:

a. A rede será formada pelas barras de fronteira e as barras PV da rede externa retidas;

b. As barras de fronteira devem ser consideradas como do tipo V $\theta$, considerando os seus valores de $\mathrm{V}$ e $\theta$ do caso original;

c. As barras PV devem manter os seus valores de P e V do caso original;

ii. Após o cálculo dos estados das barras de fronteira e das barras PV retidas da rede externa e sabendo-se os estados da rede interna, devem-se calcular as injeções equivalentes nas barras de fronteira conforme as equações (2.5) e (2.6);

\section{5.}

\section{Equivalente Ward Estendido}

Este método é uma extensão do método convencional de Ward, decorrente da introdução de barras PV fictícias conectadas às barras de fronteira, de forma que as respostas em MVAr das barras PV não retidas possam ser representadas, ao menos aproximadamente.

Para tal, são mantidas as ligações equivalentes entre as barras de fronteira e suas respectivas injeções equivalentes, como no método convencional, porém são 
acrescentadas ligações entre as barras de fronteira e as barras PV fictícias, como ilustrado na Figura 2.2, a seguir.

Fronteira

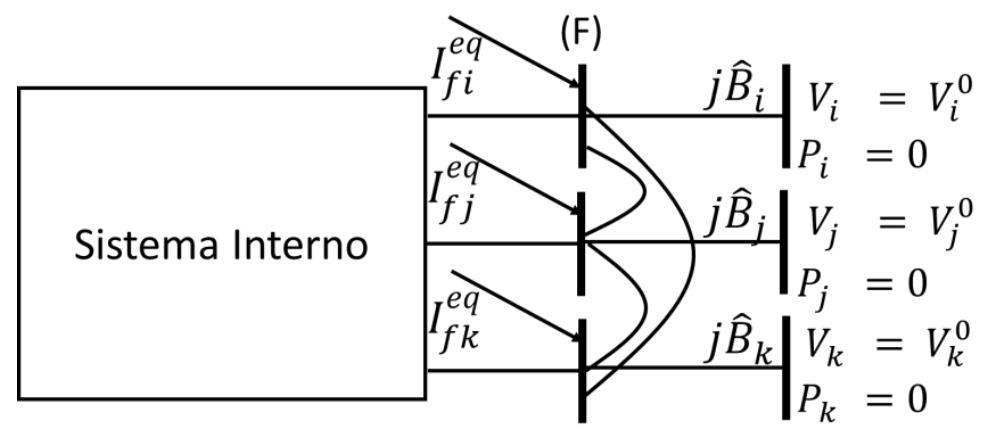

Figura 2.2. Ligações entre barras de fronteira e barras PV fictícias.

As barras PV fictícias têm as seguintes características:

i. Módulo da tensão igual aos valores do caso base das barras de fronteira ás quais estão conectadas;

ii. Potência ativa nula;

iii. A contribuição das barras PV fictícias, para eventos na rede interna que causem variações de tensão nas barras de fronteira, são dadas por:

$$
\Delta Q_{k}=V_{k} \hat{B}_{k} \Delta V_{k}
$$

A matriz $\widehat{B}_{k}$ será comentada com mais detalhes mais à frente. No entanto, pode-se obter, de forma aproximada, a resposta do sistema externo aos eventos na rede interna por:

$$
\Delta \underline{Q}^{r e d} / V=B_{r e d}^{\prime \prime} \Delta \underline{V}
$$

onde:

$\Delta \underline{Q}^{\text {red }}$ vetor das alterações nas injeções de potência reativa na fronteira devido à resposta do sistema externo;

$\Delta \underline{V}$ é o vetor dos desvios nos módulos de tensão nas barras da fronteira; 
$B_{\text {red }}^{\prime \prime}$ pode ser obtida pela redução da matriz $B^{\prime \prime}$ (método desacoplado rápido) considerando-se apenas o sistema formado pelas ligações do sistema externo e as suas ligações com as barras de fronteira.

Dessa forma, a resposta externa pode ser dividida em duas componentes:

i. Primeira Componente: advinda das susceptâncias equivalentes entre as barras de fronteira, é correspondente aos elementos fora da diagonal principal da matriz $B_{r e d}^{\prime \prime}$;

ii. Segunda Componente: advinda das susceptâncias de $\widehat{B}_{k}$, que são a soma algébrica dos elementos da linha k matriz $B_{r e d}^{\prime \prime}$;

Cabe destacar, que o método Ward estendido, apesar de ter sido descrito em termos da matriz $B^{\prime \prime}$, do método desacoplado rápido, pode ser utilizado em conjunto com qualquer método de fluxo de potência, uma vez que os dados do equivalente têm o mesmo formato dos dados do sistema interno.

\section{6.}

\section{Zona Intermediária}

Conforme mencionado em [4] e ilustrado na Figura 2.3, a seguir, uma zona intermediária, que consiste em elementos da área externa adicionalmente retidos, pode ser útil para várias condições de estudo e é bastante importante para modelos usados na avaliação de segurança on-line.

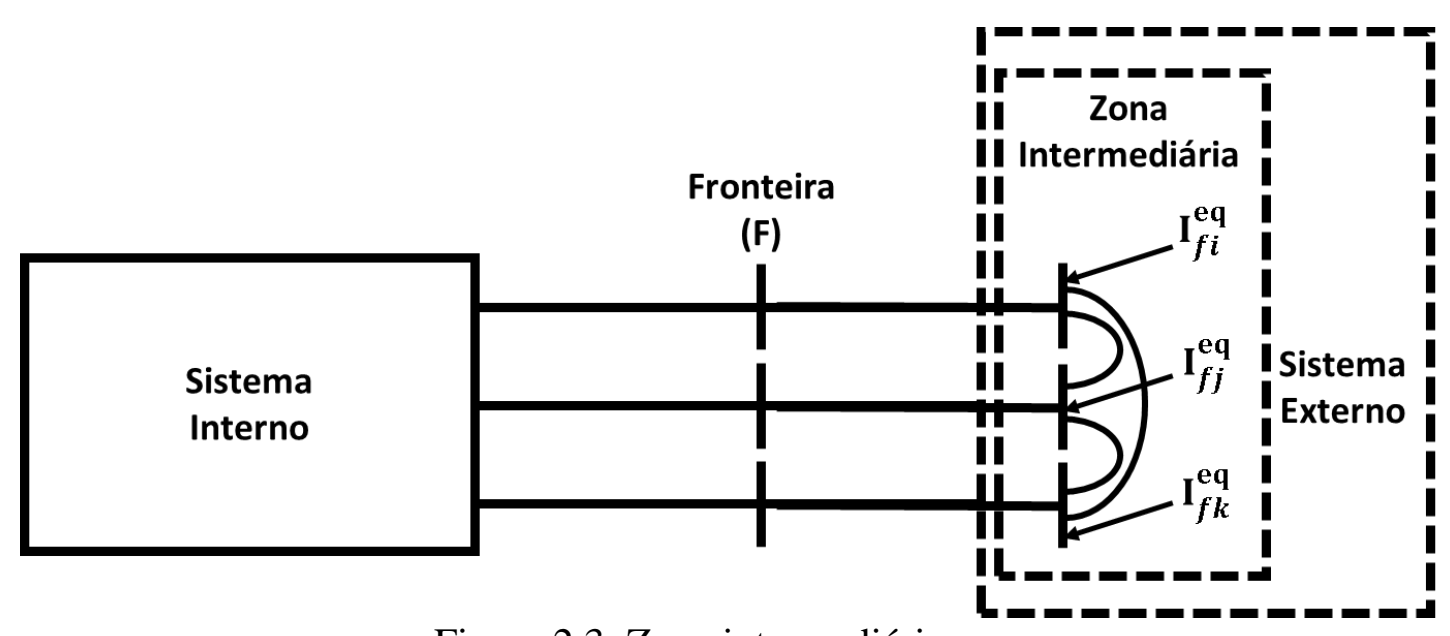

Figura 2.3. Zona intermediária. 
Uma forma simples de determinar uma zona intermediária é forçar a retenção de um certo número de barras de vizinhança, onde este número é definido pela experiência do usuário. Uma abordagem analítica mais sofisticada para o problema é realizar uma análise de sensibilidade para determinar quais dos elementos externos impactam o desempenho do sistema interno.

Em geral, os dois aspectos mais relevantes para a determinação acurada do sistema interno são que o sistema externo represente corretamente fluxos em conexões paralelas, e que as respostas de MW e MVAr de fontes externas, para perturbações no sistema interno, sejam bastante próximas das do sistema original.

\section{7. \\ Metodologia para Redução da Rede parte Estática}

A implementação do método Ward no programa Organon é flexível o suficiente para representar a rede externa com vários graus de detalhe, incluindo o tipo Ward-PV.

\subsection{1. Método de Ward}

No Organon, os únicos elementos de derivação incluídos em (2.1) são as capacitâncias das linhas de transmissão. Algumas propostas defendem que mesmo esses elementos podem ser omitidos, mas nenhum efeito negativo significativo na sua inclusão foi observado até agora.

Outra consideração muito importante é que o cálculo em (2.3) tipicamente resulta em uma submatriz $Y_{f f}^{e q}$ densa, se não for tomado cuidado para evitar a adição de admitâncias de valor muito reduzido nesta submatriz, como resultado do cálculo $Y_{e e}^{-1}$ pelo método de eliminação de Gauss. Assim, durante o processo de fatoração, preenchimentos que estão abaixo de um limite especificado pelo usuário não são incluídos. Outra verificação possível é observar, também durante o processo de fatoração, se a eliminação de um nó específico resulta em um número significativo de preenchimentos, e se for esse o caso, o nó não é eliminado, e sim retido. No entanto, o número de circuitos para a rede equivalente é proporcionalmente maior (mas não muito) do que no caso original, mas isso é esperado. 
A eliminação de Gauss implementada no Organon considera a rede simétrica e consequentemente opera com uma matriz triangular, que economiza tempo de armazenamento e computação. Após a eliminação de Gauss, os circuitos equivalentes são recuperados da submatriz $Y_{f f}^{e q}$. A parte resistiva desses ramos é ignorada, i.e., os circuitos equivalentes consistem em reatâncias puras $[10,17]$.

\subsection{2.}

\section{Método de Ward - PV}

Como visto anteriormente, uma das consequências da redução para (2.2) é que as fontes de controle de tensão no sistema externo são perdidas. Assim, embora o ponto de operação do sistema interno seja exatamente o mesmo que no sistema original, a resposta global do sistema às mudanças de tensão no sistema interno pode ser bastante diferente, o que afeta negativamente a acurácia da análise de contingências estáticas, por exemplo.

Uma maneira de contornar essa deficiência é reter todas ou algumas das barras PV que mais afetam o subsistema interno. No Organon, duas formas de incluir barras PV do sistema externo estão implementadas [17]. Uma delas é mantê-las na zona intermediária com base em análise de sensibilidade, e o outro é através da retenção forçada dessas barras com base em filtros definidos pelo usuário. Essas abordagens são explicadas na sequência.

\subsection{3.}

\section{Zona Intermediária}

A redução de Ward cria ligações equivalentes que interconectam as barras de fronteira que representam parcialmente o efeito dos fluxos dessas conexões paralelas. Entretanto, isso pode não ser suficiente para fornecer respostas precisas, uma vez que vários componentes são removidos. Uma estratégia útil para melhorar a precisão é reter os circuitos externos, para os quais a resposta interna do sistema é sensível.

A verificação desses circuitos externos mais influentes no Organon é implementada por meio de análises de sensibilidade, como segue [17]: 
i. Para cada contingência (desconexão) de um circuito externo, é calculada a mudança do fluxo de potência em circuitos na área interna, normalizada pelo carregamento do próprio circuito;

ii. Se alguma variação de fluxo no sistema interno for maior do que o limite especificado, o circuito externo é retido na zona intermediária;

iii. Para as barras PV externas, as mesmas são mantidas caso afetem significativamente qualquer uma das tensões de barramentos internos;

iv. A verificação é realizada por meio da análise de sensibilidade com base em equações de fluxo de potência CA e comparada com o limite especificado.

\subsection{4.}

\section{Retenção Forçada}

Além de definir o sistema interno e especificar ou calcular uma zona intermediária, é importante ser capaz de reter elementos externos que possam ser úteis para um determinado propósito.

Por exemplo, isso pode ser usado para reter os principais caminhos de propagação de modos eletromecânicos no caso em que o equivalente de rede vai ser usado em simulações dinâmicas. Para o mesmo propósito, é útil reter as barras PV em áreas remotas, se os geradores conectados a elas participam de modos de oscilação interárea observados no sistema interno.

\subsection{5.}

\section{Outras Considerações Práticas}

O Organon retém automaticamente os seguintes componentes:

i. Transformadores elevadores e as barras controlados remotamente dos geradores retidos (barras PV);

ii. Todos os enrolamentos de um transformador, se pelo menos um dos seus terminais for retido. 


\subsection{6. \\ Definição do Sistema Interno}

Na metodologia implementada no Organon, a parte interna do sistema deve ser definida e isso é feito por declarações de regiões internas ou externas processadas sequencialmente. As seguintes declarações estão disponíveis:

- $\quad$ Sistema externo

- Área externa <número da área>

- Zona externa <número da zona>

- Barra externa <número da barra >

- $\quad$ Sistema interno

- Área interna <número da área>

- Zona interna <número da zona>

- Barra Interna <número da barra $>$

- Gerador Interno > Limite de MW < valor de limiar>

- Barra interna > Limite de $\mathrm{kV}<$ valor de limiar>

Por exemplo, para definir uma área específica como interna, as duas declarações seguintes são suficientes:

- $\quad$ Sistema externo

- Área interna <número da área>

Como estas duas declarações são processadas sequencialmente, primeiro, todos as barras são declaradas como sendo externas e, em seguida, a área especificada é declarada como interna.

Um exemplo inverso é a situação em que o sistema externo consiste em uma área. Nesse caso, as declarações seriam:

- Sistema interno

- Área externa <número da área> 


\subsection{7. Remoção (Corte) de Elementos}

Outra característica útil do algoritmo utilizado (isto é, o Organon), é permitir a remoção simples de componentes. Por exemplo, pode ser de interesse remover todas ou algumas das ilhas elétricas que não estão contidas no sistema interno $[17,18]$.

No Organon, são implementados quatro tipos de opções de corte de componentes / subsistemas, como segue:

- Links HVDC;

- Ilhas elétricas, identificadas por barras swing;

- Geradores abaixo de um limite específico de MW;

- Barras de carga abaixo de uma base de tensão especificada.

Normalmente, as remoções são processadas antes da redução da rede. A remoção não altera o fluxo de potência original nos circuitos retidos. Por exemplo, se uma barra de carga for removida e, consequentemente, todos os componentes conectados a ela forem removidos, os fluxos de potência originais nos circuitos removidos são modelados como injeções nas barras vizinhas.

\subsection{8.}

\section{Análise de Precisão Estática}

É importante realizar uma análise de acurácia para verificar a adequação do modelo para os estudos pretendidos. Dependendo do tipo de estudo, verificações diferentes podem ser feitas. No Organon, os testes de acurácia implementados para a análise de contingências estáticas são feitos da seguinte maneira:

i. Uma lista de contingência é fornecida pelo usuário ou gerada automaticamente pelo software. No caso automático, uma lista $\mathrm{N}-1$, contendo todos os circuitos internos conectados às barras de fronteira (primeira barra de vizinhança);

ii. Os circuitos monitorados são definidos automaticamente pelo programa como o sistema interno; 
iii. A lista de contingências é processada para as redes originais e equivalentes. Para cada contingência, as tensões e os fluxos nas barras e circuitos monitorados são armazenados e posteriormente comparados;

iv. Os maiores desvios de tensão e fluxo, por contingência e respectivos locais, são impressos.

\section{8.}

\section{Comentários Finais}

A implementação do método Ward e Ward-PV no Organon é extremamente flexível e robusta. A possibilidade de ajustar diversas sensibilidades para a determinação das regiões internas e zonas intermediária de forma automática, juntamente com ferramentas para a retenção forçada de elementos, permite aliar o automatismo à experiência do usuário. 


\section{3 \\ Detalhamento do Método de Equivalentes Dinâmicos}

\section{1. Introdução}

Neste capítulo serão apresentados, de forma sucinta, alguns dos métodos para a determinação de equivalentes dinâmicos mais conhecidos e explorados na literatura, incluindo-se o método recente de agrupamento proposto em [10]. Também serão abordados diferentes métodos para a agregação de geradores.

\section{2. \\ Conceito Geral dos Métodos de Equivalentes Dinâmicos}

Uma vez definida a região de interesse, denominada de área interna, para determinar o seu comportamento dinâmico frente às contingências mais significativas, pode ser necessário, dependendo do grau de precisão esperado para os resultados dessas simulações, que todos os geradores eletricamente próximos tenham seus controles representados com a maior exatidão possível. Tais geradores são aqueles que se encontram na área interna. Com a utilização do conceito de zona intermediária, aqueles geradores que forem englobados nesta zona também deverão ser fielmente representados, como mostrado na Figura 2.3 do capítulo anterior.

Por outro lado, para os geradores na área externa, considerando que eles estão eletricamente distantes dos pontos de distúrbio, pode-se usar um modelo simplificado. No entanto, um equivalente estático pode não ser aceitável para a área externa, especialmente quando a geração e os efeitos da inércia não são desprezíveis. Dessa forma, um equivalente dinâmico deve ser definido para os geradores de área externa, tendo em conta a condição operacional inicial pré-falta.

Um bom equivalente, quando acoplado ao modelo detalhado da área interna, deve replicar consistentemente a amplitude e frequência das oscilações de potência e tensão nas barras de fronteira (extensível a todas as barras do sistema 
de interesse) assegurando dessa forma um comportamento dinâmico comparável ao do sistema original.

Cabe destacar que, assim como no problema de redução estática da rede, não existe um cálculo exato para os equivalentes, mas sim, uma aproximação do comportamento dinâmico original da rede, de acordo com critérios de acurácia compatíveis com os estudos a que o modelo se destina. Portanto, sempre existirá um compromisso entre o nível de redução e a acurácia exigida.

Os métodos podem ser divididos em duas categorias:

i. Os métodos que não permitem a representação do equivalente em programas usuais de simulações eletromecânicas e;

ii. Os métodos que permitem.

O método Modal pertence ao primeiro grupo e tem o propósito de representar partes do sistema elétrico simulado por equações computacionalmente mais eficientes do que as equações não lineares/algébricas usadas nos programas usuais. Para isso, a análise modal é usada para se obter um conjunto de equações diferenciais lineares de ordem reduzida, que compõem o equivalente dinâmico. Conforme formulado em [19], é utilizado um procedimento para a linearização das equações algébricas e diferenciais de uma área externa do sistema, considerando os geradores e seus controles.

No entanto, a aplicação do equivalente modal se manteve restrita, uma vez que, por não possuir uma identidade estrutural, sendo apenas uma representação matemática do comportamento linearizado da região externa, este não pode ser representado nos programas usuais, ficando limitado ao programa que o gerou.

A seguir serão brevemente descritos outros métodos de definição dos geradores equivalentes existentes na literatura e pertencentes ao segundo grupo.

\section{3. \\ Detalhamento dos Métodos com Representação Padrão}

$\mathrm{Na}$ categoria dos métodos em que o equivalente pode ser representado por modelos padronizados (geradores e modelos de rede), várias abordagens e 
variantes foram propostas. Apesar das especificidades de cada uma, o procedimento geral é:

i. Definir o grupo de geradores que são coerentes ou apresentam comportamento semelhante no sistema externo;

ii. Agregar cada grupo em um gerador equivalente;

iii. Realizar a redução da rede.

As etapas "ii" e "iii" são intercambiáveis. A maioria das proposições aborda o problema na etapa "i", ou seja, como classificar os geradores externos em grupos. Por outro lado, também existem algumas alternativas para agregar os geradores em modelos equivalentes. O problema pode ser descrito como segue:

Dada a representação do sistema.

$$
\begin{aligned}
& \dot{x}=\mathrm{f}(x, y) \\
& 0=\mathrm{g}(x, y)
\end{aligned}
$$

onde,

$x \in \boldsymbol{R}^{\boldsymbol{n}}$ é o vetor de variáveis diferenciais do sistema;

$y \in \boldsymbol{R}^{\boldsymbol{n}}$ é o vetor das variáveis algébricas do sistema.

Por exemplo, para um modelo de sistema de energia clássica, $x$ contém as variáveis ângulo e velocidade dos rotores dos geradores, e y contém a parte real e imaginária das tensões de barra.

O equivalente dinâmico trata a redução de (3.1), enquanto o equivalente de rede trata a redução de (3.2).

Alguns dos métodos propostos para os equivalentes dinâmicos baseiam-se na análise linear de (3.1) e (3.2). Nesses casos, essas equações são linearizadas no ponto de operação, resultando em:

$$
\begin{aligned}
& \dot{x}=A x+B y \\
& 0=C x+D y
\end{aligned}
$$


Se $y$ é eliminado em (3.3) e (3.4), teremos:

$$
\dot{x}=A_{r} x
$$

onde,

$$
A_{r}=A-B D^{-1} C
$$

$A_{r}$ - matriz de estado, dependente dos parâmetros e condições inicial do sistema;

$x$ - vetor das variáveis de estado;

$C x$ - corresponde às injeções de corrente do gerador na rede.

Para a seleção/definição dos grupos, foram identificados seis conceitos principais, que são abordados na sequência nesta Dissertação.

\subsection{1. \\ Método da coerência}

De acordo com o princípio básico desta abordagem, geradores síncronos que oscilam juntos podem formar um grupo coerente e, consequentemente, podem ser agregados em um único gerador equivalente $[6,14]$. A coerência é medida pela semelhança das trajetórias de ângulos entre os geradores externos para uma falha no sistema interno, ou seja:

$$
\Delta \theta_{i}(t)-\Delta \theta_{r}(t)<\varepsilon
$$

Para todo o tempo de simulação, onde:

$\varepsilon$ - Tolerância especificada;

$i$ - número do gerador a ser agrupado;

$r$ - número do gerador de referência do grupo.

A simulação no domínio do tempo para obter essas trajetórias pode ser baseada em modelos lineares para minimizar o esforço computacional. Uma vez 
que os índices de coerência (semelhança) são encontrados, um algoritmo de agrupamento é aplicado para definir os conjuntos. Por ser uma técnica quase puramente empírica, são reconhecidos três principais inconvenientes nesta abordagem:

i. A coerência é afetada pelo local de falha, sendo extremamente difícil a definição de critérios para a escolha da perturbação;

ii. Geradores eletricamente afastados podem ser classificados no mesmo grupo;

iii. A coerência do gerador também pode ser altamente dependente das condições de carregamento do sistema.

A conjunção desses fatores não permite o uso deste método para uma ampla gama de condições de funcionamento ou contingências, sem a necessidade do cálculo de novos equivalentes.

\subsection{2.}

Método da Coerência Modal

Para contornar a maioria dos problemas na abordagem tradicional de coerência, este método foi proposto em [7,8]. A ideia básica é realizar uma análise de autovalores em (3.5) para identificar os modos de oscilação do sistema de interesse, e, assim, os grupos coerentes.

Dessa forma, a solução de (3.5) pode ser escrita como:

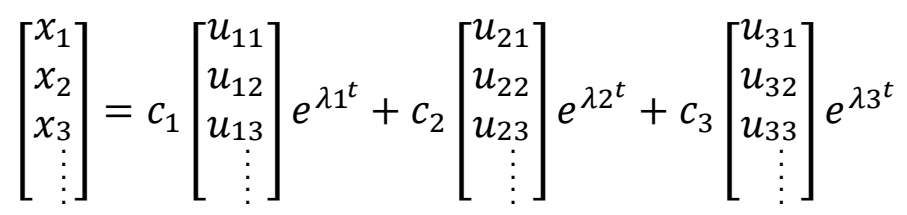

onde,

$c_{n}-$ constantes de integração determinadas pelas condições iniciais;

$\lambda n$ - autovalores ou modos de resposta do sistema;

$u_{n}-$ autovetores associados.

O módulo e ângulo de cada modo de oscilação de cada variável de estado são dados pelos seus autovetores correspondentes nos elementos $u_{i j}$. 
Para uma melhor visualização, um autovetor do elemento $\mathrm{n}$ pode ser retratado como um vetor no espaço multidimensional e os elementos $u_{i j}$ do autovetor, correspondentes ao $\mathrm{W}$-subespaço, podem ser plotados como um vetor para cada autovalor, como mostrado na Figura 3.1, extraída de [7].

\section{Modelo de Máquina de $5^{\mathrm{a}}$ Ordem}

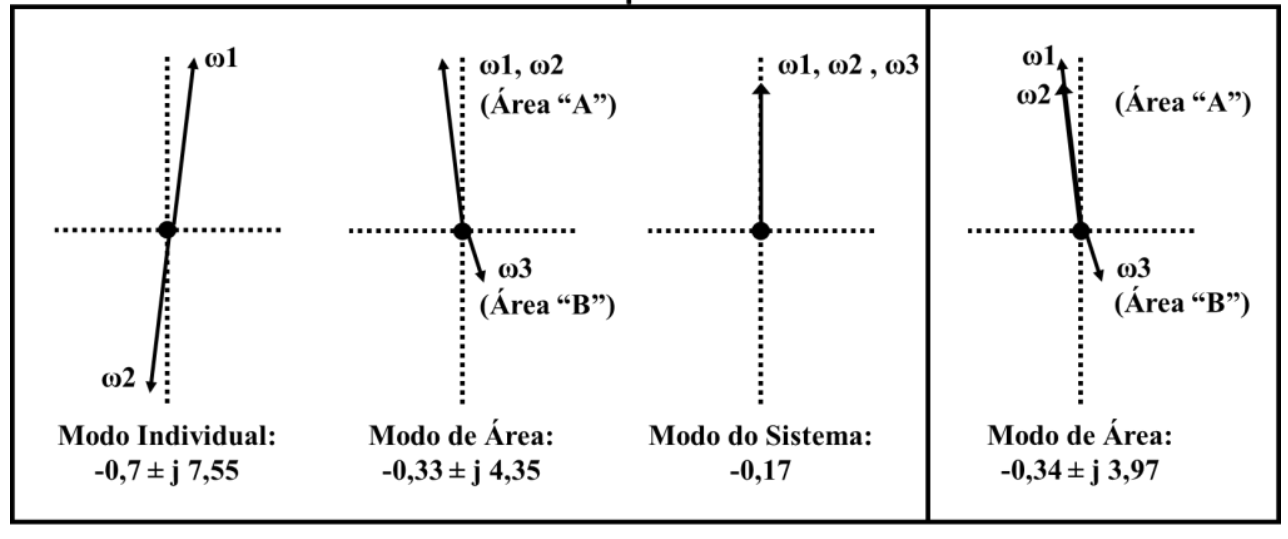

Figura 3.1. Modos de oscilação [7].

Da Figura 3.1, acima, tem-se [7]:

i. No modo real, não oscilatório, todas as três máquinas oscilam de forma coerente. Este modo pode ser chamado de modo de sistema;

ii. No modo oscilatório, de baixa frequência, as máquinas 1 e 2, na área A, oscilam de forma coerente contra a máquina 3, na área B. Este modo permite a divisão inicial do sistema em duas áreas e pode, portanto, ser chamado de modo interárea;

iii. No modo oscilatório de alta frequência, a máquina 1 oscila contra a máquina 2, mas a máquina 3 não participa. Este modo mostra a divisão de uma área para cada máquina, podendo ser chamado de modo individual.

Estas divisões hierárquicas e subdivisões do sistema são reveladas através da análise modal e pode ser apresentada graficamente como uma estrutura de árvore, chamada árvore modal, como mostra a Figura 3.2, a seguir, também discutida em [7]. 


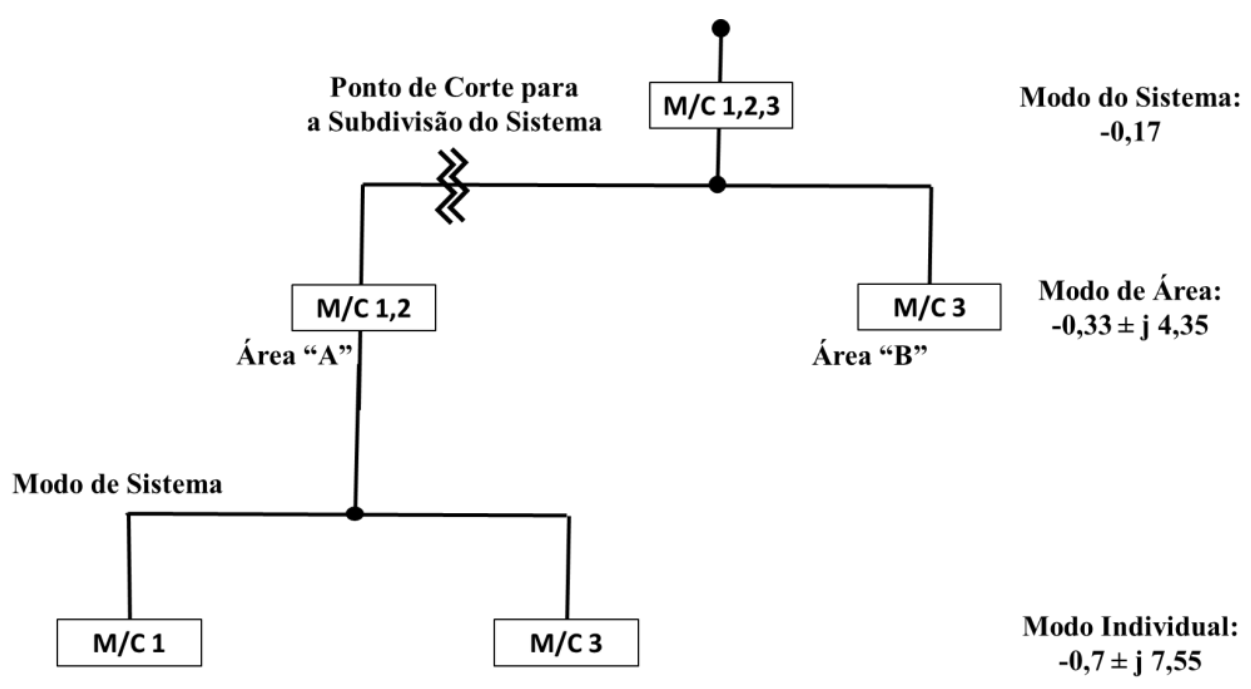

Figura 3.2. Árvore modal - modos eletromecânicos [7].

A árvore modal é usada para determinar grupos coerentes de máquinas (que devem ser substituídas por equivalentes), da seguinte maneira. Primeiro a área de estudo é escolhida. Qualquer modo que envolva uma das máquinas na área interna precisa ser mantido e o resto dos modos pode ser descartado. A árvore modal exibe as informações necessárias para fazer esta escolha. Os modos a serem descartados formarão uma ou mais subárvores desconectadas. Se essas subárvores forem removidas da árvore, as barras de fronteira serão formadas por grupos de geradores coerentes.

No entanto, existem alguns problemas computacionais com esta abordagem:

i. A matriz em (3.5) é densa e, consequentemente, para sistemas muito grandes, o seu armazenamento e tempo de computação são bastante ineficientes;

ii. A computação de todos os autovalores dominantes ainda é um desafio. 


\subsection{3.}

\section{Métodos da Coerência Lenta, Vínculos Fracos e Sincronismo}

Essas abordagens baseiam-se na análise modal e consideram apenas os modos lentos (aqueles modos de oscilação entre áreas) que afetam a interação entre os sistemas externos e internos; ou seja, correspondentes à oscilação entre os centros de inércia de diferentes grupos de máquinas firmemente conectados. Os modos de oscilação mais rápidos são relevantes somente para as oscilações locais e não afetam as áreas remotas.

Dessa forma, o método da Coerência Lenta, baseia a identificação dos grupos coerentes na semelhança dos modos de oscilação lenta das máquinas [15]. Como esta abordagem também é baseada na computação dos autovalores e autovetores de (3.5), ela é submetida às mesmas questões computacionais da coerência modal.

O método dos Vínculos Fracos tem como sua principal vantagem o fato de não requerer a computação de autovalores e autovetores de (3.5). Ao invés disso, os índices de acoplamento são derivados de partições de $A_{r}$. Isso evita o problema da análise de autovetores, mas permanece a questão de trabalhar, para sistemas muito grandes, com uma matriz de alta dimensão e não esparsa.

Por fim, o método de Sincronismo $[9,16]$ se baseia numa seleção de modos de interesse menos restritiva do que na coerência lenta. Assim, ele pode incluir modos mais rápidos também.

\subsection{4. Método dos Agrupamentos por Distância Elétrica (Organon)}

O método de agrupamento por distância elétrica parte do conceito utilizado no método de Vínculos Fracos [20], onde os acoplamentos fortes e fracos dos geradores são identificados pelos elementos fora da diagonal da matriz $A_{r}$. Isto tem uma desvantagem computacional por $A_{r}$ ser uma matriz densa.

Para os modelos de máquinas síncronas clássica, $A$ é um bloco diagonal $2 \times 2$. Consequentemente, o acoplamento é afetado principalmente por $B D^{-1} C$, e em particular por $D^{-1}$, que é a matriz $Z_{\text {bus }}$ (ou seja, o inverso da matriz $Y_{\text {bus }}$ ).

Outra característica da matriz $Z_{b u s}$ é que seus elementos $z_{i j}=\frac{\Delta V_{i}}{\Delta I_{j}}$ são sensibilidades que podem ser usadas como índices de proximidade. A injeção de 
uma corrente na barra $j$ causa variações de tensão em todo o sistema. Quanto mais perto da barra $j$, maior será sua variação de tensão. Assim, estes elementos fornecem uma medida de proximidade elétrica. A matriz $Z_{b u s}$ é densa e isto torna o seu cálculo e armazenamento bastante ineficiente. Isto é evitado, no Organon, pela cuidadosa implementação do algoritmo de agrupamento, como explicado a seguir.

Além da proximidade elétrica dos geradores, a estratégia de agrupamento leva em consideração os tamanhos dos geradores. O conceito é que, nos modos de oscilação interárea, os geradores com maior inércia tendem a dominar o movimento angular dos geradores próximos. Assim, os maiores geradores são candidatos a serem selecionados como "medóides". Um medóide é um objeto central em torno do qual o agrupamento é formado. A proximidade entre os demais geradores e o medóide, é medida pela sensibilidade de tensão quando de uma injeção de corrente na barra do gerador medóide, tal que se produza 1 pu (por unidade) de mudança de tensão na sua própria barra. Uma tolerância de sensibilidade estabelece um raio de proximidade com o medóides, ou seja, se a sensibilidade é maior que o limite, o gerador é adicionado ao grupo. Logo o algoritmo para agrupamento fica:

i. Construir a matriz de $Y_{\text {bus }}$ com o inverso da reatância de cada gerador adicionado à sua respectiva linha e fatorar;

ii. Classificar todos os geradores por tamanho, de MVA ou inércia, referidos à base do sistema;

iii. Selecionar o maior gerador $j$, que já não pertença a um grupo, como o medóide de um novo grupo;

iv. Calcular as sensibilidades de tensão em relação ao medóide, o que corresponde aos elementos da coluna $j$ da matriz $Z_{b u s}$ referentes às barras terminais dos geradores;

v. Normalizar as sensibilidades para que aquela associada à barra do medóide seja igual a 1 ;

vi. Adicionar ao grupo, todos os geradores cujas sensibilidades sejam superiores ao limite especificado. Se o gerador já pertence a outro grupo, decidir se este 
deve ser transferido para outro grupo, comparando as sensibilidades em ambos;

vii. Armazenar apenas as sensibilidades dos geradores em grupos;

viii. Se todos os geradores foram classificados em grupos, finalizar o processo de agrupamento. Se não, volte ao passo (iii).

O número de sensibilidades armazenadas é igual ao número de geradores no sistema original. O número de vezes que as sensibilidades são calculadas na etapa (iv) é igual ao número de grupos de geradores.

Além disso, o algoritmo impõe restrições sobre a diferença entre o ângulo do rotor de um gerador e sua medóide, e caso o limite especificado seja ultrapassado, o gerador não é incluído no grupo. Quaisquer geradores não agrupados podem ser mantidos ou descartados, dependendo de seu tamanho e do limite de MVA especificado. Se mantido, seu modelo pode permanecer original ou ser reduzido.

\section{4. Métodos de Agregação de Geradores no Modelo Clássico}

Um modo de oscilação entre duas áreas é uma função da distância entre os respectivos centros de ângulo (ângulo médio ponderado pela inércia), inércia total da área e o efeito de amortecimento composto de geradores individuais. No cálculo do equivalente dinâmico, a redução da rede mantém as distâncias elétricas perto dos valores originais. A inércia da máquina agregada é simplesmente a soma das constantes de inércia das máquinas individuais no agrupamento. $\mathrm{O}$ efeito de amortecimento é o resultado da ação de controles do gerador, em especial seus sistemas de excitação. Ao mesmo tempo, como os geradores no sistema externo são remotos, seus efeitos sobre o controle de tensão de qualquer barra na área interna são insignificantes. Assim, enquanto seus efeitos de amortecimento são relevantes, suas funções de controle de tensão não são.

Em decorrência disso, o modelo clássico de máquinas síncronas pode ser adaptado para um modelo reduzido. Se o equivalente a ser simulado for submetido a desvios de frequência significativos, o regulador de velocidade, e seus efeitos, precisam ser representados. 
Se os geradores a serem agregados forem representados por um modelo clássico, a reatância transitória equivalente será o paralelo dos valores de reatância individual e o coeficiente de amortecimento equivale à soma dos amortecimentos de cada gerador no agrupamento. Ou seja, para dois geradores temos:

$$
\begin{gathered}
\mathrm{m}_{e q}=\mathrm{m}_{A}+\mathrm{m}_{B} \\
\mathrm{D}_{e q}=\mathrm{D}_{A}+\mathrm{D}_{B} \\
\left(x_{d}^{\prime}\right)_{e q}=\left(\frac{1}{x_{d_{A}}}+\frac{1}{x_{d_{B}}^{\prime}}\right)^{-1}
\end{gathered}
$$

onde,

$$
\begin{aligned}
& \mathrm{m}_{A}, \mathrm{~m}_{B} \text { - inércia dos geradores "A" e "B"; } \\
& \mathrm{D}_{A}, \mathrm{D}_{B}-\text { amortecimento dos geradores " } \mathrm{A} \text { " e "B"; } \\
& \left(x_{d}^{\prime}\right)_{A},\left(x^{\prime}{ }_{d}\right)_{B} \text { - reatâncias transitórias dos geradores "A" e "B". }
\end{aligned}
$$

\subsection{1. \\ Método de Agregação de Podmore}

Como exemplificado em [15], neste método, uma vez determinada a coerência para dois geradores, "A" e " $B$ ", as suas barras terminais "a" e " $b$ " são ligadas a uma barra "q" comum. A tensão em "q" pode ser definida como o valor médio das tensões ou ponderada pelas potências ativa e reativa.

Para manter os fluxos originais, entre a barra "q" e as barras "a" e "b", são utilizados dois transformadores ideais com as relações de transformação complexas, $\propto_{a} \tan ^{-1}\left(\emptyset_{a}\right)$ e $\propto_{b} \tan ^{-1}\left(\emptyset_{b}\right)$, e impedância nula. As fases, $\emptyset_{a}$ e $\emptyset_{b}$, também podem ser representadas como transformadores defasadores, como mostrado na Figura 3.3, a seguir, e retirada de [15]. 


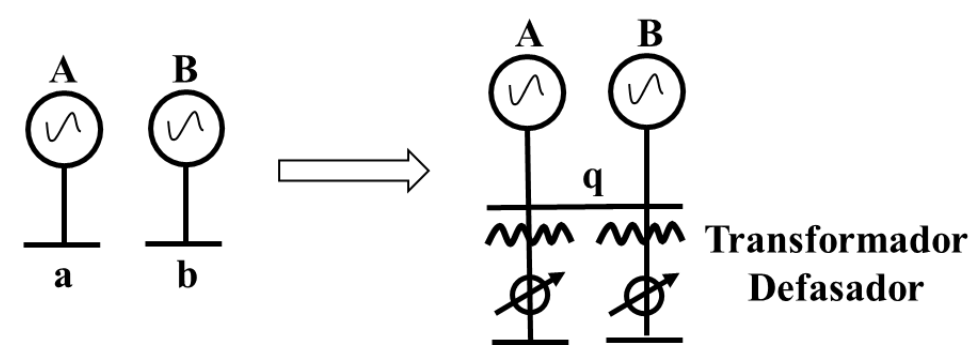

Figura 3.3. Esquema de agregação "Podmore" [15].

Em seguida, os geradores são agrupados em um único gerador com uma inércia equivalente, $\mathrm{m}_{e q}$, e uma reatância transitória equivalente, $\left(x_{d}^{\prime}\right)_{e q}$, como definido em (3.8) e (3.10), respectivamente.

\subsection{2.}

\section{Modelo de Agregação Inercial}

Como exemplificado em [15], neste método, uma vez determinada a coerência para dois geradores, "A" e "B", sendo suas barras terminais "a" e "b", são calculadas as tensões das barras internas dos geradores, $E^{\prime}{ }_{A}$ e $E^{\prime}{ }_{B}$.

As barras internas são ligadas a uma barra "p" comum. A tensão em "p", $E^{\prime}{ }_{e q}$, pode ser definida como o valor médio das tensões ou ponderada pelas potências ativa e reativa.

Para manter os fluxos originais, entre a barra "p" e as barras "a" e "b", são utilizados dois transformadores ideais com relações de transformação complexas, $\propto_{a} \tan ^{-1}\left(\emptyset_{a}\right)$ e $\propto_{b} \tan ^{-1}\left(\emptyset_{b}\right)$, e impedância nula. As fases, $\emptyset_{a}$ e $\emptyset_{b}$, também podem ser representadas como transformadores defasadores.

A conexão das barras internas cria um gerador equivalente com múltiplas barras terminais, o que não é a forma usual de representação de geradores em programas de simulação. Dessa forma, a rede deve ser estendida por mais duas barras com reatâncias $-\left(x^{\prime}{ }_{d}\right)_{e q}$ e $\left(x_{d}^{\prime}\right)_{e q}$, considerando (3.10), como mostrado na Figura 3.4, a seguir e retirada de [15]. 


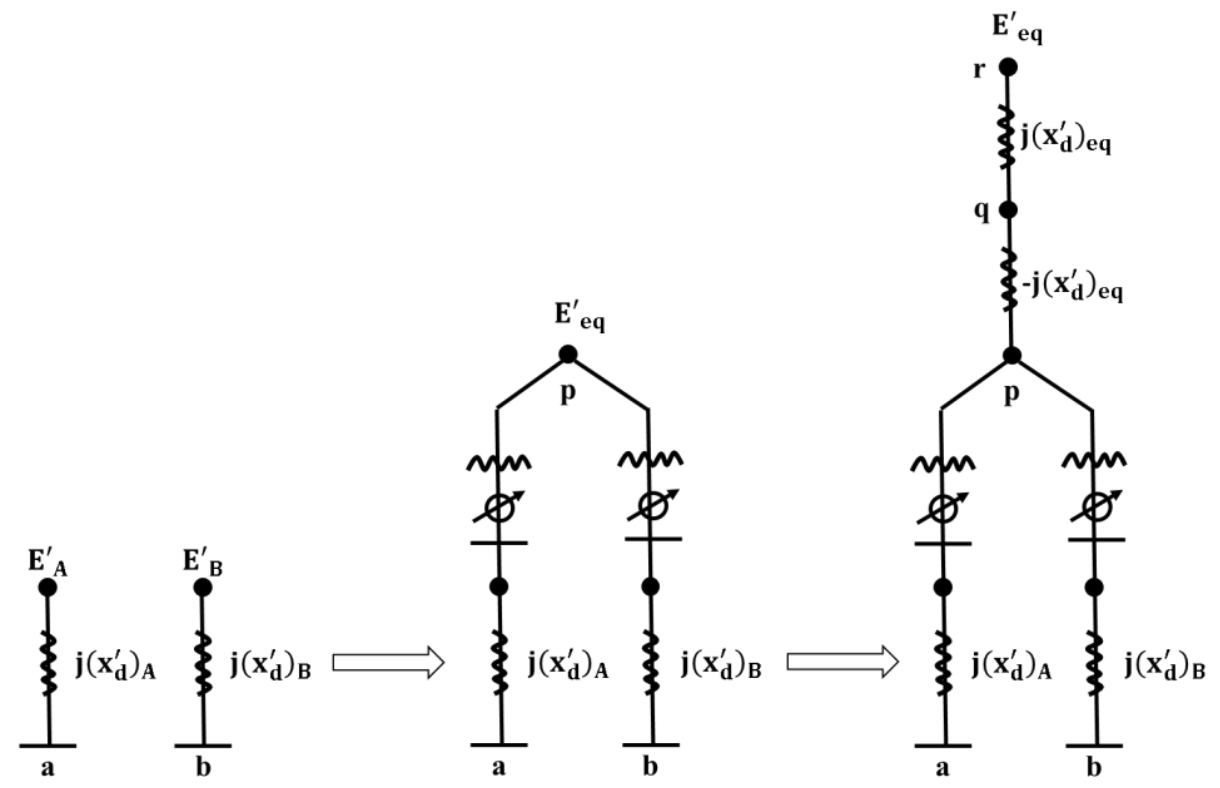

Figura 3.4. Esquema de agregação inercial [15].

Os nós "r" e " $q$ " servem como barra interna e terminal do gerador equivalente, respectivamente. Em seguida, pode-se determinar a inércia equivalente, $m_{e q}$, como definido em (3.8).

\subsection{3.}

\section{Método de Agregação de Zhukov}

Nos métodos anteriores, uma vez que as barras dos geradores possuem tensões com diferentes módulos e ângulos, as mesmas são conectadas através de transformadores defasadores ideais. No entanto, transformadores defasadores atrapalham a linearidade e simetria das equações de rede, sendo problemático para a redução de rede através da eliminação de Gauss. Como alternativa, o Organon utiliza o método de Zhukov, no qual não são necessários transformadores ideais.

O método de Zhukov consiste em substituir um conjunto de nós “A”, em uma única barra equivalente "a". O conjunto de barras retidas é definido como "R" e a agregação deve satisfazer as seguintes condições:

i. Não modificar as correntes e tensões nas barras retidas;

ii. A potência do gerador equivalente na barra "a" deve ser a soma das potências dos geradores no agrupamento. 
Tal transformação pode ser descrita como o particionamento da matriz $Y_{b u s}$, em componentes retidos e reduzidos. Considerando que o conjunto " $A$ " de $n$ elementos será agregado numa única barra "a", o sistema original pode ser particionado como a seguir:

$$
\left[\begin{array}{l}
I_{R} \\
I_{A}
\end{array}\right]=\left[\begin{array}{ll}
Y_{R R} & Y_{R A} \\
Y_{A R} & Y_{A A}
\end{array}\right] \times\left[\begin{array}{l}
V_{R} \\
V_{A}
\end{array}\right]
$$

Enquanto o sistema reduzido será:

$$
\left[\begin{array}{c}
I_{R} \\
I_{a}
\end{array}\right]=\left[\begin{array}{ll}
Y_{R R} & Y_{R a} \\
Y_{a R} & Y_{a a}
\end{array}\right] \times\left[\begin{array}{l}
V_{R} \\
V_{a}
\end{array}\right]
$$

Para a manutenção de $I_{R}$ e $V_{R}$, devemos ter:

$$
Y_{R a}=\frac{1}{V_{a}} Y_{R A} V_{A}
$$

Enquanto que para a segunda afirmação é necessário que as expressões de potência também sejam equivalentes, como a seguir:

$$
V_{a}^{T} I_{a}^{*}=V_{A}^{T} I_{A}^{*}
$$

Ao substituir (3.14) em (3.11) e (3.12), obtém-se:

$$
\begin{gathered}
Y_{a R}=\frac{1}{V_{a}^{*}} V_{a}^{* T} Y_{A R} \\
Y_{a a}=\frac{1}{V_{a}^{2}} V_{A}^{* T} Y_{A A} V_{A}
\end{gathered}
$$

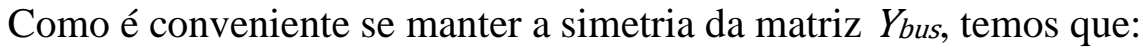

$$
Y_{a R}=\left[Y_{R a}\right]^{T}
$$


Neste caso, será necessário compensar com uma admitâncias shunt na barra "a", o que resulta em:

$$
\left[\begin{array}{l}
I_{R} \\
I_{a}
\end{array}\right]=\left[\begin{array}{cc}
Y_{R R} & Y_{R a} \\
Y_{R a}{ }^{T} & Y_{a a}+\frac{I_{c}}{V_{a}}
\end{array}\right] \times\left[\begin{array}{l}
V_{R} \\
V_{a}
\end{array}\right]
$$

onde:

$$
I_{c}=\left(\frac{1}{V_{a}^{*}} V_{A}^{*}-\frac{1}{V_{a}} V_{A}\right)^{T} Y_{A R} V_{R}
$$

$\mathrm{O}$ valor $I_{c}$ é pequeno quando comparado com $I_{a}$ se a diferença $\left(\frac{1}{V_{a}^{*}} V_{A}^{*}-\right.$ $\left.\frac{1}{V_{a}} V_{A}\right)$ também for pequena, o que ocorrerá caso os ângulos das barras no conjunto "A" estiverem próximos. Sendo um motivo adicional para se manter um limite de máxima diferença angular durante o processo de agrupamento.

Essa formulação necessita que a tensão $V_{a}$ seja conhecida. Usualmente a tensão de $V_{a}$ é definida como a média ponderada das barras do conjunto "A". Os pesos podem ser o MVA base ou a inércia de cada gerador.

$$
\left|V_{a}\right|=\frac{1}{n} \sum_{I=1}^{n} V_{I}
$$

$$
\left|\delta_{a}\right|=\frac{\sum_{I e A} S_{I} \delta_{I}}{\sum_{I e A}^{n} S_{I}} \text { ou }\left|\delta_{a}\right|=\frac{\sum_{I e A} M_{I} \delta_{I}}{\sum_{I e A}^{n} M_{I}}
$$

onde,

$\mathrm{S}_{I}$ - potência base, em MVA, do gerador I

$\mathrm{M}_{I}-$ coeficiente de inércia do gerador I; 
Quando as barras do conjunto "A" possuem múltiplas ligações com as barras no conjunto "R" (3.15), podem ocorrer impedâncias negativas devido aos fluxos invertidos em algumas dessas ligações. Dependendo da magnitude dessas impedâncias, é possível que elas produzam um coeficiente de sincronização negativo $\left(\frac{V_{1} V_{2}}{X_{12}} \cos \delta_{12}\right)$ com os geradores próximos e, consequentemente, instabilidade. Uma forma de se evitar este problema é impor limites nos valores dessas impedâncias (ex.: > 0). Outra forma, é permitir que $Y_{R}$ seja modificada. Neste caso, $Y_{R a}=Y_{a R}$ será a impedância paralela das barras do conjunto "R" que se conectam com a barra "a"; ou seja, $Y_{R a}$ é calculado como a soma das colunas de $Y_{R a}$, enquanto $\Delta Y_{R R}$ e $Y_{a a}$ são calculados para se manter $I_{a}, I_{R}, V_{a}$ e $V_{R}$.

$$
\left[\begin{array}{c}
I_{R} \\
I_{a}
\end{array}\right]=\left[\begin{array}{cc}
Y_{R R}+\Delta Y_{R R} & Y_{R a} \\
Y_{a R} & Y_{a a}
\end{array}\right] x\left[\begin{array}{c}
V_{R} \\
V_{a}
\end{array}\right]
$$

\subsection{4. \\ Método de Agregação de Geradores: Modelo de $2^{\text {a. }}$ Ordem}

Sendo o modo de oscilação entre duas áreas uma função das suas respectivas distâncias elétricas, inércias e a combinação do efeito individual dos amortecimentos de cada gerador, no cálculo de um equivalente dinâmico, a redução da rede se encarrega de manter as distâncias elétricas próximas às originais. As inércias dos geradores equivalentes são a soma das constantes de inércia dos geradores agrupados. Caso esses geradores sejam originalmente representados por modelos clássicos, a reatância transitória equivalente será o paralelo das reatâncias transitórias individuais dos geradores agrupados e o coeficiente de amortecimento equivalente será a soma das constantes de amortecimento dos geradores agrupados.

No entanto, caso esses geradores estejam originalmente representados com modelos de maior ordem e demais controles, os simples procedimentos anteriores podem levar a erros não desprezíveis.

Dessa forma, dois problemas devem ser resolvidos: 
i. Qual modelo ou modelos devem ser adotados para os geradores equivalentes;

ii. Como deverão ser determinados seus parâmetros de forma que se obtenha uma boa acurácia para distúrbios na área de interesse.

Este método, como mostrado em [10], consiste em calcular a resposta de frequência para uma relação pré-estabelecida de entrada-saída. Neste caso, os geradores respondem a variações de potência causadas por variações angulares. Em seguida, um modelo de segunda ordem é ajustado para esta resposta em frequência. Em outras palavras, o método é uma técnica de ajuste de curva, ou seja, é encontrado um modelo (de segunda ordem) que melhor se ajuste à resposta em frequência determinada.

A resposta em frequência do gerador pode ser obtida com a representação linear do modelo de sistema multimáquina, mas para um melhor desempenho, o modelo detalhado do gerador é conectado a uma barra infinita fictícia através de uma impedância externa, definida no intervalo $[0,4-0,8]$ pu sobre a base do gerador, uma vez que este intervalo representa bem as distâncias interárea [21]. Adicionalmente, a condição de operação do gerador (tensão terminal e potência aparente) é definida para ser a mesmo do caso original.

Tendo em conta a relação de entrada-saída, o modelo tem a forma:

$$
\begin{gathered}
\Delta \dot{x}=A \Delta x+b \Delta P_{m} \\
\Delta \delta=c \Delta x
\end{gathered}
$$

onde,

$A_{(m \times 1)}-$ vetor de entrada;

$b_{(1 \times m)}$ - vetor de saída;

$\Delta P_{m}$ - sinal de entrada do gerador (variações de potência mecânica);

$\Delta \delta$ - sinal de saída do gerador (variações de ângulo do rotor). 
Dessa forma, a resposta de um gerador de frequência é dada por:

$$
\frac{\Delta \delta(j \omega)}{\Delta P_{m}(j \omega)}=c[(j \omega) I-A]^{-1} b
$$

onde,

$\omega$ - frequência angular em $\mathrm{rad} / \mathrm{s}$;

Uma vez que a resposta em frequência de (3.25) foi calculada, um modelo de segunda ordem é identificado usando uma técnica de ajuste de curvas complexas por ponderação [22], resultando no seguinte modelo:

$$
M(s)=\frac{b_{2} s^{2}+b_{1} s+b_{0}}{a_{2} s^{2}+a_{1} s+a_{0}}
$$

A linearização do modelo clássico do gerador acoplado a um barramento infinito através de uma reatância é descrita pelas seguintes equações escalares:

$$
\Delta \dot{\delta}=\omega_{0} \Delta \omega
$$

$$
\begin{gathered}
\Delta \dot{\omega}=\frac{1}{M}\left(\Delta P_{m}-\Delta P_{e}-D \Delta \omega\right) \\
\Delta P_{e}=K_{1} \Delta \delta \\
K_{1}=\frac{\left|E_{q}\right|\left|V_{\infty}\right|}{x_{g}+x_{e}} \cos (\delta) \\
\bar{E}_{q}=V_{\infty}+j\left(x_{g}+x_{e}\right) \bar{I}
\end{gathered}
$$


onde,

$\delta$ - ângulo do rotor do gerador referido ao ângulo da tensão da barra infinita;

$\omega$ - velocidade do rotor do gerador;

$\mathrm{P}_{\mathrm{e}}$ - potência elétrica do gerador;

$\mathrm{P}_{\mathrm{m}}$ - potência mecânica;

M - constante de inércia;

D - coeficiente de amortecimento;

$\overline{\mathrm{E}}_{\mathrm{q}}$ - tensão interna do gerador;

$\mathrm{V}_{\infty}$ - magnitude da tensão da barra infinita;

$\mathrm{x}_{\mathrm{g}}$ - reatância transitória do gerador $\left(\mathrm{x}_{\mathrm{d}}^{\prime}\right)$;

$\mathrm{x}_{\mathrm{e}}$ - reatância externa conectando a barra terminal do gerador a barra infinita.

No entanto, para representar o modelo equivalente em programas de simulação convencional, não é possível a utilização de (3.26), pois não se trata de um modelo padrão. Pode-se usar no lugar a função de transferência de um modelo clássico de gerador:

$$
\frac{\Delta \delta(s)}{\Delta P(s)}=M_{D}(s)=\frac{\omega_{0}}{M s^{2}+D s+K_{1} \omega_{0}}
$$

$\mathrm{O}$ mapeamento é feito considerando $\mathrm{M}$ invariável, negligenciando $\mathrm{b}_{1}$ e $\mathrm{b}_{2}$, que são tipicamente muito pequenos, e preservando o modo de oscilação (denominador) em (3.26). Uma possível alternativa, caso $\frac{\mathrm{b}_{1}}{\mathrm{~b}_{0}}$ seja muito grande, é não agregar a respectiva máquina em um grupo, utilizando o seu modelo original. Observou-se que esta proporção é maior em geradores com estabilizadores de potência (PSS) com elevados valores de ganho. 
Dessa forma, o mapeamento corresponde as seguintes identidades:

$$
\begin{gathered}
K_{1}=\frac{M}{\omega_{0} a_{2}} \\
D=\frac{a_{1} M}{a_{2}}
\end{gathered}
$$

Devido a não linearidade de $\mathrm{K}_{1}$ em (3.30) e (3.31), as equações (3.33) e (3.34) são resolvidas iterativamente pelo método de Newton.

Em seguida os geradores são agrupados em um único gerador com inércia, $m_{e q}$, amortecimento, $D_{e q}$, e uma reatância transitória, $\left(x_{d}^{\prime}\right)_{e q}$, como definido em (3.8), (3.9) e (3.10), respectivamente.

\section{5 .}

\section{Análise de Precisão Dinâmica}

Para as análises dinâmicas de forma a permitir uma avaliação automática e criteriosa, o Organon utiliza os índices de Diferença de Trajetórias (TD) e de Estabilidade Transitória (TS), definidos como a seguir:

$$
T D(\%)=\frac{100}{\Delta x T} \sqrt{\int_{0}^{T}\left(x_{0}-x_{r}\right)^{2} d t}
$$

$$
\begin{aligned}
& T S_{+}=\frac{\delta_{u}-\delta_{r}}{\delta_{u}-\delta_{s}+\tau} \text { (para resultados de simulações estáveis) } \\
& T S_{-}=\frac{V k e_{\min }}{V k e_{\max }} \text { (para resultados de simulações instáveis) }
\end{aligned}
$$

onde,

T - intervalo de simulação;

$\mathrm{x}_{0}$ - trajetória do sistema original;

$\mathrm{x}_{\mathrm{r}}$ - trajetória do sistema reduzido;

$\Delta \mathrm{x}$ - diferença entre os valores máximo e mínimo de $\mathrm{x}_{0}$; 
$\delta_{r}, \delta_{\mathrm{s}} e \delta_{\mathrm{u}}-$ ângulos de retorno, de equilíbrio estável e de equilíbrio instável, respectivamente, considerando o método de máquina equivalente (SIME);

$\mathrm{Vke}_{\max }$ e $\mathrm{Vke}_{\min }$ - energia cinética máxima e mínima, respectivamente, calculadas para a curva instável.

O índice TD compara e quantifica a diferença dos resultados das simulações dos sistemas equivalente e completo, durante o período de simulação e contingência definidos pelo usuário. Já o índice TS, utilizados na análise de segurança dinâmica do Organon, compara e quantifica a margem de estabilidade transitória de ambos os sistemas.

Para trajetórias estáveis, o índice TS varia entre "0" e "1", enquanto que para trajetórias instáveis o índice varia entre "-1" e "0". Os maiores valores de TD são, em geral, encontrados nas barras de fronteira e usados como medida de precisão.

Com base nos resultados de precisão, o analista pode tentar ajustar o procedimento de redução para melhorar o equivalente de acordo com os critérios especificados.

\section{6.}

\section{Comentários Finais}

A implementação da técnica de agrupamento baseado em distâncias elétricas em conjunto com a sua agregação e representação por modelos de segunda ordem, dota o programa Organon com uma capacidade de reduzir não somente as dimensões da rede, mas também o número de variáveis dos modelos dinâmicos considerados, enquanto mantêm, com boa precisão, o comportamento dinâmico dos mesmos. Por outro lado, a possibilidade de se manter a representação completa daqueles geradores cuja influência no cenário estudado é relevante, permite obter-se melhor acurácia.

Com uma característica empírica, inerente ao processo de redução de rede e de equivalentes dinâmicos, a possibilidade de avaliar de forma fácil e automática os resultados obtidos com certo conjunto de limites de sensibilidade é indispensável e crucial para o processo de melhoria do equivalente. 


\section{4 \\ Aplicação do Equivalente Dinâmico no Sistema Elétrico Brasileiro}

\section{1. Introdução}

Após o levantamento teórico, se faz necessário testar a sua aplicação em sistemas reais de grande porte. Os testes realizados, a seguir, têm como objetivo, de forma progressiva, averiguar quais são as condições de contorno que produzem os melhores resultados e, se possível, apontar melhorias nos modelos empregados e/ou no programa computacional.

Dessa forma, será utilizado um caso base do SIN, planejado para o mês de agosto de 2018, apenas com o primeiro bipolo de Belo Monte em operação, Xingu - Estreito. Foram considerados dois cenários bases, descritos a seguir, nos quais foram realizados vários testes:

1. Um equivalente dinâmico, considerando como região interna a rede de atendimento aos estados do Acre e Rondônia, enquanto o restante do SIN será reduzido. Serão aplicadas diversas contingências, com níveis de severidade diversos, inclusive algumas com o potencial de provocar a perda de sincronismo entre a rede retida e o restante do sistema

2. Um equivalente dinâmico considerando a contingência do Bipolo EstreitoXingu, operando neste sentido, com uma potência transmitida de $4.000 \mathrm{MW}$. A rede interna considerada será a rede de $500 \mathrm{kV}$ paralela ao Bipolo, ou seja, a interligação Norte-Sul.

Para permitir a identificação clara dos diferentes cenários e seus respectivos testes, será adotada a notação, T1_N, para o cenário “1”, e T2_N, para o cenário "2", onde "N" é a sequência numérica dos testes de cada cenário. 


\section{2.}

\section{Sistema do Acre e Rondônia (Cenário 1)}

O sistema elétrico dos estados do Acre e Rondônia é atendido de forma síncrona através de três circuitos de $230 \mathrm{kV}$ entre as subestações de Vilhena, em Rondônia, e de Jauru, no Mato Grosso. Adicionalmente, esse sistema se interliga de forma assíncrona com as usinas do Rio Madeira, Santo Antônio e Jirau, através de duas estações conversoras "back to back", de 400 MVA cada, como pode ser observado na Figura 4.1, a seguir.

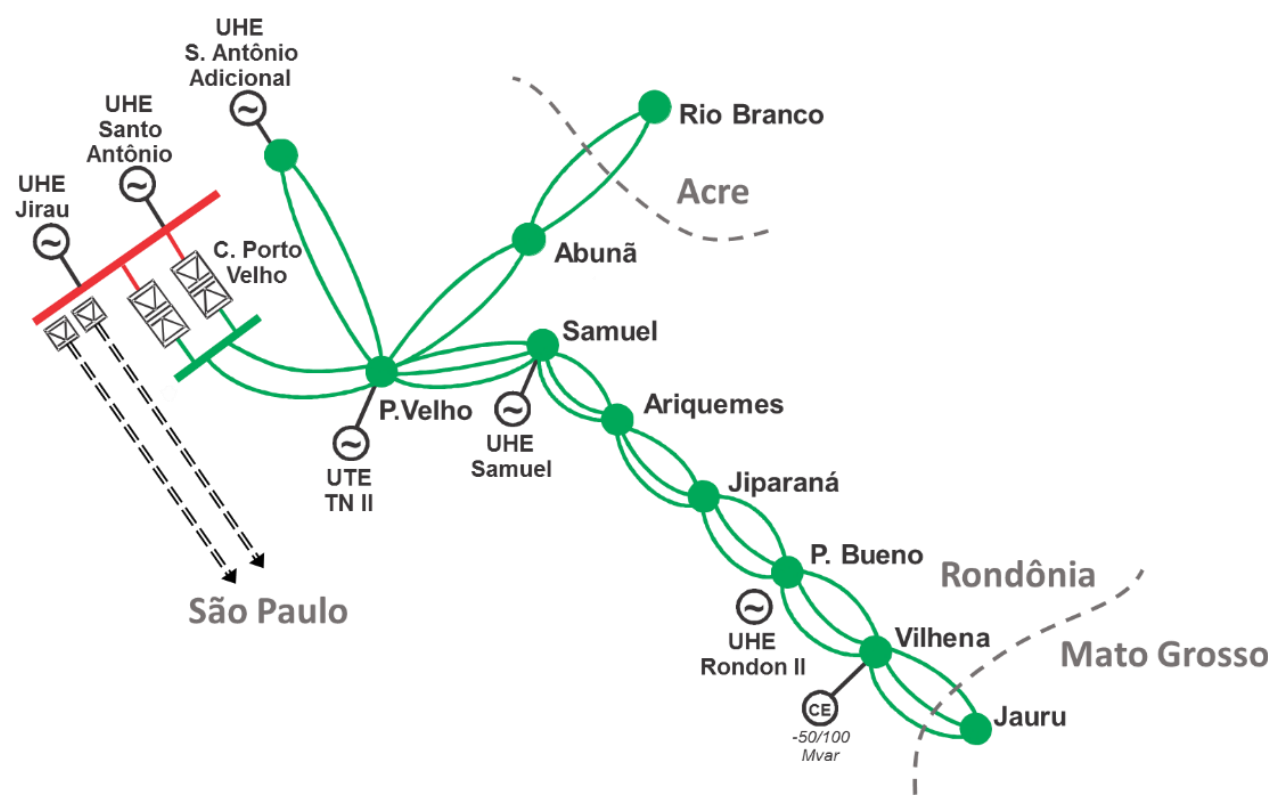

Figura 4.1. Diagrama unifilar do sistema Acre e Rondônia.

A escolha desse sistema como área teste se deve ao fato de sua característica quase radial possibilitar, de forma bastante direta, a percepção do sucesso da escolha dos critérios de definição das áreas internas e externas.

No entanto, esta mesma característica, que a princípio confere simplicidade às análises, por outro lado torna o sistema bastante vulnerável a contingências em suas interligações. A severidade dessas perdas é tamanha que para a sua simulação é necessário o uso de programas de estabilidade eletromecânica.

Por ser uma rede fraca, com baixo nível de curto circuito, os efeitos da redução de partes da rede e da representação aproximada de geradores podem ter grandes impactos. 
Neste sentido, tanto a contingência de dois circuitos da interligação com o Mato Grosso, entre Jauru e Vilhena, quanto à perda dos dois blocos conversores "back to back", são as contingências mais severas para este sistema e um excelente teste para o equivalente dinâmico.

Embora tenham sido feitos inúmeros testes, a seguir, serão explicitados dois dos resultados obtidos, definidos como T1_1 e T1_2.

\subsection{1.}

\section{Definição das Regiões Internas, Externas e da Zona Intermediária}

Após vários testes, optou-se por definir a região interna apenas como as barras das regiões elétricas do Acre e Rondônia com tensões igual ou superior a $230 \mathrm{kV}$. No entanto, durante o processo de equivalência de rede e através dos testes de sensibilidade, algumas poucas barras de 69 e $138 \mathrm{kV}$ foram retidas.

Cabe destacar que, nos testes T1_1 e T1_2 foi necessário a definição das barras contendo os CEs (Compensador Estático) do sistema do Mato Grosso como barras adicionais, ou seja, as mesmas foram retidas com seus modelos completos, porém desconsideradas nos cálculos de acurácia do sistema equivalente.

\subsection{2.}

\section{Lista de Contingências}

Para que fossem aplicados os testes de precisão, foi apresentado ao programa Organon uma lista com 12 contingências simples e 2 contingências duplas em circuitos de $230 \mathrm{kV}$ do sistema Acre e Rondônia. Na Tabela 4.1, a seguir, estão listadas as contingências consideradas.

Tabela 4.1. Lista de contingências

\begin{tabular}{|l|lll|}
\multicolumn{2}{l}{ Contingêneias } \\
\hline 1. & P. Bueno-Vilhena (Circ. 1) & 2. & JiParana-P. Bueno (Circ. 1) \\
\hline 3. & Jaru-JiParana (Circ. 1) & 4. & Ariquemes-Jaru (Circ. 1) \\
\hline 5. & P. Velho-S.A.Ad1 (Circ. 1) & 6. & Samuel-Ariquemes (Circ. 1) \\
\hline 7. & Samuel-P. Velho (Circ. 1) & 8. & P. Velho-N. M. Paraná (Circ. 1) \\
\hline 9. & P. Velho-Abunã (Circ. 1) & 10. & Abunã-N. M. Paraná (Circ. 1) \\
\hline 11. & Abunã-R. Branco (Circ. 1) & 12. & C. P. Velho-P. Velho (Circ. 1) \\
\hline 13. & Jauru-Vilhena (Circ. 1 e 2) & 14. & C. P. Velho-P. Velho (Circ. 1 e 2) \\
\hline
\end{tabular}


Como comentado anteriormente, e pelos motivos já abordados, as contingências críticas para o sistema de atendimento aos estados do Acre e Rondônia são as de número 13, interligação com o Mato Grosso, e 14, perda dos dois blocos do "back-to-back".

\subsection{3.}

\section{Definição dos Valores de Sensibilidades}

Nos testes apresentados a seguir, foram utilizados diferentes valores para as sensibilidades de retenção de circuitos e de agrupamento de geradores, de forma a identificar a combinação que permita os melhores resultados, os quais são mostrados abaixo.

Opções relativas à rede:

- Retenção de barras PV no sistema externo devido a variações de tensão nas barras de fronteira (parâmetro RETVLT): 5,00 (\%), no T1_1, e 10,00 (\%), no T1_2;

- Retenção de circuitos no sistema externo devido a variações de fluxos em circuitos conectados às barras de fronteira (parâmetro RETFLW): 5,00 (MW), no T1_1, e 10,00 (MW), no T1_2;

- Descarte de ligações equivalentes cujas impedâncias sejam elevadas (parâmetro MAXZ): 5,00(\%).

Opções relativas à representação dos geradores:

- Retenção dos modelos completos de geradores através da sensibilidade $d V g_{\text {Int }} / d I g_{\text {ext }}$ devido às variações de tensão nas barras dos geradores internos para variações na injeção de corrente nos geradores externos (parâmetro EXDST): 0,020 (pu);

- Inclusão de geradores em clusters através da sensibilidade $d V g_{\text {ext } i} / d I g_{\text {ext }} j$ devido às variações de tensão nas barras dos geradores externos para variações na injeção de corrente nos demais geradores externos (parâmetro DVMIN): 0,100 (pu); 
- Valor máximo da diferença angular entre dois geradores do sistema externo, para que pertençam ao mesmo cluster (parâmetro ANGDIF): 20,0 $0^{\circ}$ no T1_1, e 50,0, no T1_2;

- Valor máximo para remoção dos geradores do sistema externo que não tenham tido seus modelos completos retidos ou selecionados para um cluster (parâmetro OUTMW): 300,0 MW;

- Valor mínimo da faixa de reativo [Qmin, Qmax] de um gerador externo para selecioná-los para um cluster (parâmetro RETGENMVA): 1,0 pu (base 100 MVA).

\subsection{4.}

\section{Resultados do Teste T1_1}

Como se pode observar na Figura 4.2, a seguir, foi possível efetuar a redução de cerca de $90 \%$ da rede original, obtendo-se uma diferença em relação às tensões pré e pós a redução da rede, de no máximo $0,5 \%$, na pior contingência, e na média de todas as contingências, cerca de $0,25 \%$.

Para o índice de estabilidade, as diferenças foram significativamente maiores entre a rede completa e a reduzida, o que poderia indicar que apesar deste índice ser de extrema valia para a caracterização da distância em que um determinado ponto de operação está da instabilidade, dada uma contingência, o mesmo pode não ser o mais indicado para avaliar o sucesso da redução de rede. 


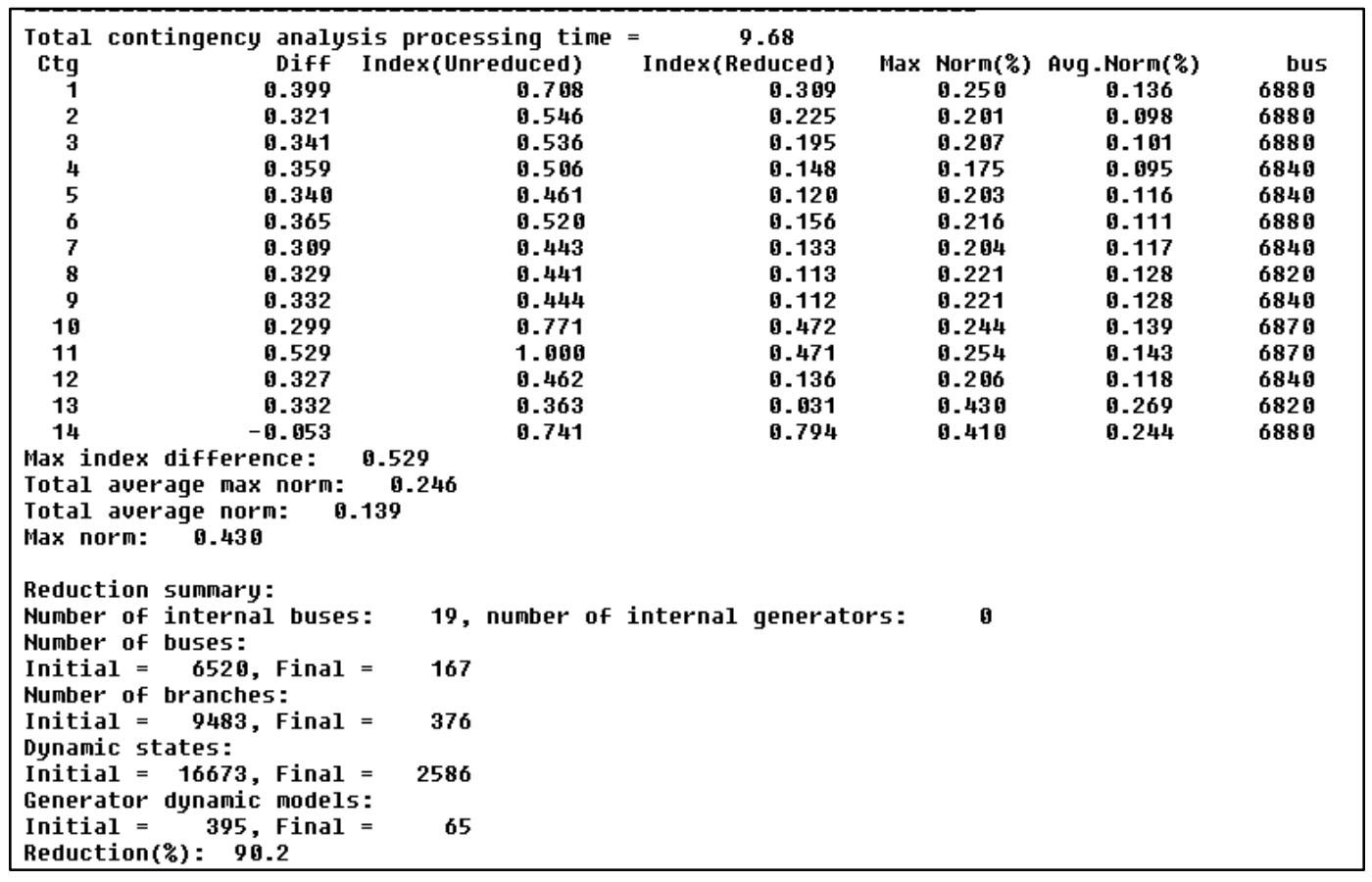

Obs.: Relatório exibido em tela pelo Organon considera o ponto “.” como separador decimal.

Figura 4.2. Síntese da redução da rede e do teste de precisão no T1_1.

A UTE Termo Norte II e as UHEs S. Antônio Adicional e Samuel foram mantidas com seus modelos completos uma vez que estão conectadas através de seus transformadores elevadores às barras de $230 \mathrm{kV}$ do Acre e Rondônia, definidas como parte da região interna do equivalente. Por outro lado, a UHE Rondon II, localizada numa rede de $138 \mathrm{kV}$ conectada à SE $230 \mathrm{kV}$ de P. Bueno também teve seus modelos completos preservados devido às análises de sensibilidade. Da mesma forma, outras usinas do Mato Grosso tiveram seus modelos completos mantidos devido às análises de sensibilidade, demonstrando que o Organon foi capaz de identificar corretamente as barras PV com influência no comportamento dinâmico do sistema Acre e Rondônia, fossem essas barras conectadas diretamente à região interna, a uma rede de tensão inferior, porém eletricamente próxima, ou conectadas a redes mais distantes na região externa.

Em relação a Figura 4.2, tem-se que, para todas as contingências consideradas, a coluna "Diff” é a diferença entre os Índices de Estabilidade (TS) dos sistemas original e reduzido, apresentados nas colunas "Index (Unreduced)" e "Index (Reduced)", respectivamente. Ainda da Figura 4.2, as colunas "Max Norm.(\%)" e “Avg Norm.(\%)" apresentam as Diferenças de Trajetória (TD) 
máximas e médias, respectivamente, para a barra de fronteira indicada na coluna "bus".

Observa-se que o índice TS apresentou, em termos numéricos, grandes diferenças entre os sistemas completo e reduzido, enquanto o índice TD as apresenta como baixas diferenças.

Por exemplo, tomando-se como base a linha referente à contingência $n^{\circ} 11$, na Figura 4.2, é possível observar que a diferença entre os índices TS, da mesma, foi de 0,529 , ou seja, uma variação de cerca de $53 \%$. Essa variação poderia ser interpretada como uma grande perda de precisão, porém ao analisarmos os resultados do TD, máximo e médio, com valores de 0,254\% e 0,143\%, respectivamente, percebemos que na realidade o grau de aderência entre as curvas dos sistemas completo e reduzido foi excelente.

Adicionalmente, analisando na Figura 4.2, a linha referente à contingência $\mathrm{n}^{\circ} 14$, observa-se que a diferença entre os índices TS do sistema original e reduzido foi negativa, o que sugeriria que o caso reduzido se mostrou mais estável que o caso completo. Apesar de tal fato não ser impossível, o mesmo seria improvável.

Dessa forma, o índice TD se mostra mais adequado para a comparação do desempenho dos sistemas completo e reduzido e será utilizado tanto para a determinação da adequabilidade, ou não, do equivalente obtido, como para a comparação entre os diversos testes.

Como se pode observar na Figura 4.3, a seguir, quando da contingência $\mathrm{n}^{\circ} 13$, a tensão da barra de Vilhena $230 \mathrm{kV}$ (Barra 6800) mostrou um grande nível de aderência entre o sistema completo e o reduzido, mesmo encontrando-se na fronteira do sistema e sendo submetida à contingência. As curvas em vermelho e azul se referem ao sistema completo, com e sem reguladores de velocidade habilitados, respectivamente, enquanto a curva em verde se refere ao sistema reduzido. 


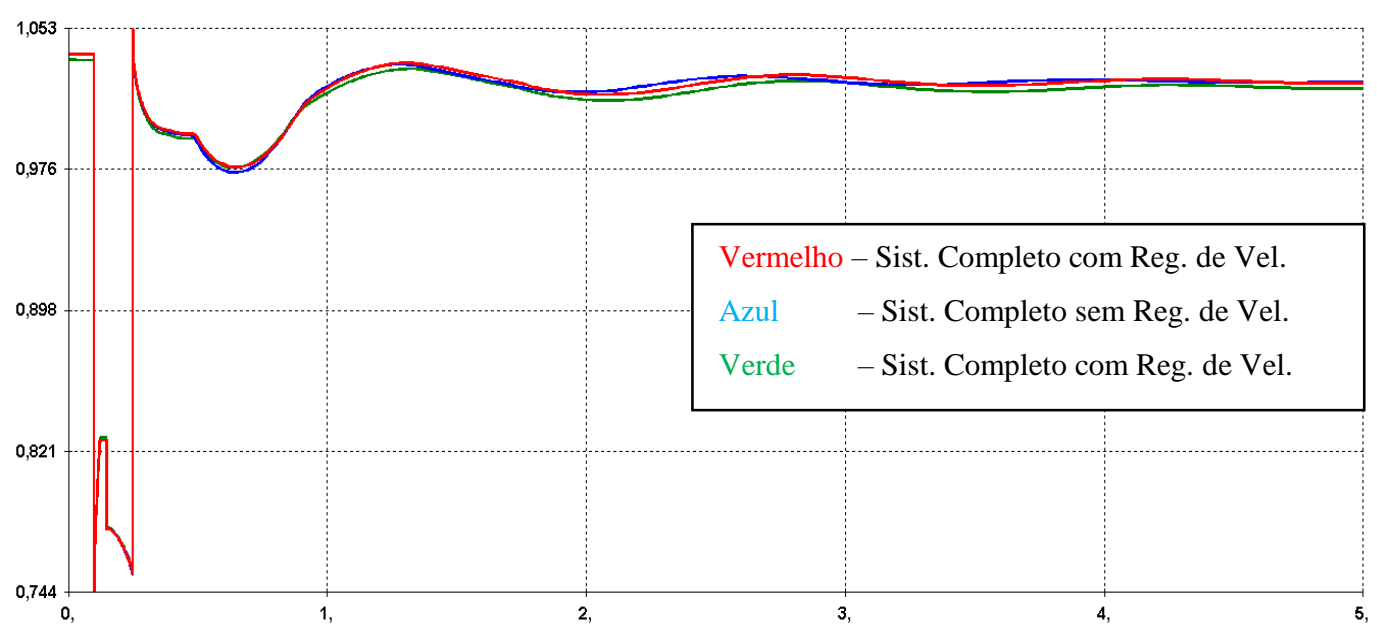

Figura 4.3. Comparação da tensão na barra de Vilhena 230 kV na contingência n¹3, LT 230 kV Jauru - Vilhena C1 e C2, no T1_1.

Da mesma forma pode-se observar na Figura 4.4, a seguir, o excelente resultado da comparação das tensões em P. Bueno $230 \mathrm{kV}$ ( $\mathrm{n}^{\circ}$ de barra: 6820), barra indicada no T1_1 como aquela com o maior valor de diferença entre as curvas do sistema completo e reduzido, quando da contingência 13.

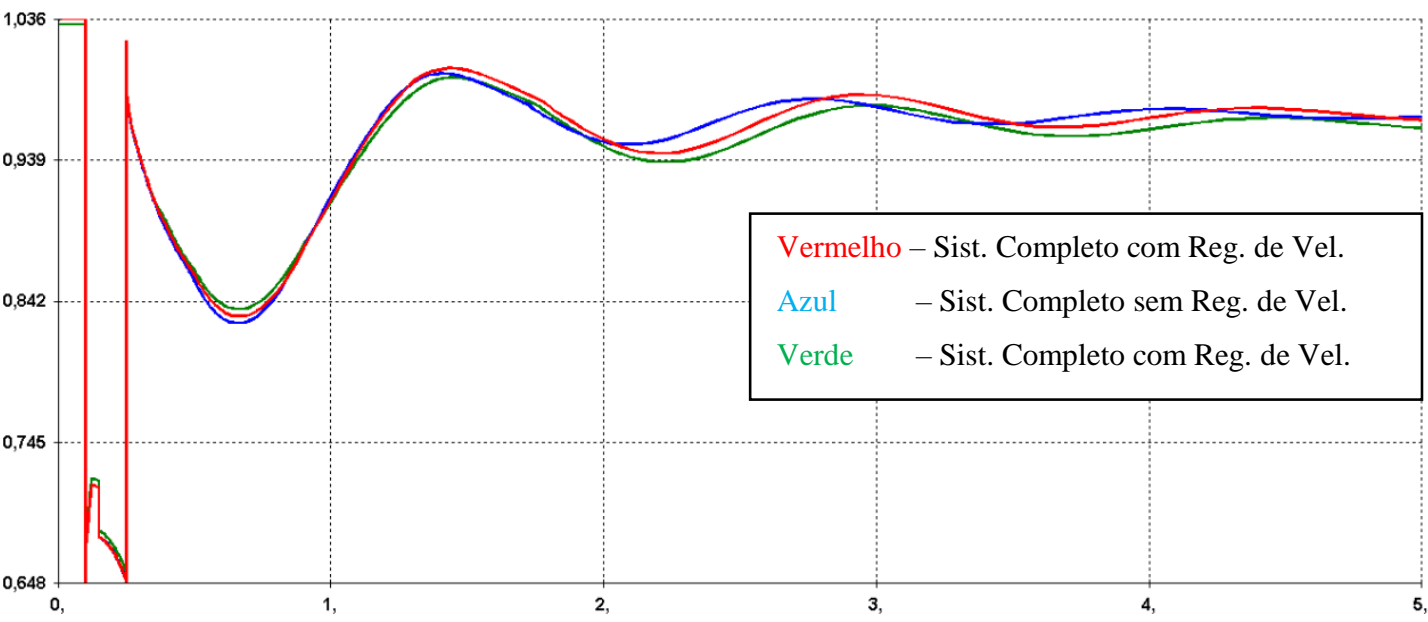

Figura 4.4. Comparação da tensão na barra de P. Bueno 230 kV na contingência n 13 , LT 230 kV Jauru - Vilhena C1 e C2, no T1_1.

Das figuras anteriores, é possível notar que os resultados obtidos no sistema reduzido do T1_1 foram mais próximos ao caso completo do que o próprio sistema completo com seus reguladores de velocidade desabilitados. 


\subsection{5.}

\section{Resultados dos Testes T1_2}

Os resultados obtidos no T1_1 foram excelentes do ponto de vista do comportamento das tensões e na tentativa de reduzir ainda mais o sistema equivalente, no T1_2 alguns parâmetros foram alterados de forma a induzir o Organon a obter menores números de clusters de geradores e barras e circuitos externos mantidos via sensibilidade.

Como esperado, ao se obter uma maior redução da rede, a precisão do equivalente, de forma geral, foi reduzida. No entanto, como pode ser observado na Figura 4.5, a seguir, além de uma pequena redução adicional da rede e do número de modelos de geradores, também se obteve uma melhora nos índices TD, máximo e médio, da contingência 4 (LT 230 kV Ariquemes - Jauru C1).

Apesar de inesperado, tal resultado confirma o caráter empírico e iterativo do processo de definição de um bom equivalente dinâmico, bem como da importância das contingências consideradas para tal.

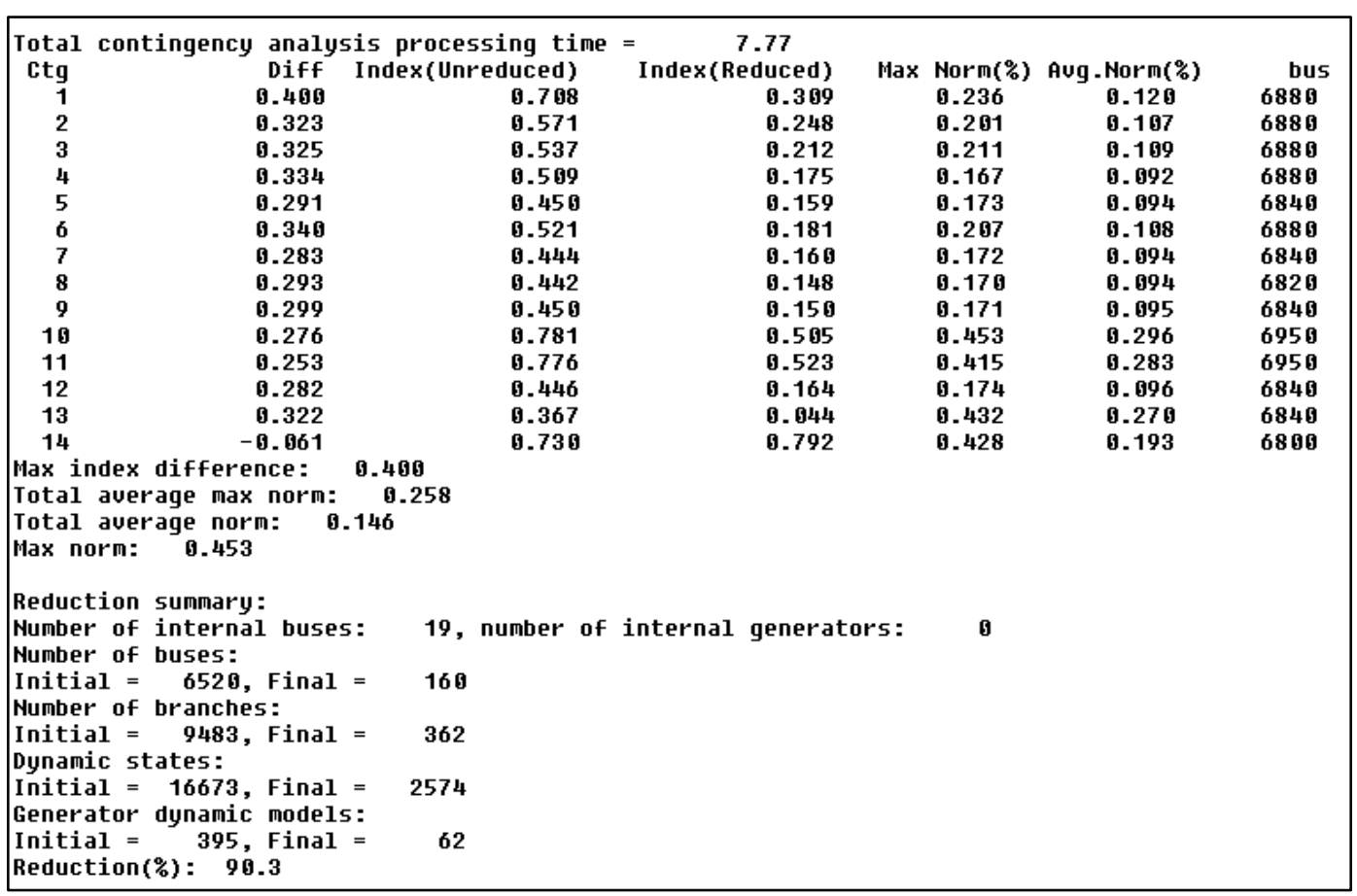

Obs.: Relatório exibido em tela pelo Organon considera o ponto “.” como separador decimal.

Figura 4.5. Síntese da redução da rede e do teste de precisão no T1_2. 
Na Figura 4.6 e na Figura 4.7, a seguir, são apresentadas as comparações das curvas de tensão, para a contingência $n^{\circ} 13$. As curvas em vermelho e azul se referem ao sistema completo, com e sem reguladores de velocidade habilitados, respectivamente, enquanto a curva em verde se refere ao sistema reduzido.
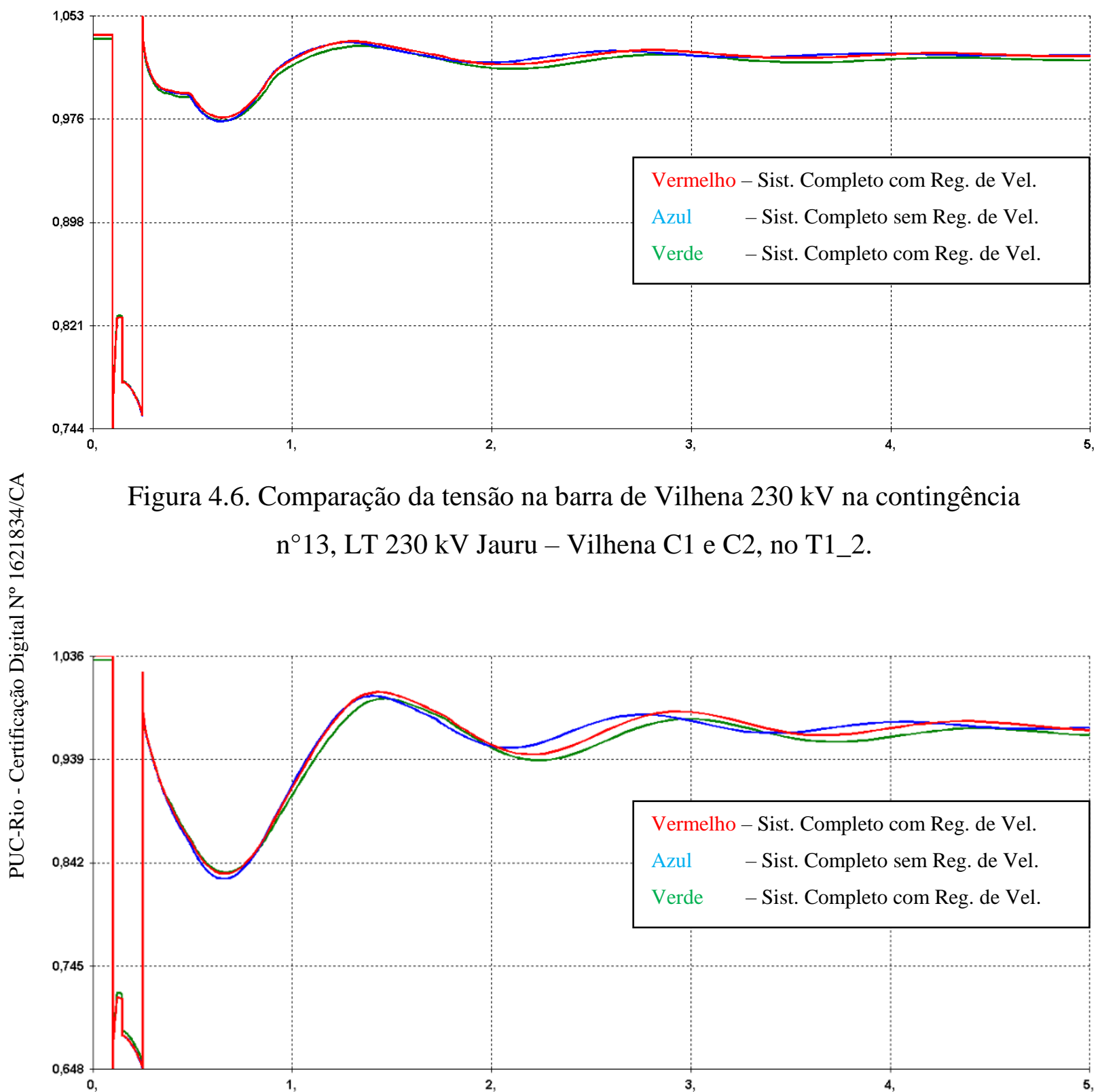

Figura 4.7. Comparação da tensão na barra de P. Bueno 230 kV na contingência n¹3, LT 230 kV Jauru - Vilhena C1 e C2, no T1_2. 


\subsection{6.}

\section{Conclusões dos Testes T1_1 e T1_2}

Foi possível obter um sistema equivalente capaz de representar de forma plenamente satisfatória o comportamento da rede completa mesmo com uma redução da rede de cerca de $90 \%$.

É de extrema importância que, caso se utilize a definição de região interna e/ou externa através de grupos base de tensão, os mesmos não possuam barras de geradores e/ou barras fictícias de transformadores de três enrolamentos definidos com tensões superiores às reais.

Durante os testes foi identificada a necessidade de se implementar algumas modificações no Organon, uma vez que ao realizar a análise de contingências, ainda com a rede completa, o programa utilizava definições, parâmetros e opções diferentes daquelas definidas nos arquivos de parâmetros (“.PRM”) e de eventos (“.EVT”) [17], fornecidos pelo usuário. Por exemplo: tempo de simulação, detecção automática de instabilidade, bloqueio de todos os reguladores de velocidade, entre outras. A análise de contingências é efetuada tanto no sistema completo quanto no sistema reduzido, sendo da comparação de seus resultados que são determinados os índices de acurácia. Ou seja, caso algumas das opções utilizadas nessa análise seja diferente das utilizadas nas simulações dinâmicas usuais, corre-se o risco de obtermos índices de precisão que não representam de forma fiel a comparação dos resultados de simulações dinâmicas do sistema completo e do sistema reduzido. De todas as modificações de parâmetros identificadas, o bloqueio dos reguladores de velocidade é aquela com o maior potencial de inserir diferenças nos resultados. Tais alterações de parâmetros foram desabilitadas para todos os testes realizados, ou seja, foram mantidos todos os parâmetros e opções definidos pelo usuário.

Foram encontrados resultados inesperados para as sensibilidades "dV/dI". Por exemplo, as barras 6900 e 6930 são barras do $230 \mathrm{kV}$ do sistema do Acre e Rondônia, enquanto a barra 7050 pertence ao sistema de $500 \mathrm{kV}$ das usinas do Rio Madeira. Esses dois sistemas estão eletricamente isolados através do "back to back". Logo, a sensibilidade entre eles deveria ser $0 \%$. No entanto, em alguns testes os seguintes resultados foram obtidos: $\mathrm{dV}_{6900} / \mathrm{dI}_{7050}=0.0 \% \mathrm{e}$ $\mathrm{dV}_{6930} / \mathrm{dI}_{7050}=31,8 \%$. Estes resultados, juntamente com outros apresentados a 
seguir, levaram à identificação da necessidade de revisão de algumas das rotinas de identificação de retenção de barras e modelos completos de geradores.

A definição das barras do sistema do Mato Grosso com CEs como barras adicionais, sendo mantidos seus modelos completos, permitiu que os resultados fossem significativamente melhores, como esperado. No entanto, não foi possível a retenção dessas barras de forma automática, através dos critérios de sensibilidade. A inclusão das barras conectadas a estes equipamentos constitui uma melhoria a ser implementada futuramente no Organon.

\subsection{7.}

\section{Resultados da Região de Segurança do Acre e Rondônia}

Devido aos excelentes resultados obtidos nos testes anteriores, decidiu-se testar o comportamento do sistema reduzido frente a mudanças no ponto de operação inicial. Dessa forma, foram comparados os resultados da região de segurança com a rede completa e reduzida, considerando apenas as duas contingências mais severas para esse sistema, ou seja, a contingência ${ }^{\circ} 13, \mathrm{LT}$ 230 kV Jauru - Vilhena C1 e C2, e a contingência ${ }^{\circ}{ }^{\circ}$ 14, LT 230 kV C.P. Velho P. Velho.

Todas as definições necessárias para a criação da região de segurança foram idênticas, tendo como única diferença, os arquivos de rede e de modelos dinâmicos, completos ou reduzidos. Os grupos de geração foram formados apenas por geradores que permaneceram com suas representações completas no sistema reduzido, sendo eles:

- Grupo 1 (usinas de Rondônia): UHEs Samuel e S. A. Adicional;

- Grupo 2 (usinas de Rondônia): UHE Rondon;

- Grupo 3 (usinas do Mato Grosso): UHEs Jauru, Guaporé, P. de Pedra, Itiquira e Manso; 


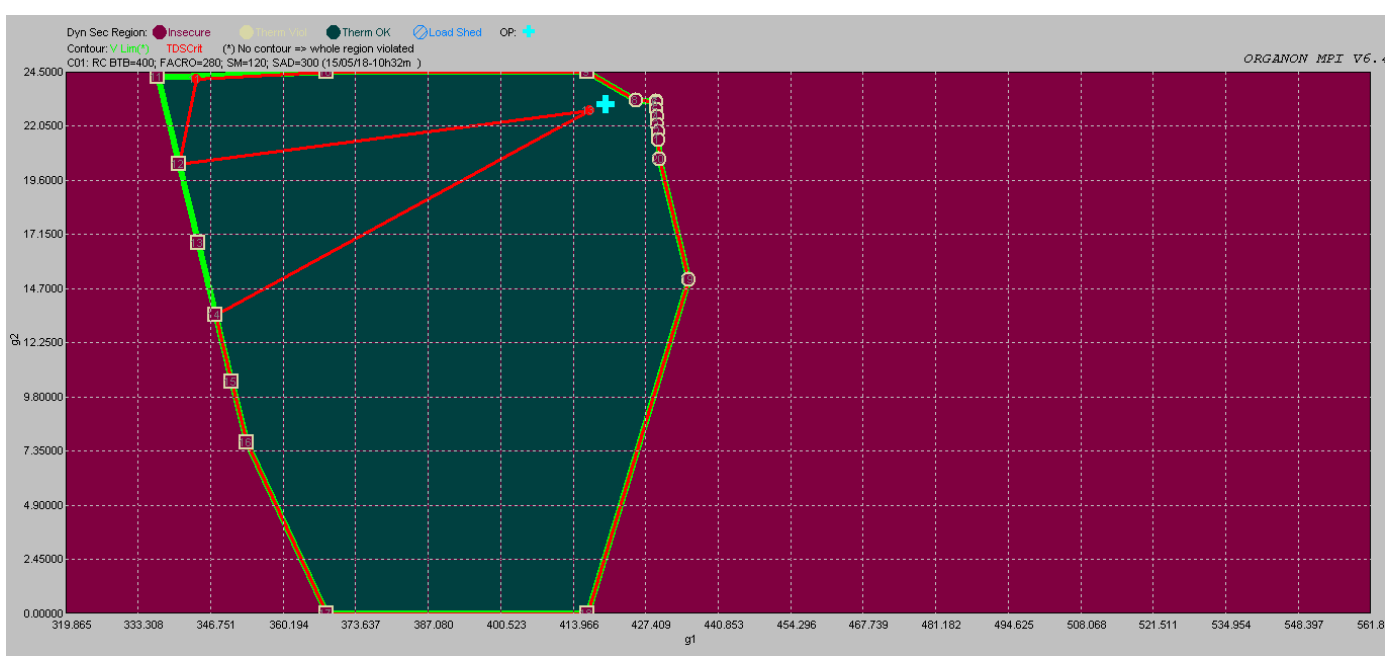

Figura 4.8. G1×G2 - Rede completa.

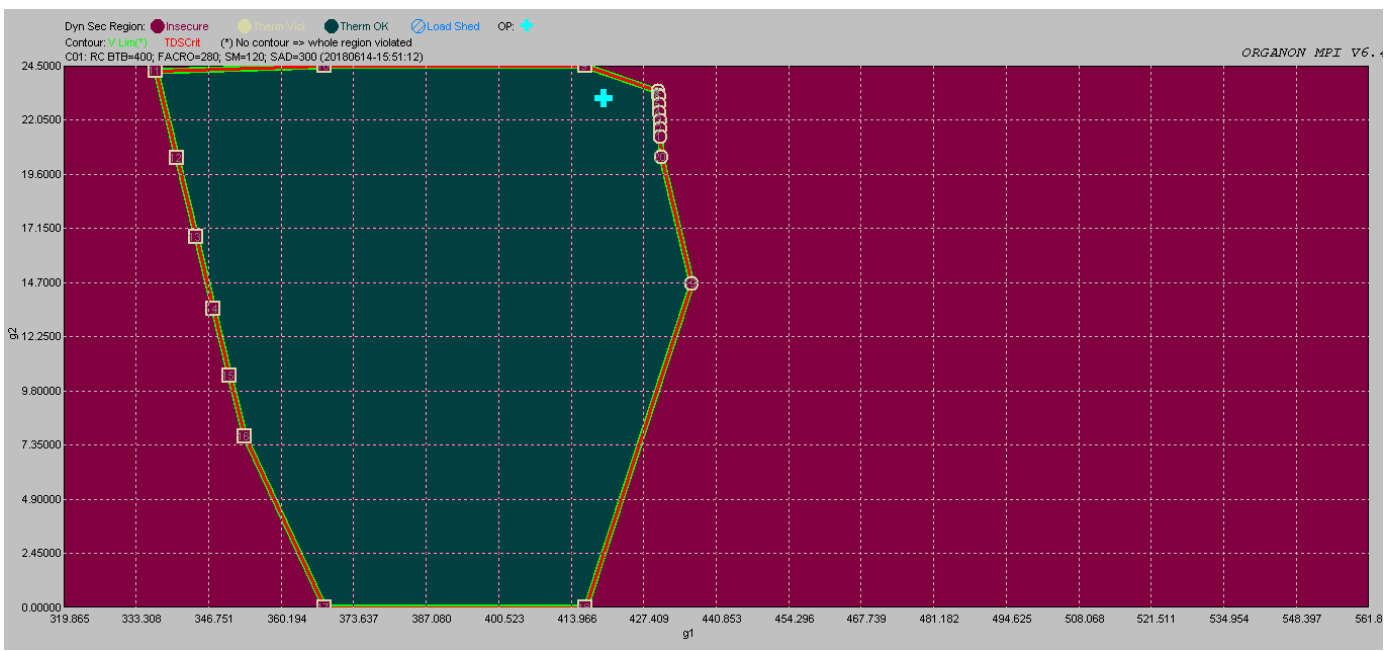

Figura 4.9. G1×G2 - Rede reduzida (T1_1).

Como mostra as figuras anteriores, a região de segurança com o sistema reduzido se mostrou aderente àquela com o sistema completo. $\mathrm{O}$ tempo de simulação para a rede completa foi de 174 s, enquanto que para a rede reduzida foi de $19 \mathrm{~s}$, ou seja, cerca de 9 vezes menor. Cabe destacar que, como os modelos utilizados nos diferentes agrupamentos de geradores foram calculados para o ponto de operação inicial, optou-se por não permitir a sincronização de novas unidades geradoras durante o cálculo da região de segurança. Embora, apenas geradores que permaneceram com seus modelos completos estejam variando o seu despacho, em tese, quanto mais distante do ponto inicial, menor a acurácia dos modelos agregados. No entanto, não se buscou determinar tal fronteira de validade e para a região em questão, os resultados foram excelentes. 


\section{3. \\ Interligação Norte Sudeste e Bipolo de Belo Monte no Sentido de Estreito para Xingu (Cenário 2)}

A interligação entre as regiões Norte e Sudeste, denominada de interligação Norte/Sul, é constituída atualmente por um sistema de transmissão composto por três circuitos em $500 \mathrm{kV}$ entre as subestações de Itacaiúnas/Imperatriz, respectivamente nos estados do Pará e do Maranhão, e a subestação de Serra da Mesa, no estado de Goiás, passando pelas subestações de Colinas, Miracema e Gurupi, no estado do Tocantins. A fronteira desta interligação acontece entre as SEs Miracema, no subsistema Norte, e as SEs Gurupi e Lajeado, no subsistema Sudeste.

A interligação Norte/Nordeste é constituída pelas linhas de transmissão em 500 kV Presidente Dutra - Boa Esperança, Presidente Dutra - Teresina C1 e C2 e, pela LT 500 kV Colinas - Ribeiro Gonçalves - São João do Piauí C1 e C2. Além dos cinco circuitos em $500 \mathrm{kV}$ mencionados, as regiões Norte e Nordeste se conectam através de uma rede de pequena capacidade em $230 \mathrm{kV}$, que interliga as subestações de Peritoró e Coelho Neto, no estado do Maranhão, à subestação de Teresina, no estado do Piauí.

Os subsistemas Sudeste e Nordeste encontram-se atualmente interligados pelas LTs 500 kV Serra da Mesa II - Rio das Éguas e Luziânia - Rio das Éguas. Este sistema se estende até a SE Camaçari II na região metropolitana de Salvador, passando pelas SEs Bom Jesus da Lapa II, Igaporã, Ibicoara e Sapeaçu, com cerca de 1.100 km de extensão, nos estados de Goiás e Bahia.

A Figura 4.10 e a Figura 4.11, a seguir, mostram a localização geográfica destas interligações e o seu respectivo diagrama unifilar. 


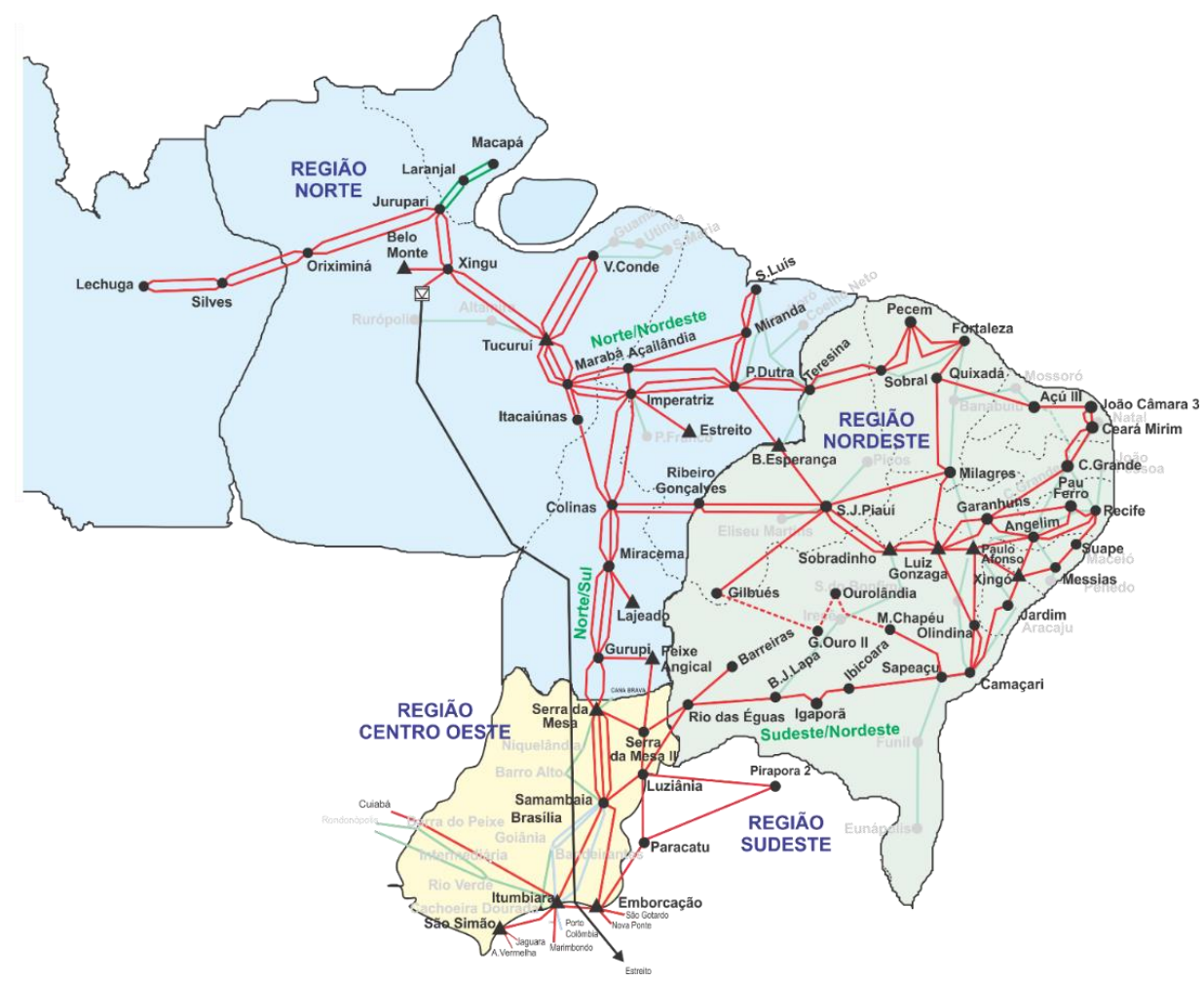

Figura 4.10. Localização Geográfica das Interligações Norte/Nordeste, Norte/Sul e Sudeste/Nordeste.

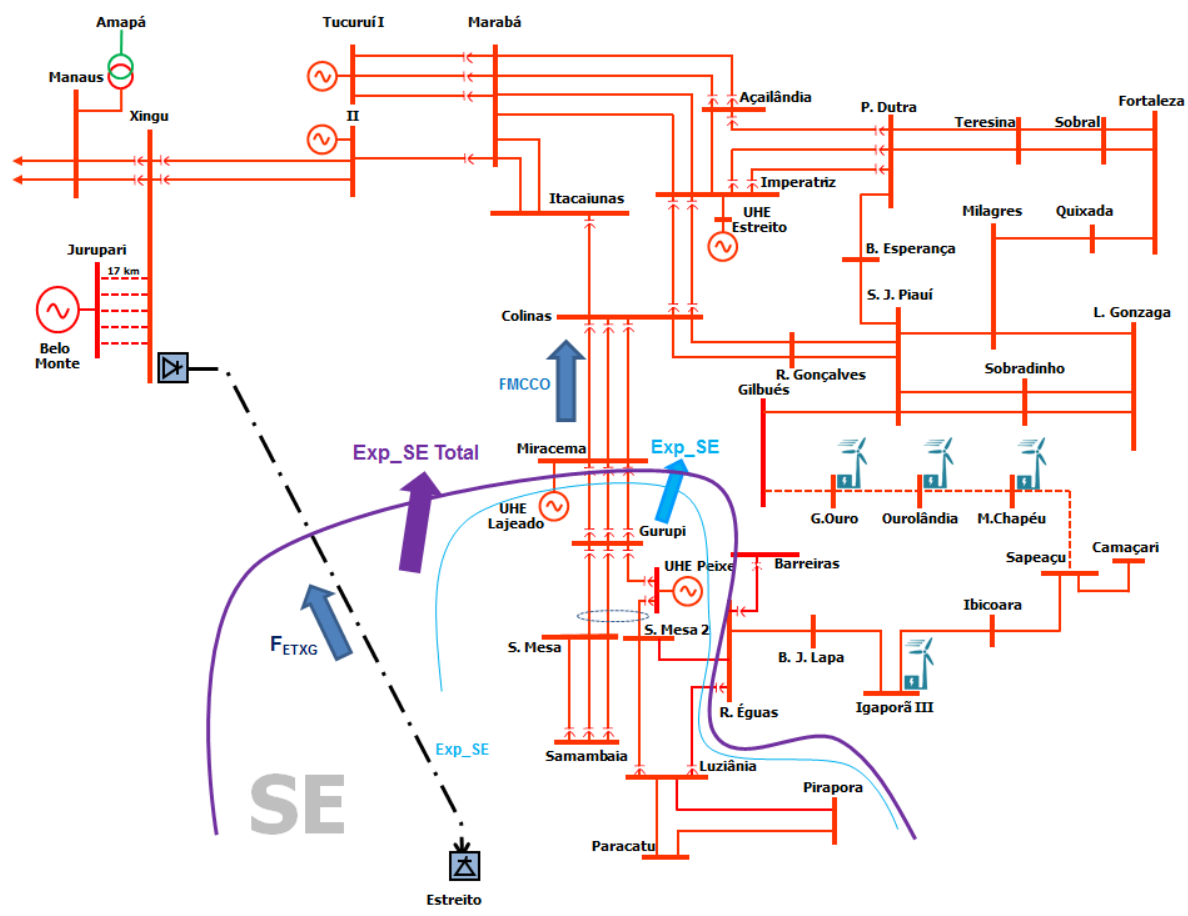

Figura 4.11. Diagrama unifilar dos sistemas Norte e Nordeste e sua interligação com o Sudeste. 
O fluxo máximo na interligação Norte-Sul no trecho entre as subestações de Miracema e Colinas (FMCCO), deverá ser da ordem de 4.000 MW por limite em regime dos Capacitores Série deste trecho. Entretanto, pela configuração topológica do Bipolo Xingu-Estreito, em paralelo ao sistema de transmissão CA, o Bipolo oferece a possibilidade de contribuir para a eliminação de sobrecargas nos circuitos remanescentes da interligação N-SE quando de perdas simples ou duplas em qualquer de seus trechos, através de uma ação de "Run-up".

Por outro lado, os limites desta interligação pela rede CA no sentido do Sudeste para o Norte é dependente do fluxo no Bipolo no sentido Estreito para Xingu. Ou seja, para que o sistema suporte a perda do Bipolo, sem que haja a perda de sincronismo entre as regiões do Norte e Nordeste com as regiões do Sudeste e Sul a soma dos fluxos FMCCO e RNE deverá ser controlada de maneira a evitar perda de estabilidade entre os subsistemas.

A escolha da interligação Norte - Sudeste como área teste deve-se ao fato de sua característica sistêmica permitir apurar se as escolhas de geradores e cluster de máquinas equivalentes conseguiram capturar os principais modos de oscilação entre as áreas.

Já a contingência escolhida, o bloqueio do Bipolo Estreito-Xingu, representa atualmente uma das perdas mais severas para o SIN. No cenário testado, fluxo no sentido do Sudeste para o Norte, esta contingência impõe ao sistema grandes variações de fluxo na interligação Norte-Sul, bem como, variações angulares severas nos geradores das regiões Norte, Nordeste e Sudeste, porém sem a interrupção de geração ou perda de carga.

Por sua grande abrangência e severidade, este é outro excelente teste para o equivalente dinâmico.

\subsection{1.}

\section{Definição das Regiões Internas, Externas e da Zona Intermediária}

Após vários testes, optou-se por definir a região interna como todas as barras do SIN com tensões igual ou superior a $340 \mathrm{kV}$ e, inicialmente, foi permitida a retenção de duas barras de vizinhança como zona intermediária.

A escolha da região interna teve como objetivo principal a observação da escolha dos geradores e clusters e não a redução máxima da rede. Cabe destacar 
que foi necessária a definição das barras contendo os CEs do sistema do Nordeste e as barras contendo os conversores dos bipolos do Madeira, Belo Monte e Itaipu como barras adicionais. Assim, as mesmas foram retidas e os elementos conectados a elas permaneceram com seus modelos completos, porém essas barras foram desconsideradas nos cálculos de precisão do sistema equivalente.

\subsection{2. \\ Lista de Contingências}

Para que fossem aplicados os testes de precisão, foi fornecido ao Organon o evento de bloqueio dos dois polos do Bipolo Estreito - Xingu.

\subsection{3.}

Definição dos Valores Limites para as Sensibilidades de Retenção de Circuitos e Agrupamento de Geradores

Após vários testes, os valores de sensibilidade que possibilitaram os melhores resultados são descritos a seguir e apresentados na Tabela 4.2.

Opções relativas à rede:

- Retenção de barras do sistema externo nas " $n$ " vizinhanças como zona intermediária (parâmetro NEIGH);

- Retenção de barras PV no sistema externo devido a variações de tensão nas barras de fronteira (parâmetro RETVLT);

- Retenção de circuitos no sistema externo devido a variações de fluxos em circuitos conectados às barras de fronteira (parâmetro RETFLW);

- Descarte de ligações equivalentes cujas impedâncias sejam elevadas (parâmetro MAXZ).

Tabela 4.2. Lista dos valores de parâmetros para redução da rede

\begin{tabular}{|c|c|c|c|c|} 
Teste & $\begin{array}{c}\text { NEIGH } \\
(\%)\end{array}$ & $\begin{array}{c}\text { RETVLT } \\
(\%)\end{array}$ & $\begin{array}{c}\text { RETHLW } \\
(\text { MW })\end{array}$ & $\begin{array}{c}\text { MAXZ } \\
(\%)\end{array}$ \\
\hline T2_1 & 2 & 10 & 10.0 & 5 \\
\hline T2_2 & 2 & 10 & 10.0 & 5 \\
\hline T2_3 & 0 & 10 & 10.0 & 5 \\
\hline T2_4 & 0 & 15 & 40.0 & 5 \\
\hline
\end{tabular}


As opções relativas à representação dos geradores variaram para cada teste conforme mostrado na Tabela 4.2 e são descritas a seguir:

- Retenção dos modelos completos de geradores através da sensibilidade $d V g_{\text {Int }} / d I g_{\text {ext }}$ devido a variações de tensão nas barras dos geradores internos para variações na injeção de corrente nos geradores externos parâmetro EXDST;

- Inclusão de geradores em clusters através da sensibilidade $d V g_{\text {ext } i} / d I g_{\text {ext }} j$ devido às variações de tensão nas barras dos geradores externos para variações na injeção de corrente nos demais geradores externos - parâmetro DVMIN;

- Valor máximo da diferença angular entre dois geradores do sistema externo, para que pertençam ao mesmo cluster - parâmetro ANGDIF;

- Valor máximo para remoção dos geradores do sistema externo que não tenham tido seus modelos completos retidos ou selecionados para um cluster - parâmetro OUTMW.

- Valor mínimo do intervalo ou faixa de reativo [Qmin, Qmax] para retenção dos geradores do sistema externo através da sensibilidade de tensão parâmetro RETGENMVA.

Tabela 4.3. Lista dos valores de parâmetros para redução de geradores

\begin{tabular}{|c|c|c|c|c|c|c|} 
Teste & $\begin{array}{c}\text { EXDST } \\
(\mathrm{pu})\end{array}$ & $\begin{array}{c}\text { DVMIN } \\
(\mathrm{pu})\end{array}$ & $\begin{array}{c}\text { ANGDIF } \\
\left({ }^{\circ}\right)\end{array}$ & $\begin{array}{c}\text { OUTMW } \\
(\mathbf{M W})\end{array}$ & $\begin{array}{c}\text { RETGENMVA } \\
(\mathrm{pu})\end{array}$ & $\begin{array}{c}\text { Modelos } \\
\text { Din. usinas } \\
\text { Eólicas }\end{array}$ \\
\hline T2_1 & 0,500 & 0,200 & 10,0 & 300,0 & 0,1 & Não \\
\hline T2_2 & 0,500 & 0,200 & 10,0 & 300,0 & 0,1 & Sim \\
\hline T2_3 & 0,500 & 0,200 & 10,0 & 100,0 & 0,1 & Sim \\
\hline T2_4 & 0,300 & 0,100 & 15,0 & 250,0 & 1,0 & Sim \\
\hline
\end{tabular}

\subsection{4.}

\section{Resultados do Teste T2_1}

Como se pode observar na Obs.: Relatório exibido em tela pelo Organon considera o ponto "." como separador decimal.

Figura 4.12, a seguir, foi possível efetuar a redução geral de cerca de $23 \%$ da rede original, tendo obtido uma redução de $48 \%$, no número de barras, e de 
$42 \%$, no número de circuitos, obtendo-se uma diferença em relação às tensões pré e pós a redução da rede, de no máximo 5,6\% e na média de cerca de $0,76 \%$.

Para o índice de estabilidade, as diferenças foram de cerca de 0,05 entre a rede completa e a reduzida, um excelente resultado ao se considerar que a contingência estudada leva o sistema perto da instabilidade dinâmica, ou seja, às margens da perda de sincronismo entre as regiões geoelétricas.

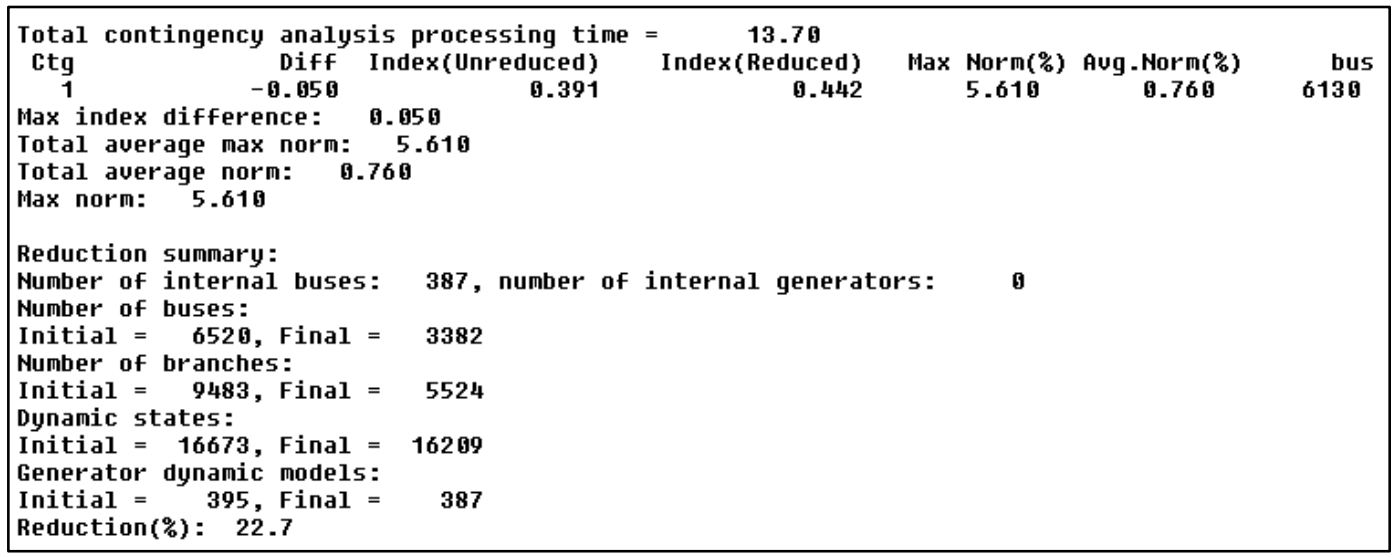

Obs.: Relatório exibido em tela pelo Organon considera o ponto “.” como separador decimal.

Figura 4.12. Síntese da redução da rede e do teste de precisão para o teste T2_1.

Nos documentos normativos para a operação do sistema elétrico, as Instruções de Operação (I.O.), são definidas como pontos de monitoração cruciais, para garantir a segurança do SIN quando desta contingência: as tensões das SEs 500 kV Ribeiro Gonçalves, Rio das Éguas e Serra da Mesa e o fluxo na LT 500 kV Miracema - Colinas.

Essas grandezas são importantes para que durante a operação em tempo real seja possível operar em pontos de operação em que a perda do Bipolo não leve à atuação das PPS's (Proteção de Perda de Sincronismo) instaladas nas LTs 500 kV R. Gonçalves - Colinas ou S. Mesa - Peixe 2.

Dessa forma, na Figura 4.13, na Figura 4.14, na Figura 4.15 e na Figura 4.16, Figura 4.17 e a Figura 4.18, a seguir, são mostradas as comparações entre os resultados da rede completa e reduzida para as tensões nas SEs R. Éguas, S. Mesa e R. Gonçalves, da corrente na LT 500 kV Miracema Colinas e da resistência aparente vista pelas PPS's instaladas nas LTs 500 kV R. Gonçalves - Colinas e S. Mesa-Peixe 2, respectivamente. 


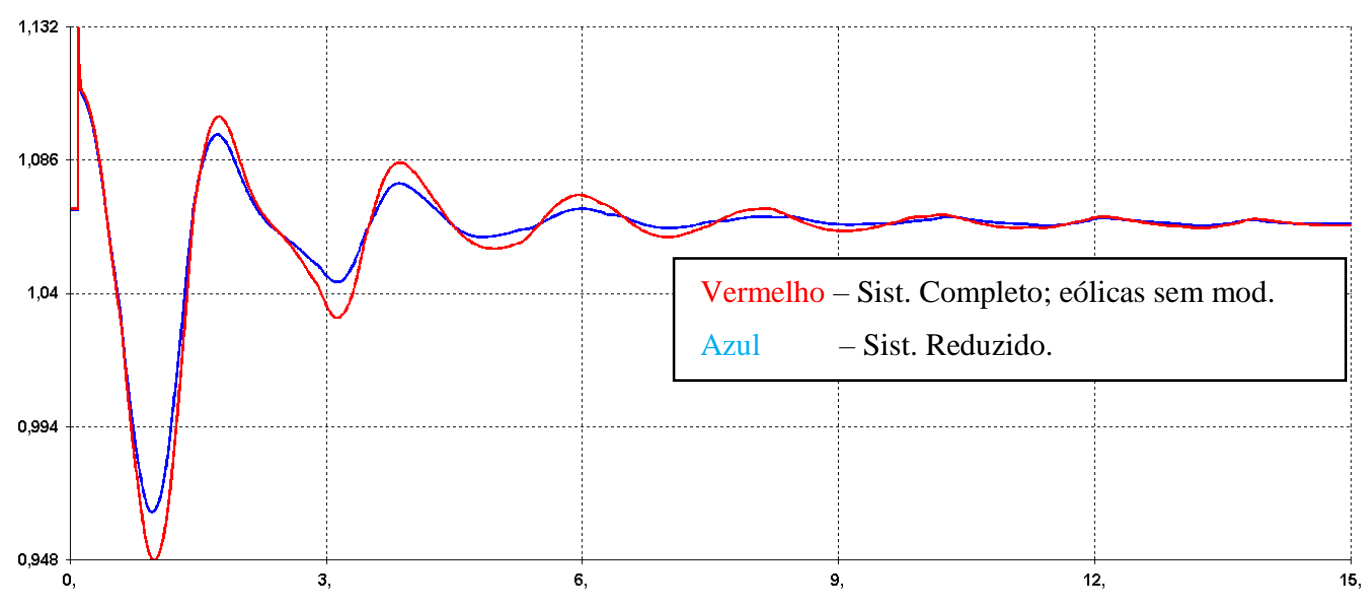

Figura 4.13. Comparação da tensão na barra de Rio das Éguas 500 kV.

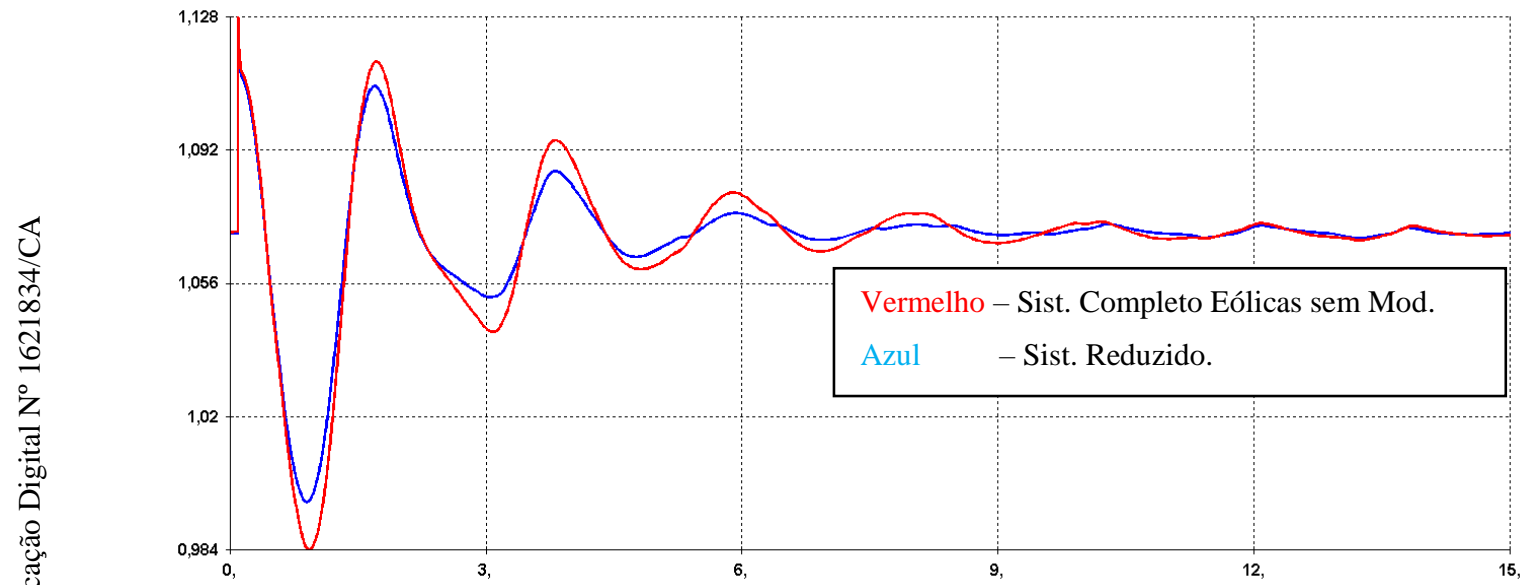

Figura 4.14. Comparação da tensão na barra de Serra da Mesa 500 kV.

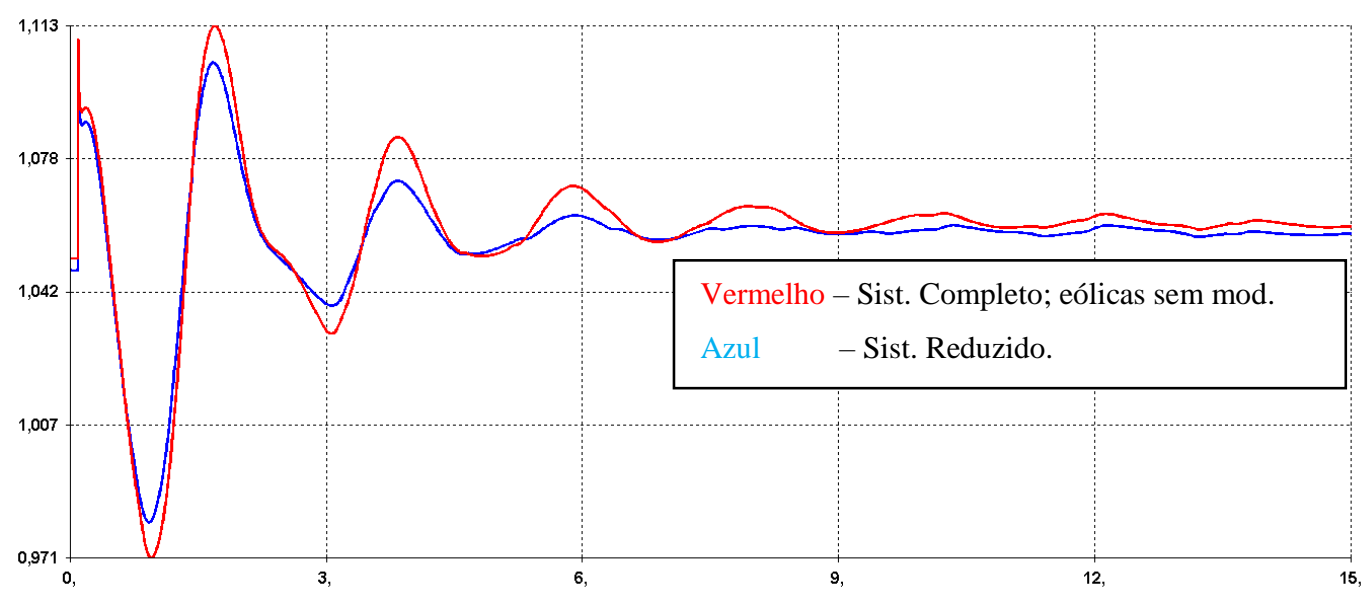

Figura 4.15. Comparação da tensão na barra de R. Gonçalves 500 kV. 


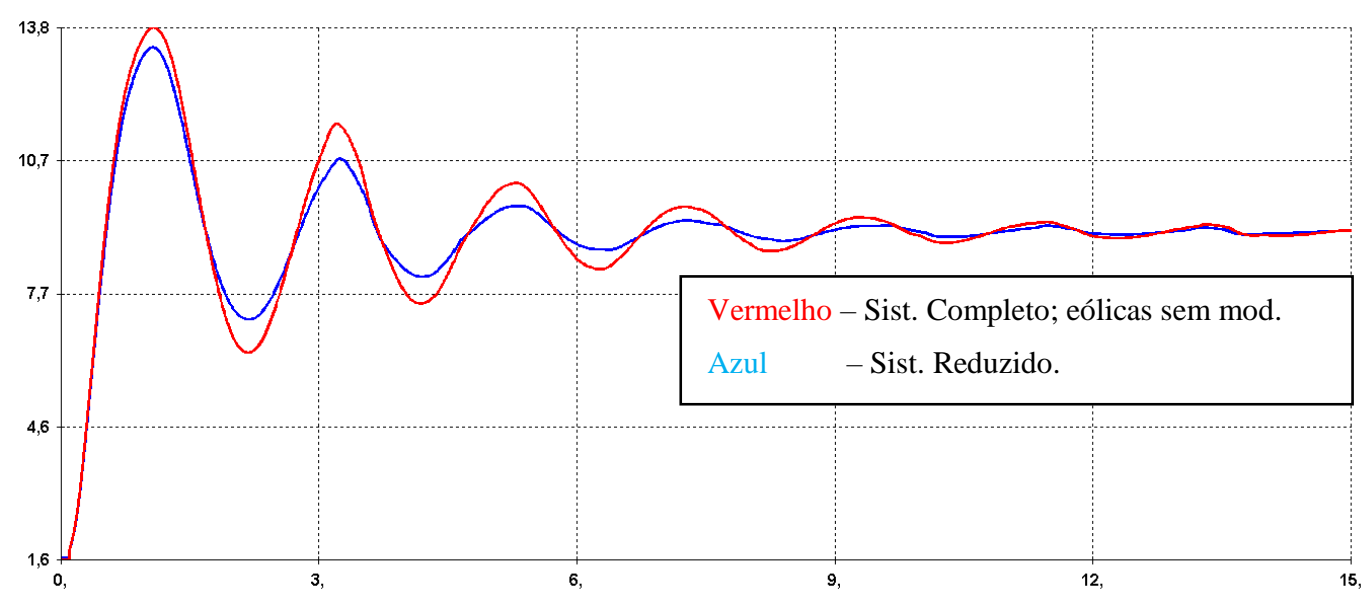

Figura 4.16. Comparação da corrente na LT 500 kV Miracema - Colinas.

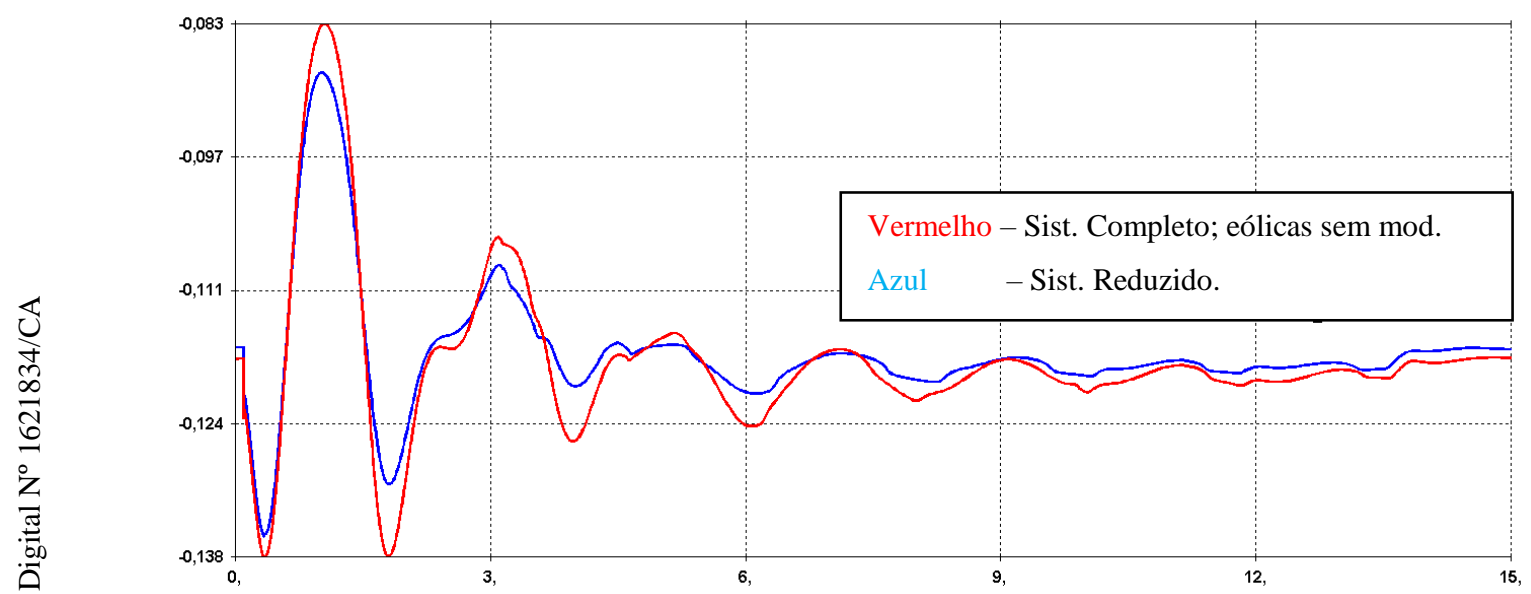

Figura 4.17. Comparação da resistência aparente na LT 500 kV R. Gonçalves Colinas.

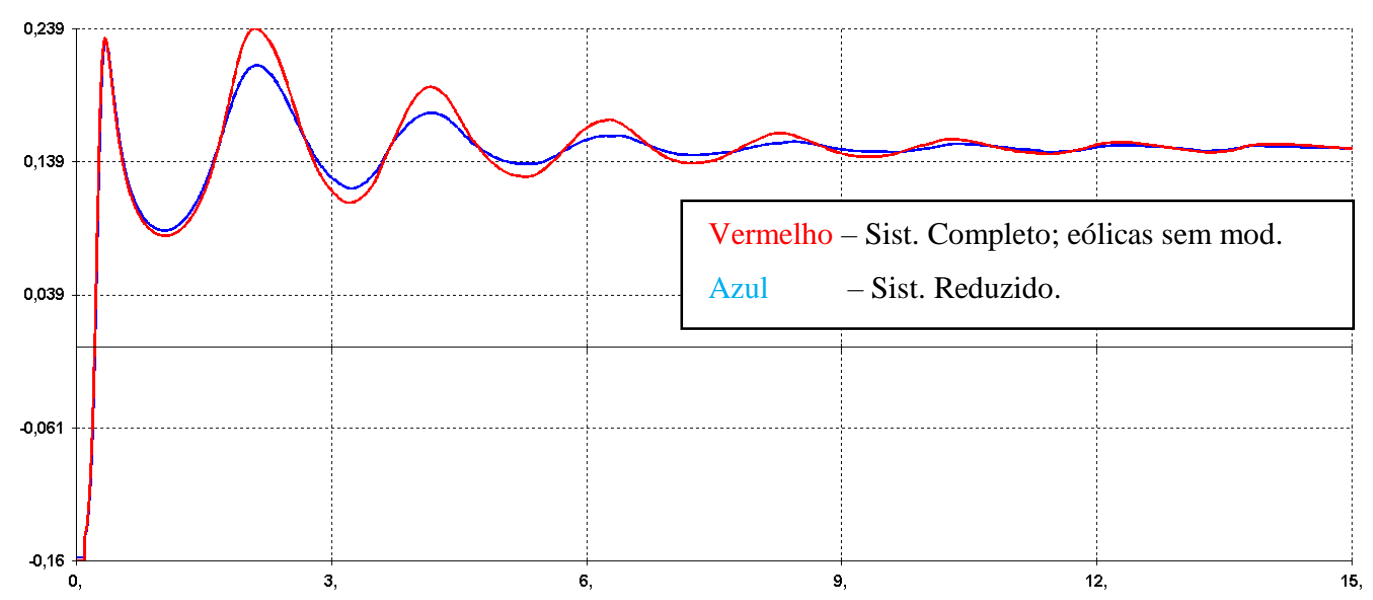

Figura 4.18. Comparação da resistência aparente na LT 500 kV S. Mesa - Peixe 2. 


\subsection{5.}

\section{Resultados do Teste T2 2}

O teste realizado anteriormente não considerou a modelagem dinâmica dos parques eólicos e por isso, apesar de apresentar excelentes resultados, deve ser refinado para que se observem as possíveis perdas de acurácia no sistema equivalente quando esses aerogeradores estão presentes na rede completa.

A Figura 4.19 e a Figura 4.20, a seguir, mostram a comparação da curva da tensão em R. Gonçalves e na excursão da resistência vista pela PPS instalada na LT 500 kV R. Gonçalves - Colinas. Nas curvas em azul os parques eólicos não estão modelados, enquanto as curvas vermelhas possuem tais modelos e serão, a partir deste momento, consideradas como o novo "benchmark" para o sistema reduzido.

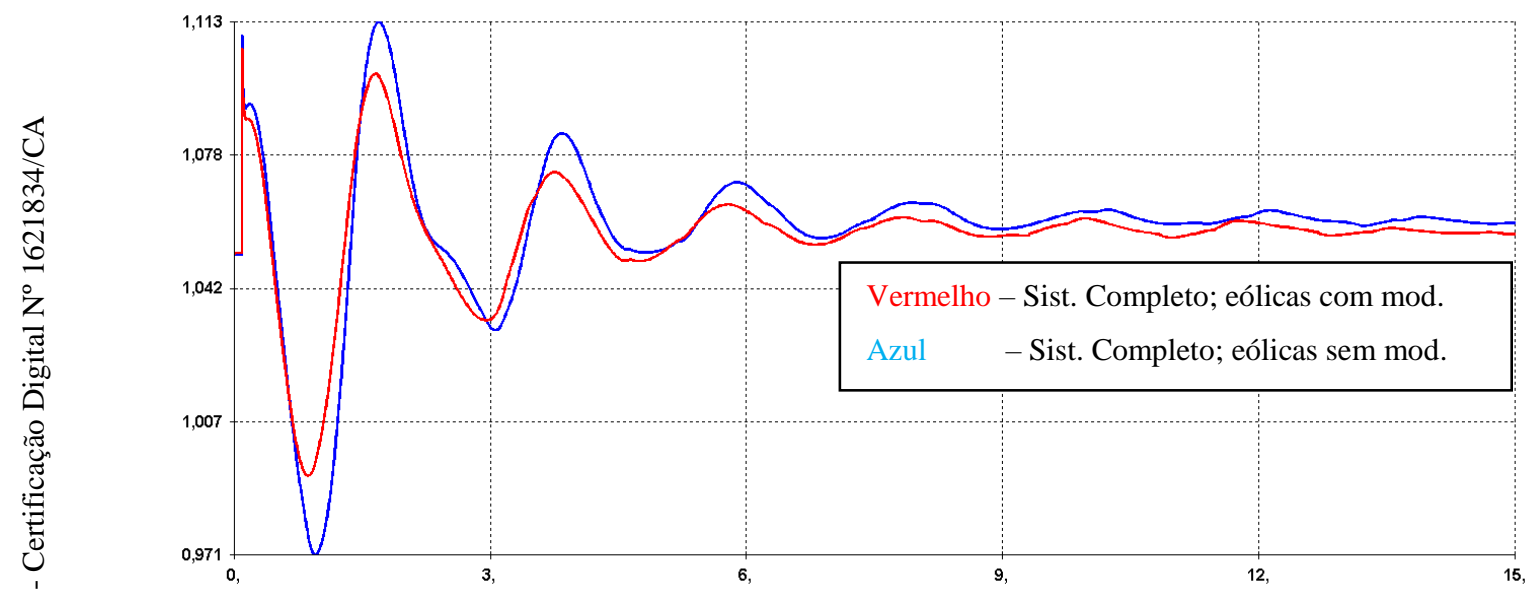

Figura 4.19. Comparação da tensão na barra de R. Gonçalves 500 kV.

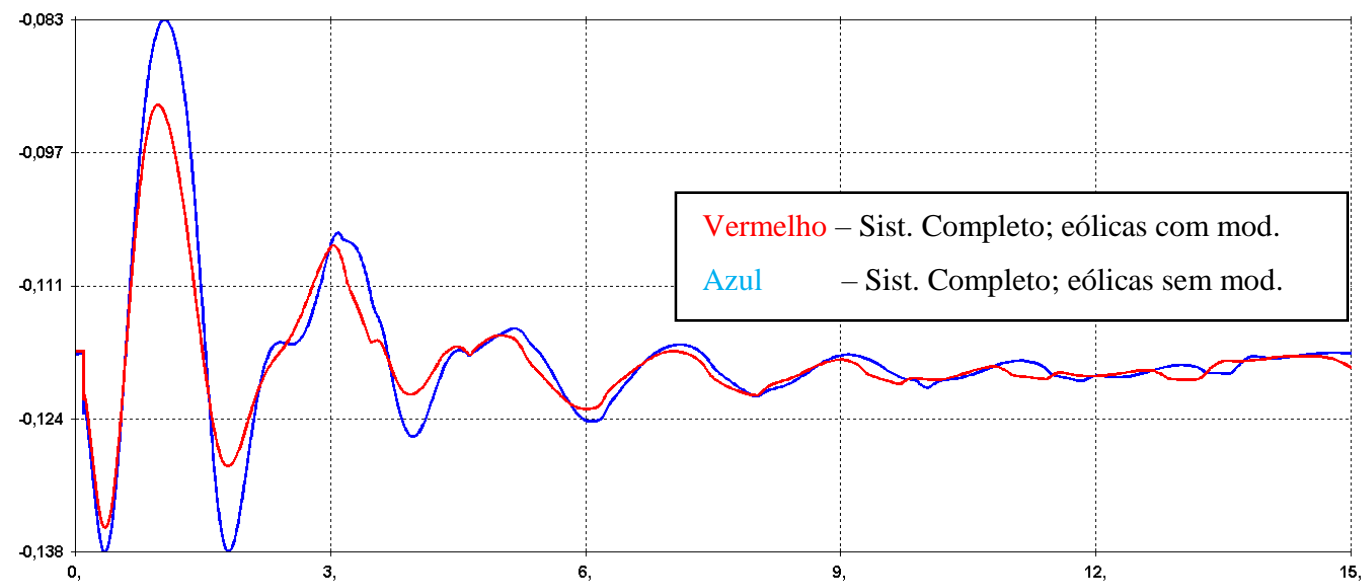

Figura 4.20. Comparação da resistência aparente na LT 500 kV R. Gonçalves Colinas. 
Apesar de não ser o foco desta dissertação, uma conclusão óbvia da comparação anterior é a importância da representação dos modelos dinâmicos desses parques eólicos, mesmo para as simulações com a rede completa.

O teste T2_2 utiliza os mesmos parâmetros para retenção da rede e de geradores, mas desta vez possui os modelos dinâmicos dos parques eólicos. Como se pode observar na Figura 4.21, a seguir, foi possível efetuar a redução geral de cerca de $30 \%$ da rede original, tendo obtido uma redução de $48 \%$, no número de barras, e de 42\%, no número de circuitos, obtendo-se uma diferença em relação às tensões pré e pós a redução da rede, de no máximo $6,6 \%$ e na média de cerca de $0,9 \%$. Resultados um pouco inferiores aos obtidos no teste T2_1.

Para o índice de estabilidade, as diferenças foram de cerca de 0,02 entre a rede completa e a reduzida, um resultado melhor do que o obtido no teste T2_1.

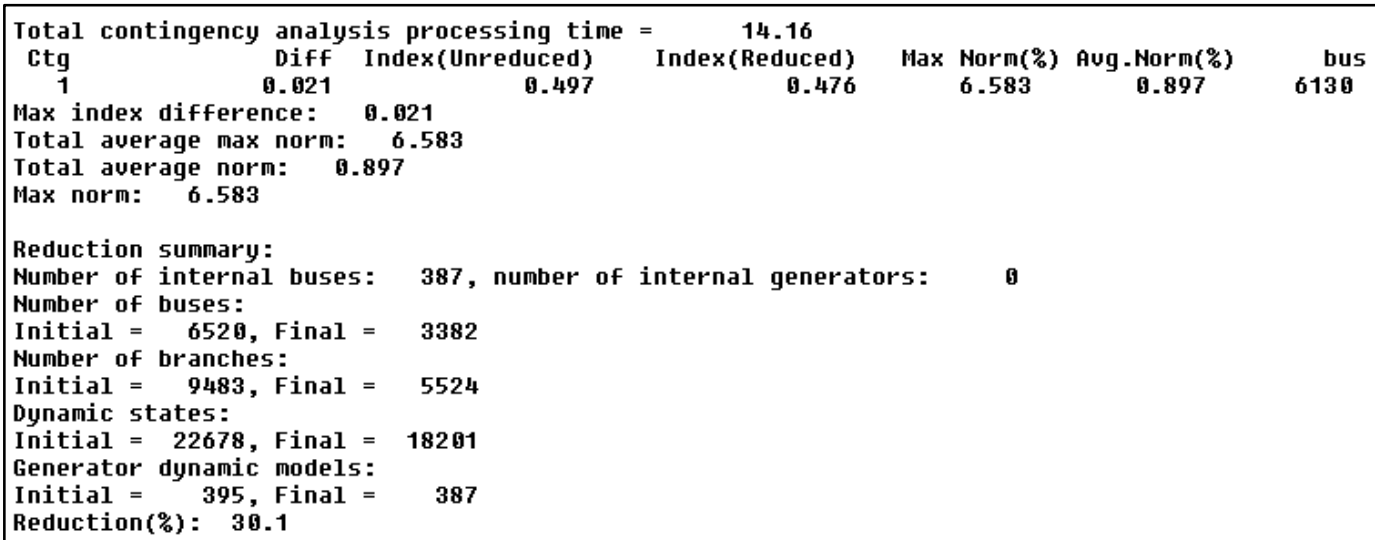

Obs.: Relatório exibido em tela pelo Organon, considera o “.” como separador decimal

Figura 4.21. Síntese da redução da rede e do teste de precisão para o teste T2_2

É importante notar, na Figura 4.12 e na Figura 4.21, que os valores de redução da rede foram exatamente os mesmos nos testes T2_1 e T2_2 (números de circuitos e barras), porém com o aumento significativo de estados dinâmicos, o valor da redução total no teste T2_2 foi maior em termos relativos.

Dessa forma, na Figura 4.22, na Figura 4.23, na Figura 4.24, na Figura 4.25, na Figura 4.26 e na Figura 4.27, a seguir, são mostradas as comparações entre os resultados da rede completa e reduzida para as tensões nas SEs R. Éguas, S. Mesa e R. Gonçalves, da corrente na LT 500 kV Miracema Colinas e da resistência aparente vista pelas PPS's instaladas nas LTs $500 \mathrm{kV}$ R. Gonçalves - Colinas e S. Mesa-Peixe 2, respectivamente. 


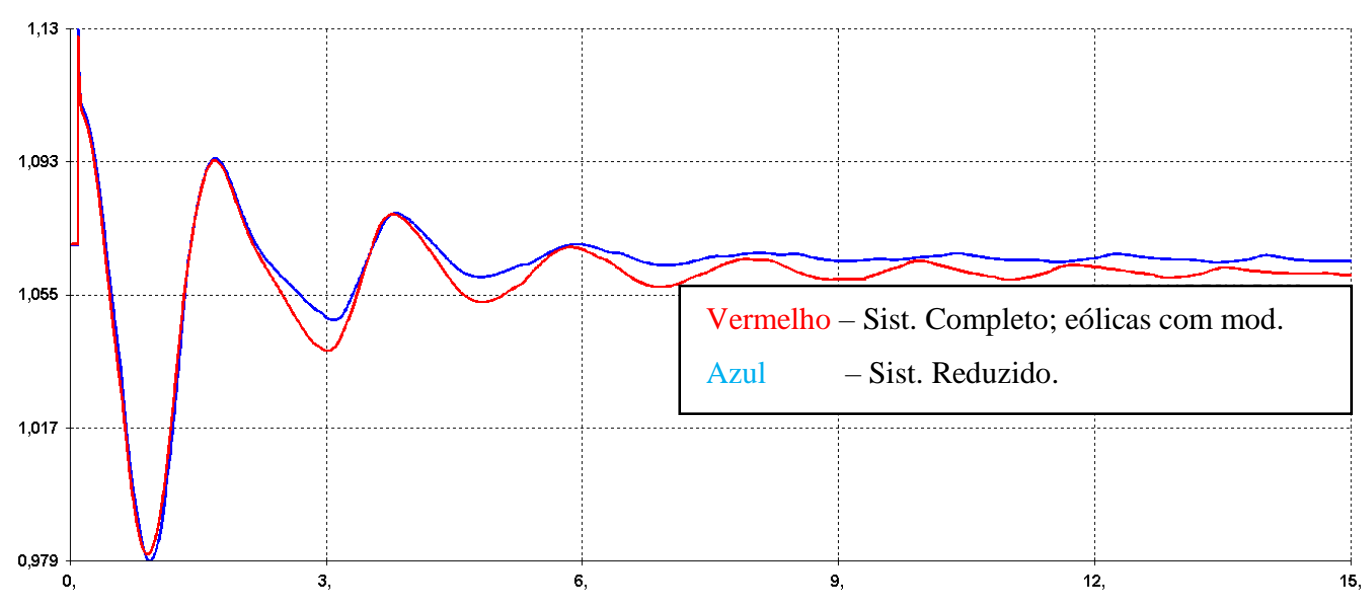

Figura 4.22. Comparação da tensão na barra de Rio das Éguas 500 kV.

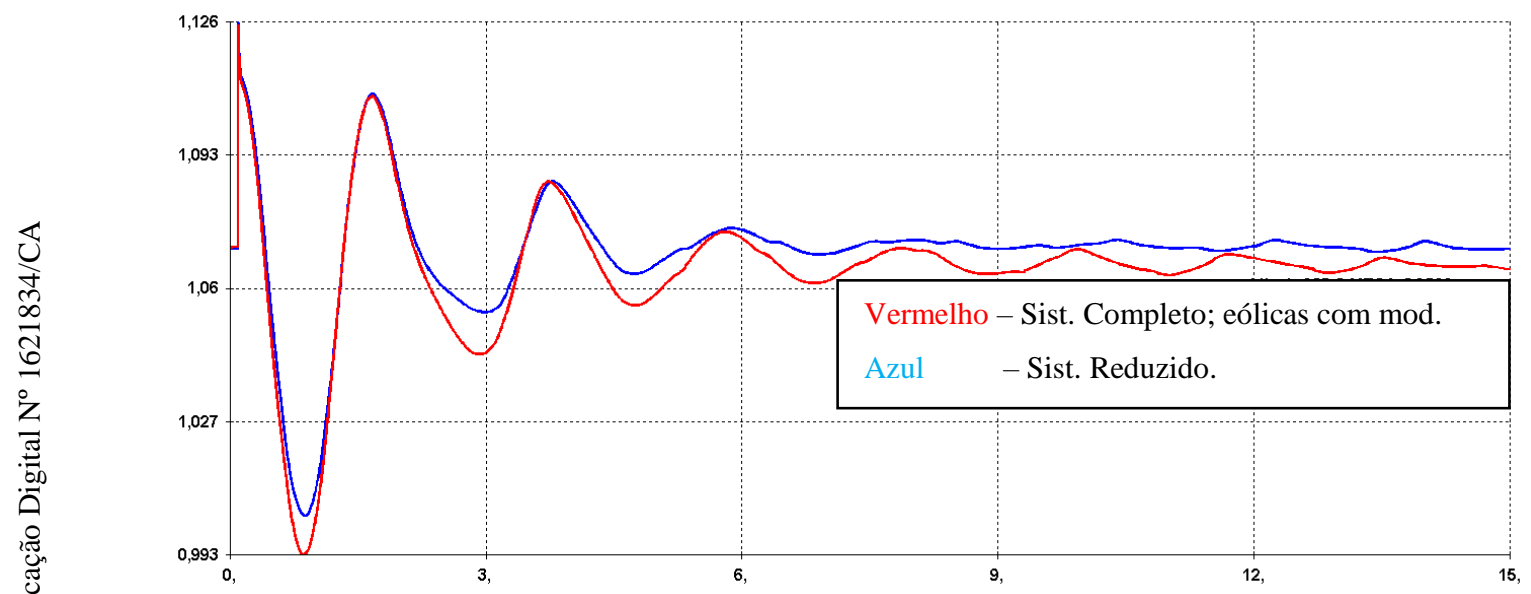

Figura 4.23. Comparação da tensão na barra de Serra da Mesa 500 kV.

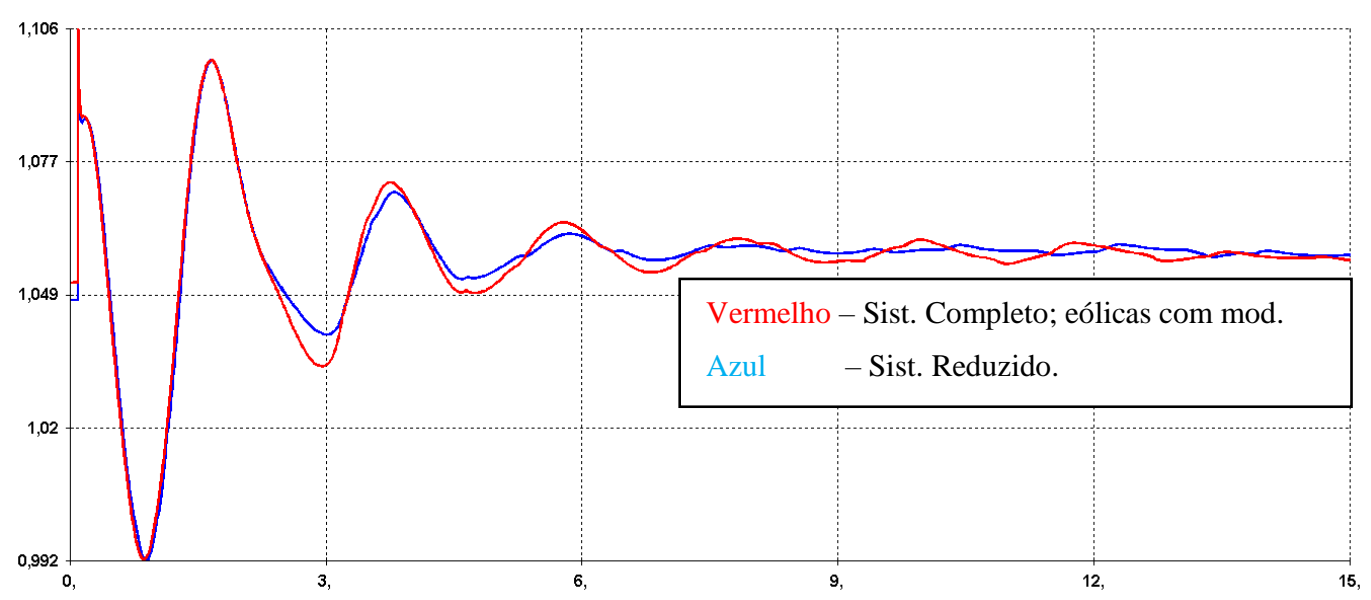

Figura 4.24. Comparação da tensão na barra de R. Gonçalves 500 kV. 


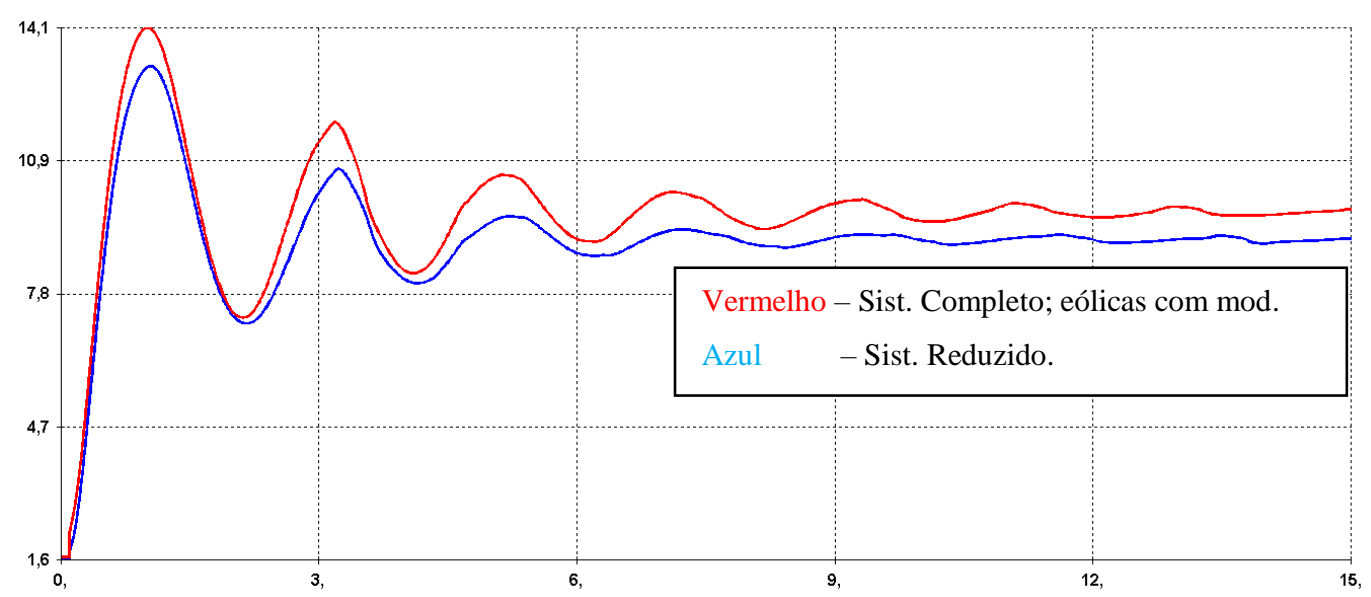

Figura 4.25. Comparação da corrente na LT 500 kV Miracema - Colinas.

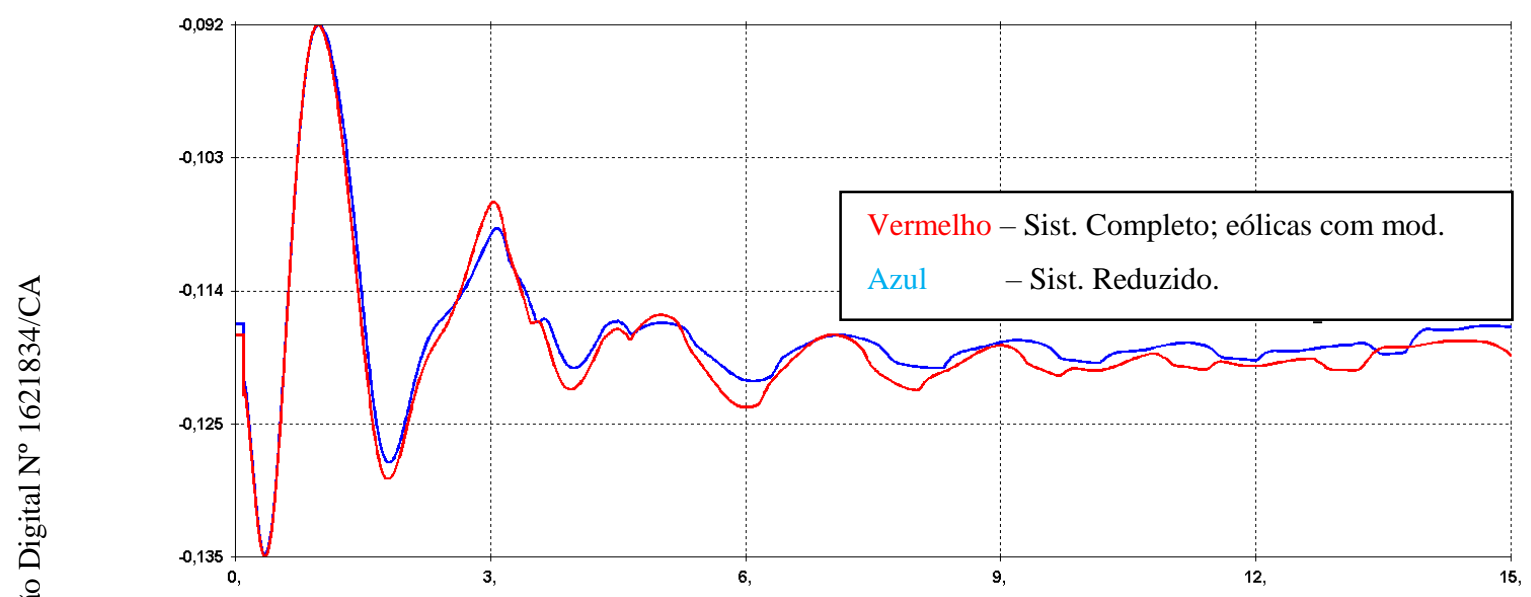

Figura 4.26. Comparação da resistência aparente medida pela PPS instalada na LT 500 kV R. Gonçalves - Colinas.

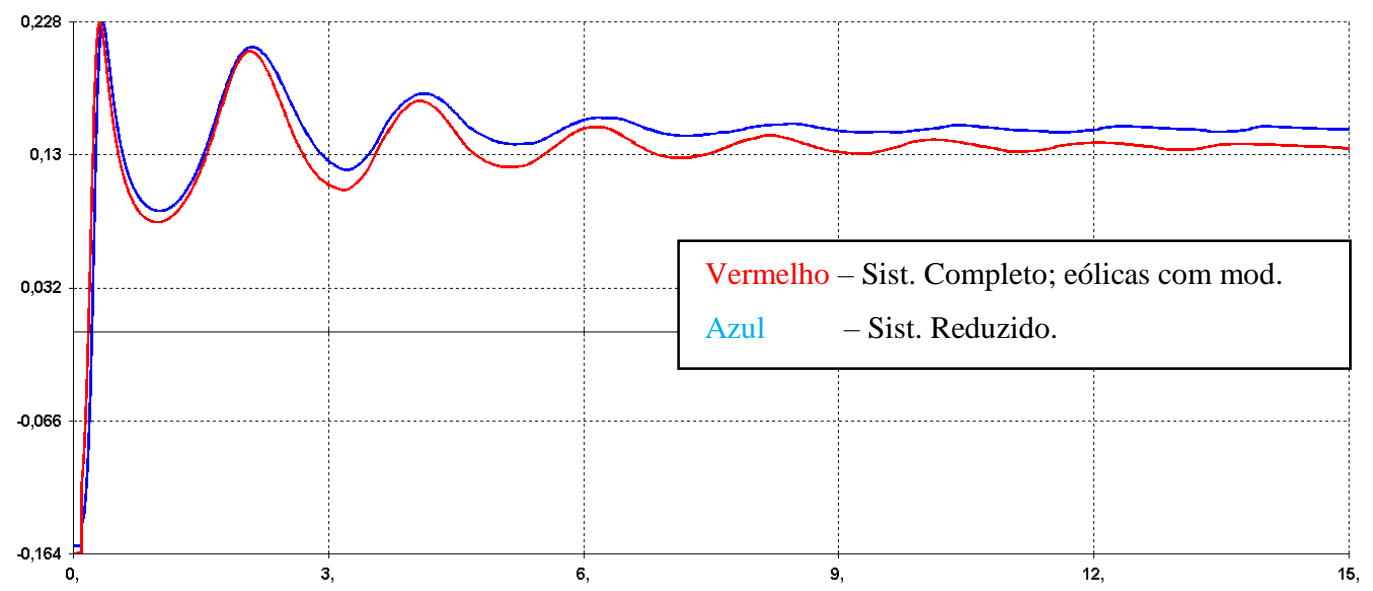

Figura 4.27. Comparação da resistência aparente medida pela PPS instalada na LT 500 kV S. Mesa - Peixe 2. 


\subsection{6.}

\section{Resultados do Teste T2 3}

O teste T2_2 apresentou excelentes resultados, mas obteve uma redução limitada. Portanto, o teste T2_3 tem como objetivo aumentar a redução do sistema e avaliar as possíveis perdas de acurácia no sistema equivalente. Para tentar minimizar a perda de acurácia, foram acrescentadas como barras adicionais os CEs de Bom Jesus da Lapa, Morro do Chapéu e Sapeaçu, para que sejam mantidos os seus respectivos modelos completos. Adicionalmente, o T2_3 se diferencia do T2_2 também na definição do número de barras de vizinhança definidas para a zona intermediária, de 2 para 0, e no valor de OUTMW (MW), modificado de 300 para $100 \mathrm{MW}$.

Como se pode observar na Figura 4.28, a seguir, foi possível efetuar a redução geral de cerca de $36 \%$ da rede original, tendo obtido uma redução de $59 \%$, no número de barras, e de $52 \%$, no número de circuitos, obtendo-se uma diferença em relação às tensões pré e pós a redução da rede, de no máximo 13,6\% e na média de cerca de $1,9 \%$. Resultados um pouco inferiores aos obtidos no teste T2_2.

Para o índice de estabilidade, as diferenças foram de cerca de 0.04 entre a rede completa e a reduzida, um resultado pior do que o obtido no teste T2_2.

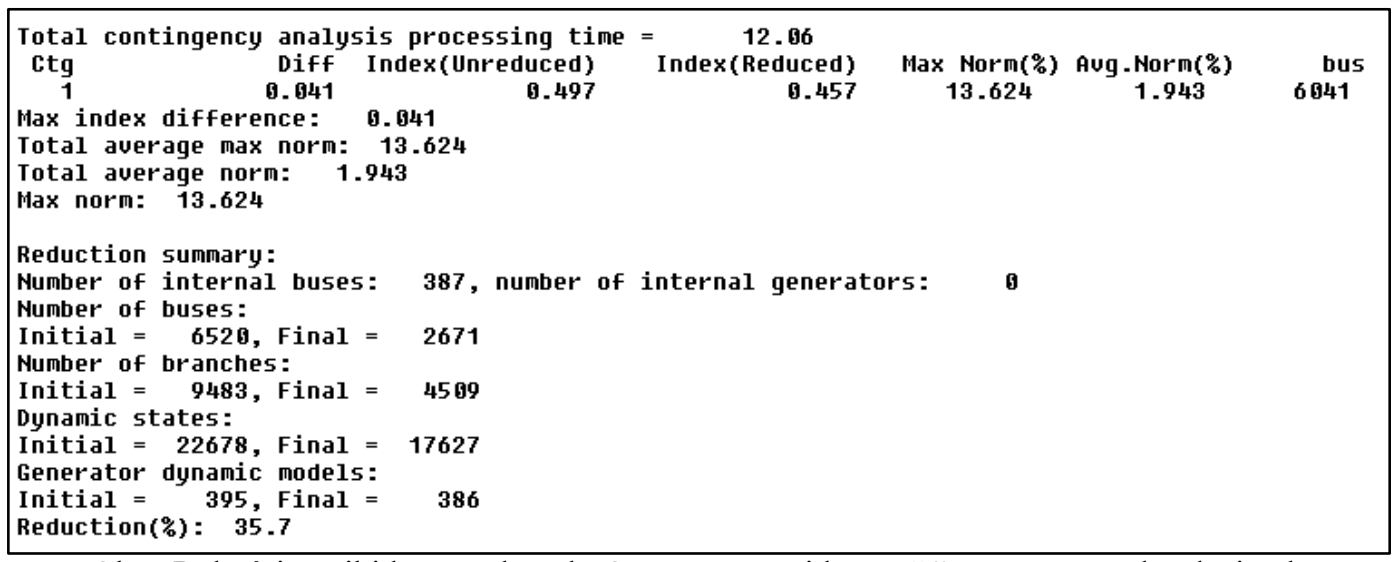
Obs.: Relatório exibido em tela pelo Organon, considera o "." como separador decimal

Figura 4.28. Síntese da redução da rede e do teste de precisão para o teste T2_10.

É importante notar que os valores de redução da rede foram bem superiores no teste T2_3 e vieram acompanhados por uma pequena diminuição no número de 
estados dinâmicos, ou seja, o valor da redução total no teste T2_3 foi maior em termos relativos e absolutos do que o teste T2_2.

Como esperado, ao se aumentar a redução da rede e dos modelos dinâmicos do sistema os resultados de acurácia pioraram. No entanto, a resposta sobre aceitar, ou não, tal "trade-off" só pode ser decidida por um analista experiente capaz de pesar os ganhos de velocidade de simulação, objetivo da aplicação do equivalente e suas limitações.

Dessa forma, na Figura 4.29, na Figura 4.30, na Figura 4.31, na Figura 4.32, na Figura 4.33 e na Figura 4.34, a seguir, são mostradas as comparações entre os resultados da rede completa e reduzida para as tensões nas SEs R. Éguas, S. Mesa e R. Gonçalves, da corrente na LT 500 kV Miracema Colinas e da resistência aparente vista pelas PPS's instaladas nas LTs $500 \mathrm{kV}$ R. Gonçalves - Colinas e S. Mesa-Peixe 2, respectivamente.

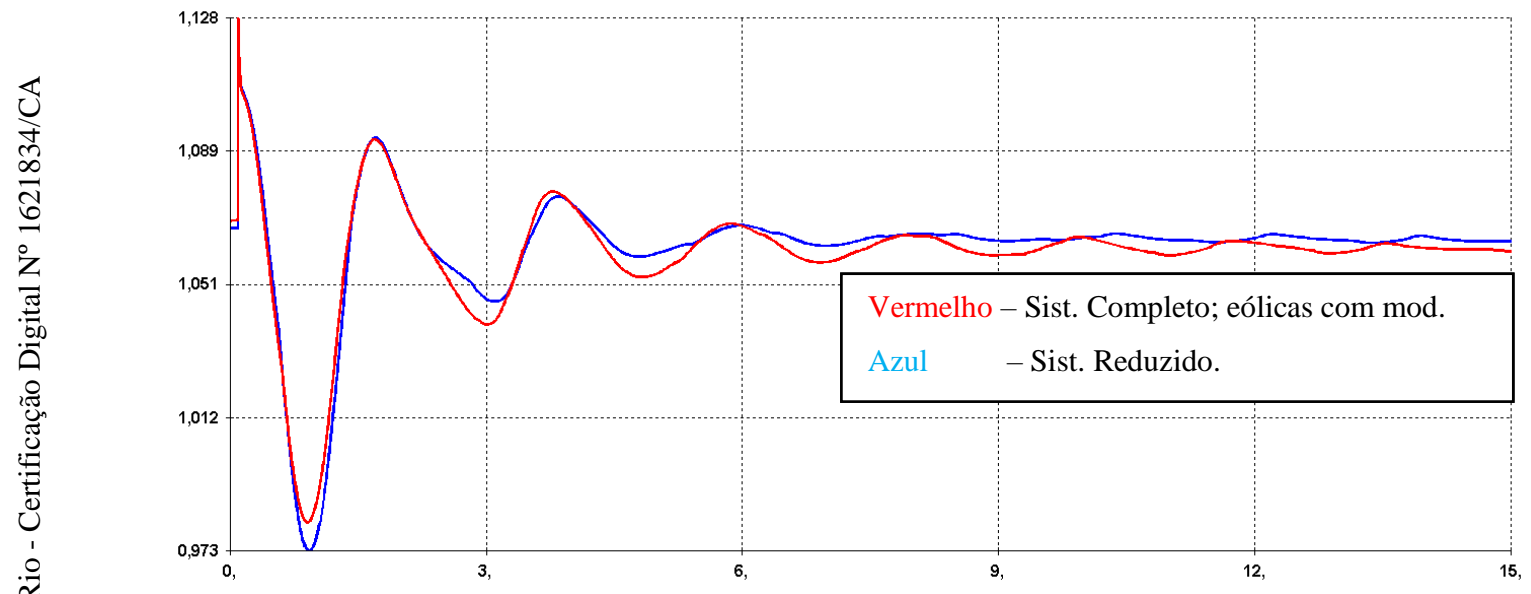

Figura 4.29. Comparação da tensão na barra de Rio das Éguas 500 kV.

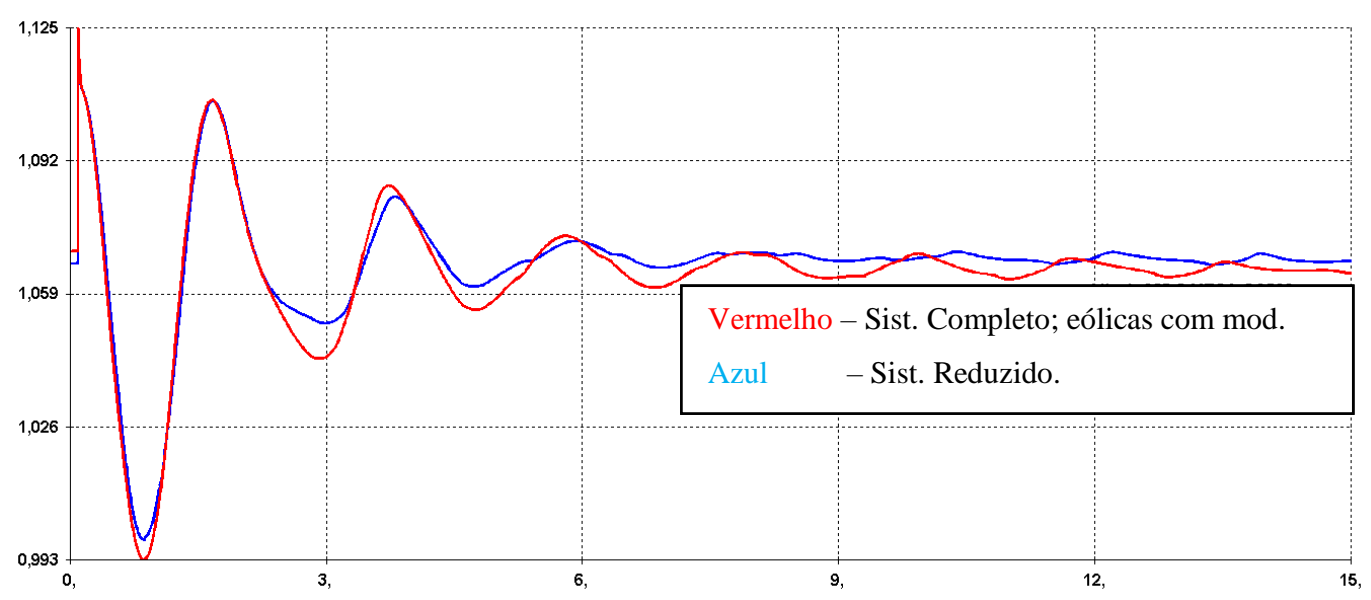

Figura 4.30. Comparação da tensão na barra de Serra da Mesa 500 kV. 


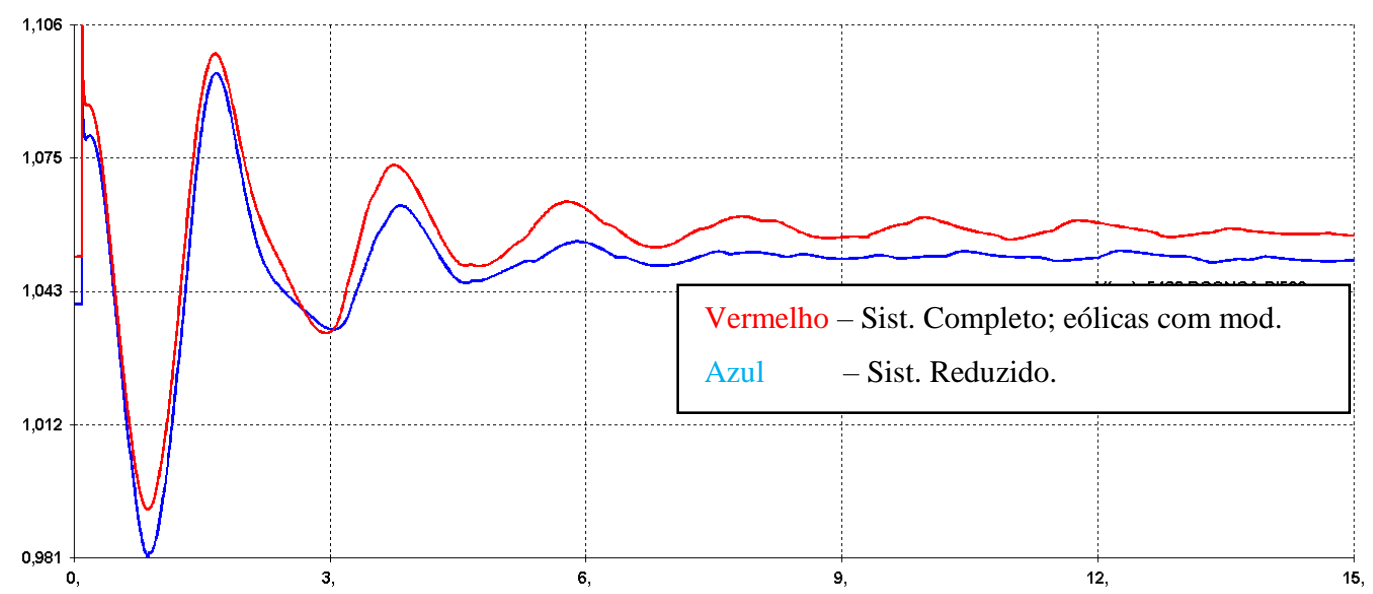

Figura 4.31. Comparação da tensão na barra de R. Gonçalves 500 kV.

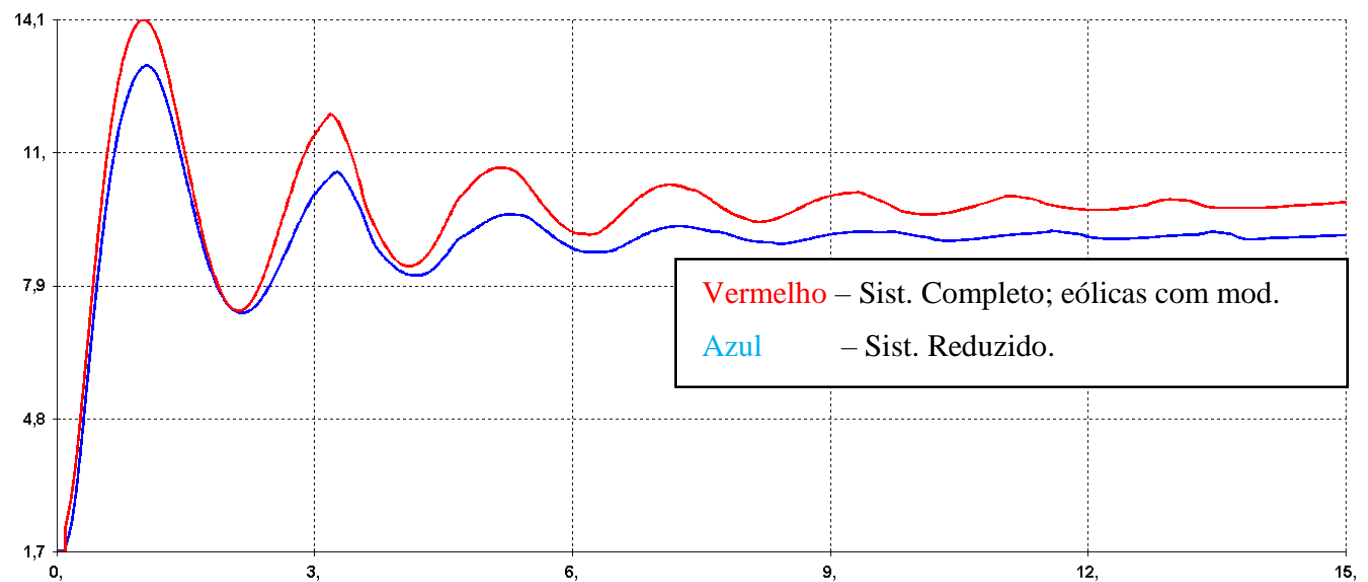

Figura 4.32. Comparação da corrente na LT 500 kV Miracema - Colinas.

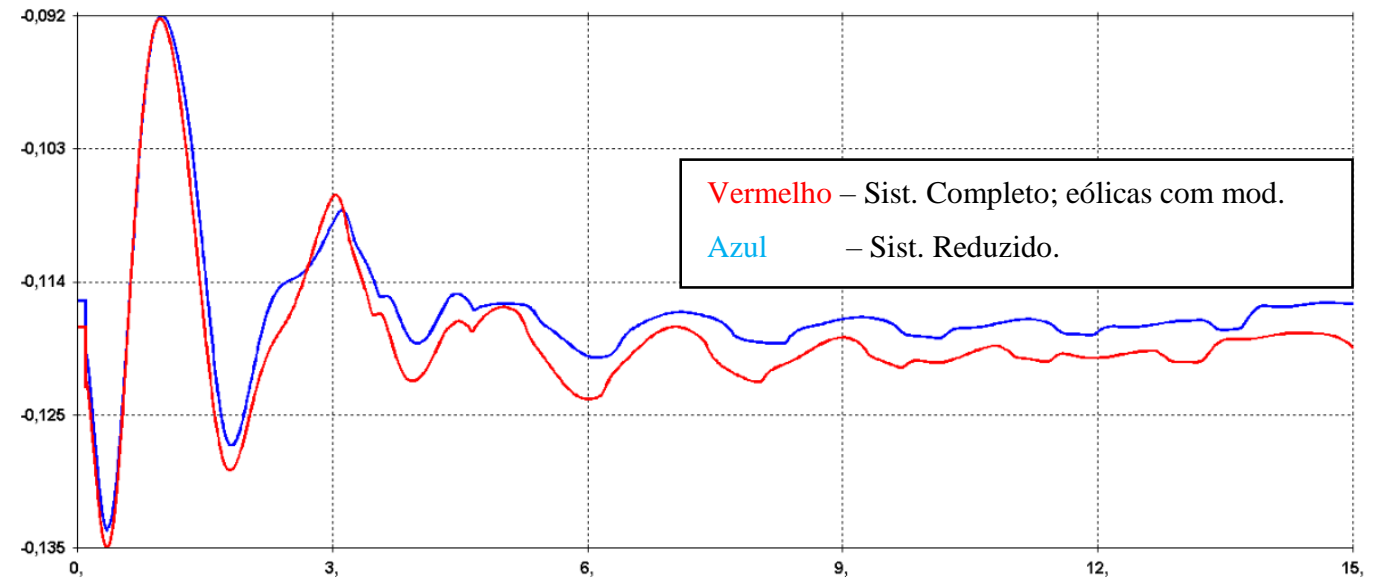

Figura 4.33. Comparação da resistência aparente medida pela PPS instalada na LT 500 kV R. Gonçalves - Colinas. 


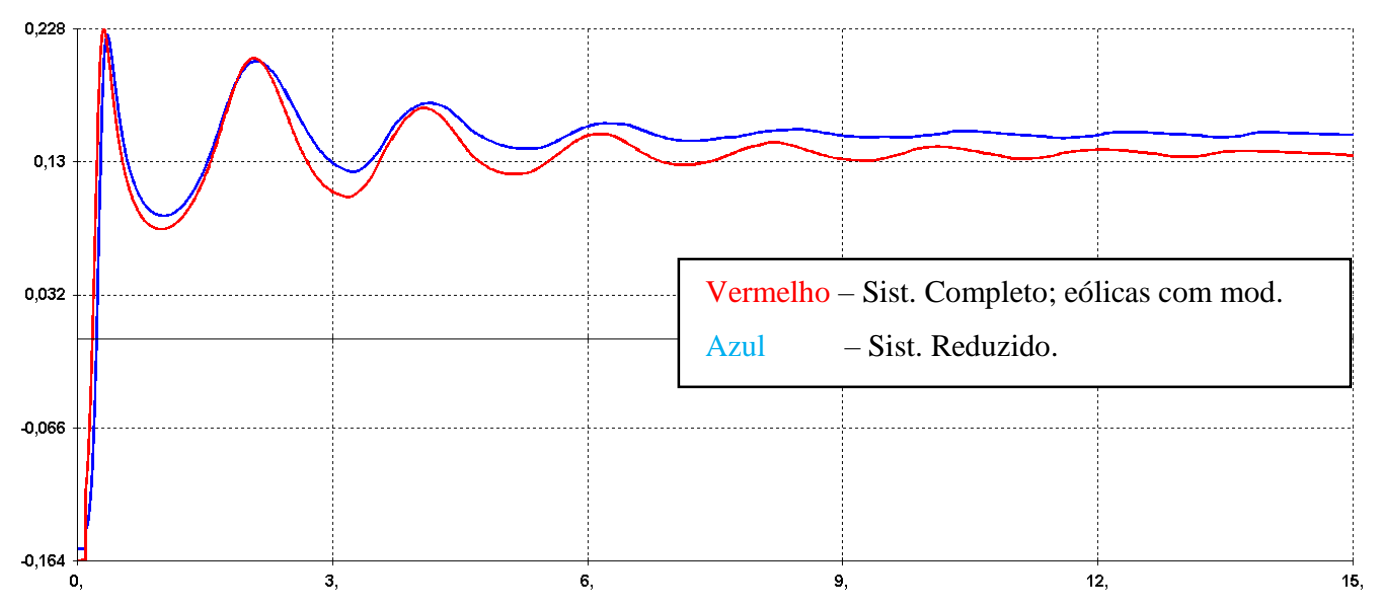

Figura 4.34. Comparação da resistência aparente medida pela PPS instalada na LT 500 kV S. Mesa - Peixe 2.

Após a análise dos resultados obtidos nos testes já apresentados, foi possível identificar a necessidade de algumas modificações no Organon, as quais serão detalhadas no item 4.3.8, a seguir. Para mensurar o impacto dessas modificações, o processo de redução da rede foi refeito com os mesmos parâmetros e opções do teste T2_3. Os resultados apresentados a seguir receberão a notação "T2_3b", como indicação da utilização de uma versão modificada do Organon.

Como se pode observar na Figura 4.35, a seguir, foi possível efetuar a redução geral de cerca de $40 \%$ da rede original, tendo obtido uma redução de cerca de 59\%, no número de barras, e de cerca de 52\%, no número de circuitos, obtendo-se uma diferença em relação às tensões pré e pós a redução da rede, de no máximo $1,36 \%$ e na média de cerca de $0,215 \%$. Para o índice de estabilidade, as diferenças foram de cerca de 0,029 entre a rede completa e a reduzida.

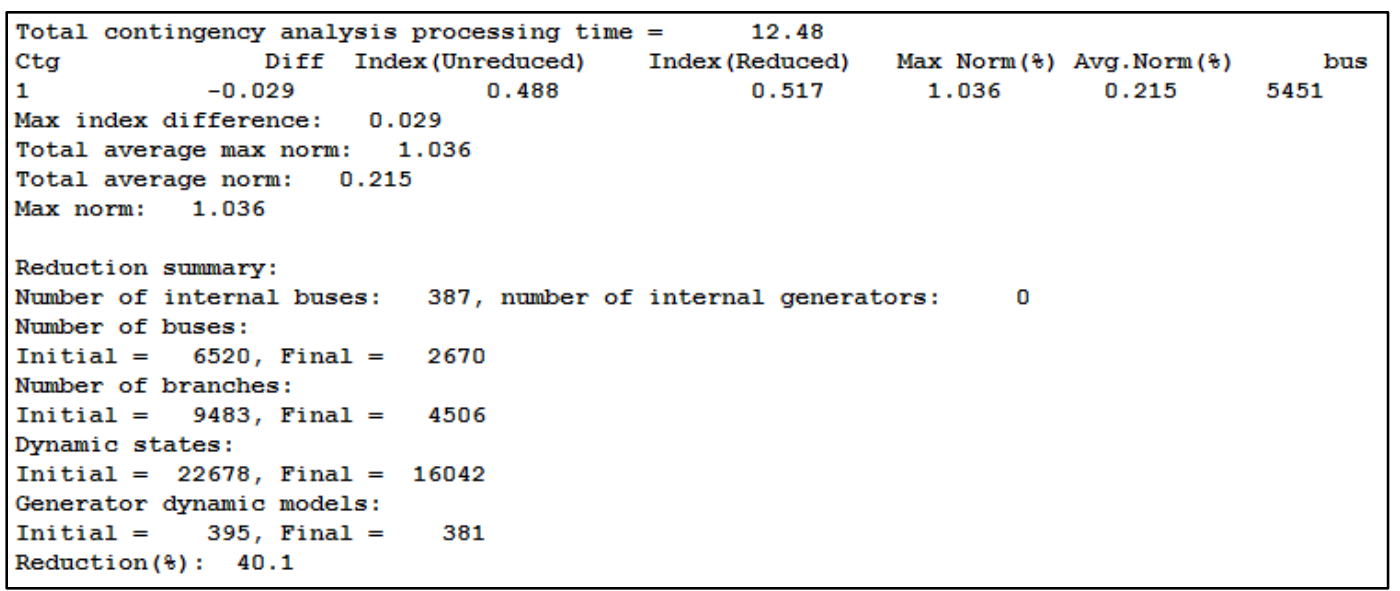

Obs.: Relatório exibido em tela pelo Organon, considera o ".” como separador decimal

Figura 4.35. Síntese da redução da rede e do teste de acurácia para o teste T2_3b. 
É importante notar que embora os valores de redução global da rede terem sido próximos aos obtidos no teste T2_3, saindo de 35,7\% para 40,1\%, por outro lado, em relação à acurácia, os resultados obtidos no teste T2_3b foram substancialmente melhores, saindo de 13,619\% de erro máximo, para 1,036\%.

Dessa forma, na Figura 4.36, na Figura 4.37, na Figura 4.38, na Figura 4.39, na Figura 4.40 e na Figura 4.41, a seguir, são mostradas as comparações entre os resultados da rede completa e reduzidas para as tensões nas SEs R. Éguas, S. Mesa e R. Gonçalves, da corrente na LT 500 kV Miracema Colinas e da resistência aparente vista pelas PPS's instaladas nas LTs 500 kV R. Gonçalves Colinas e S. Mesa - Peixe 2, respectivamente.

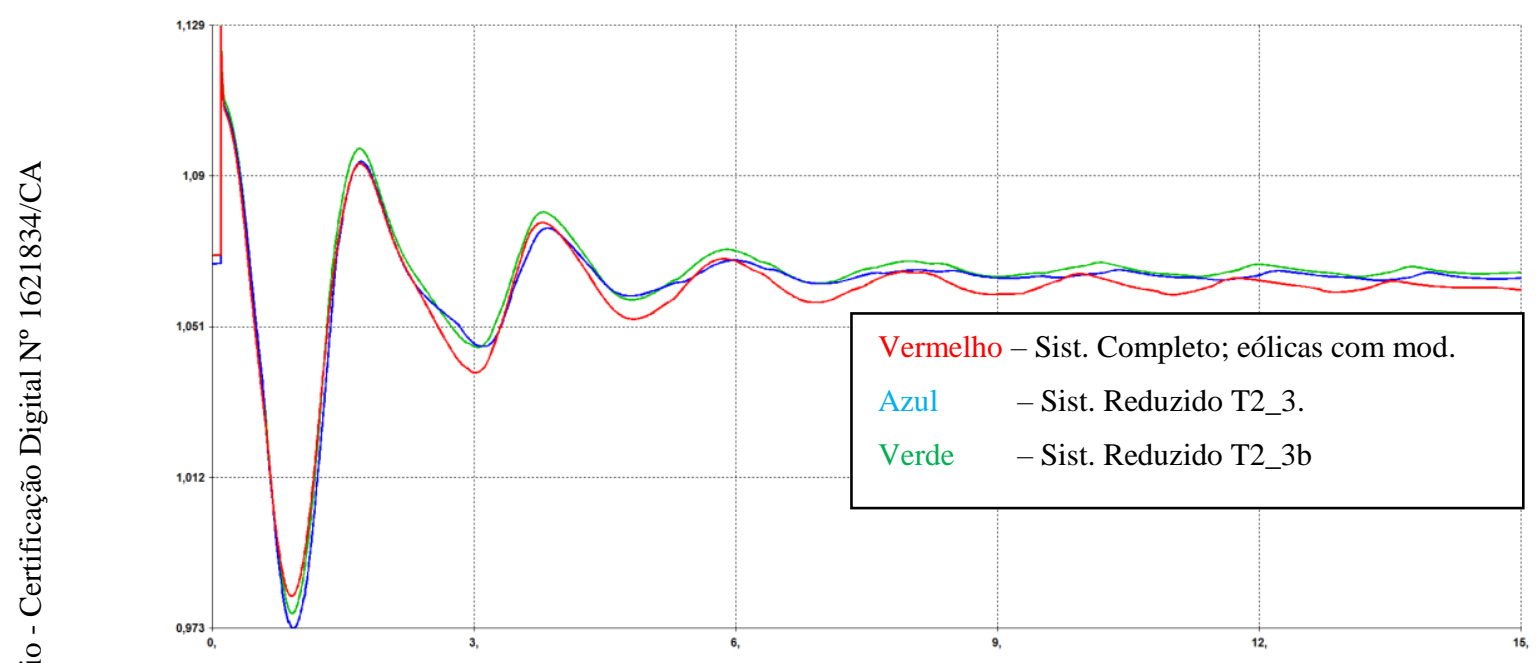

Figura 4.36. Comparação da tensão na barra de Rio das Éguas 500 kV.

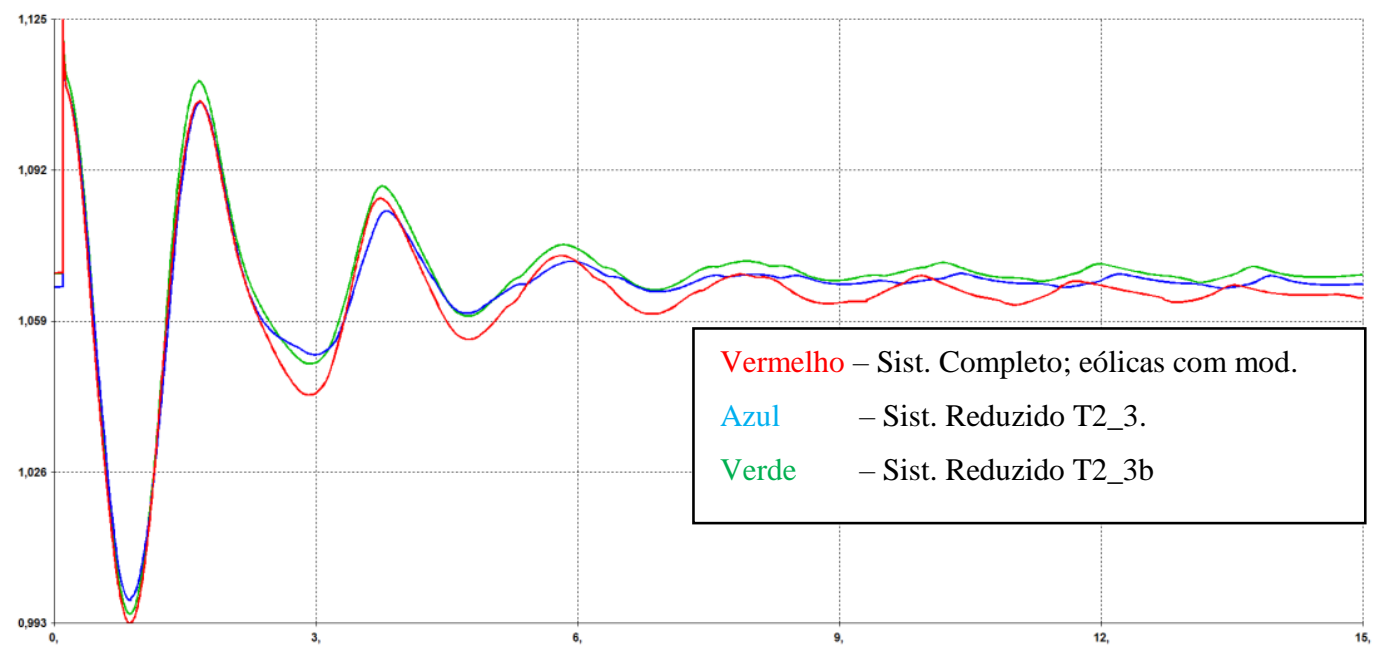

Figura 4.37. Comparação da tensão na barra de Serra da Mesa 500 kV. 


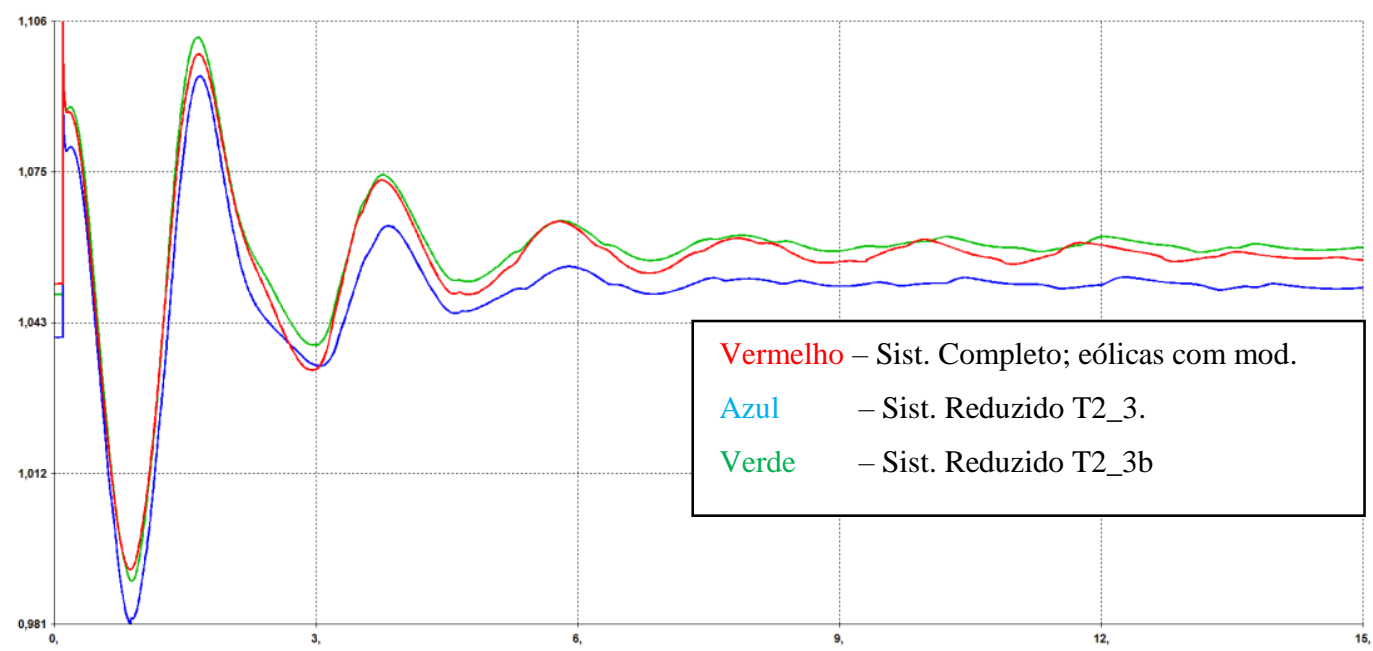

Figura 4.38. Comparação da tensão na barra de R. Gonçalves 500 kV.

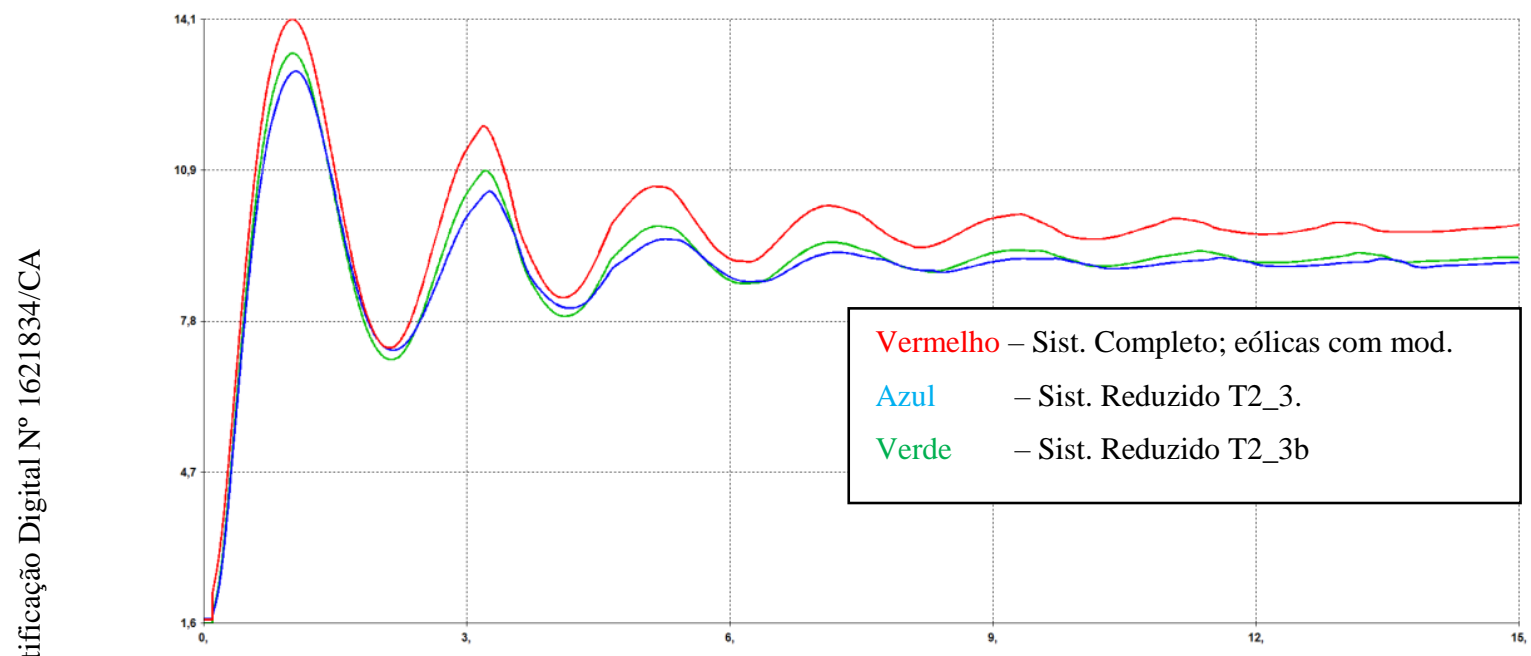

Figura 4.39. Comparação da corrente na LT 500 kV Miracema - Colinas.

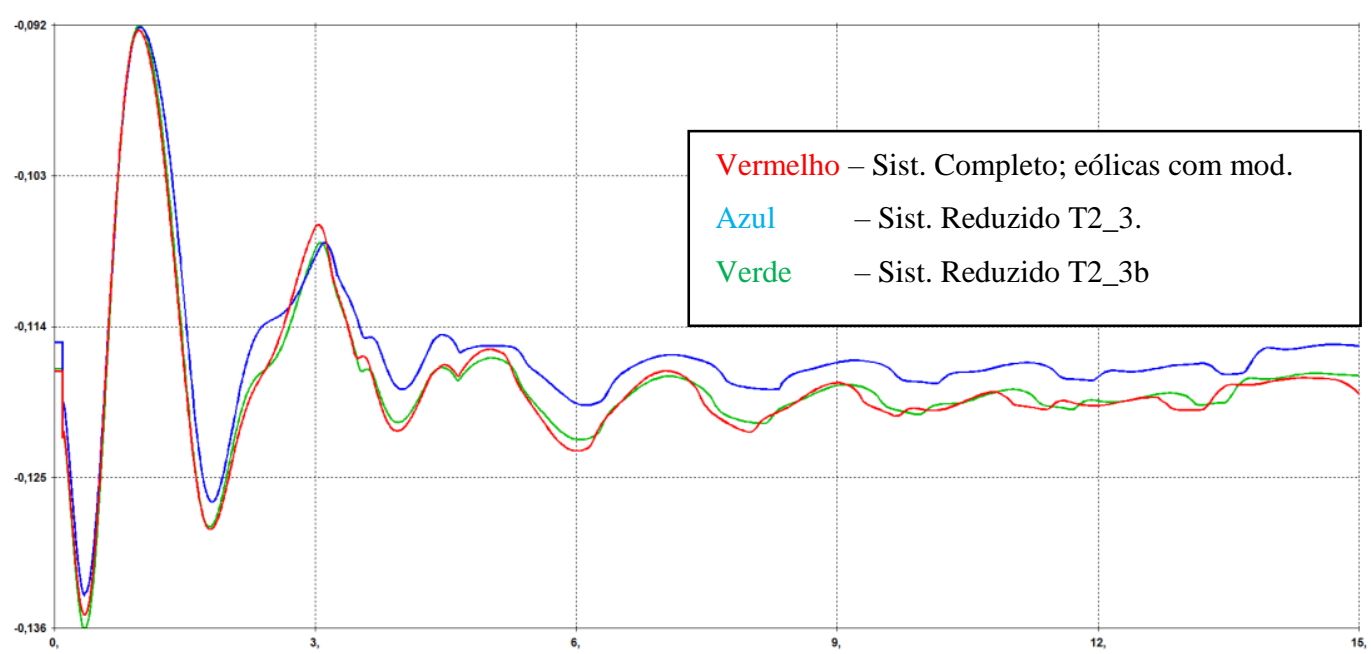

Figura 4.40. Comparação da resistência aparente na LT 500 kV R. Gonçalves Colinas. 


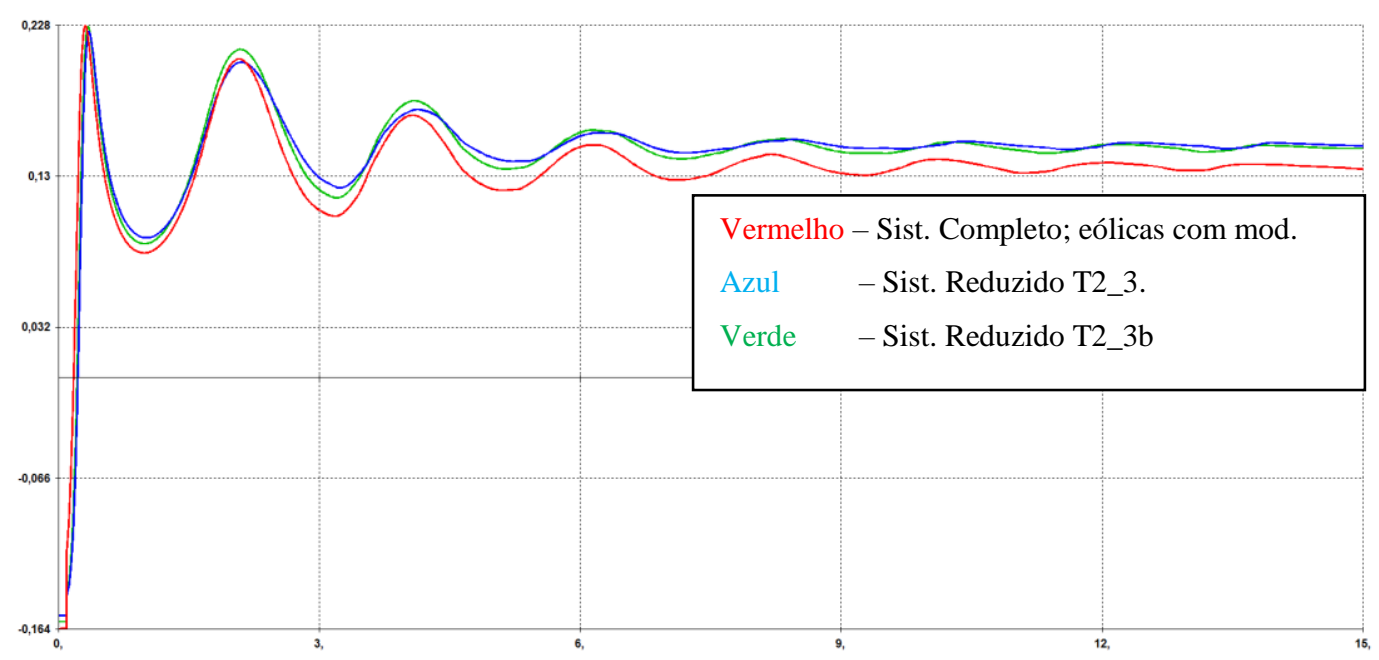

Figura 4.41. Comparação da resistência aparente na LT 500 kV S. Mesa - Peixe 2.

\subsection{7.}

\section{Resultados do Teste T2_4}

Os testes T2_3 e T2_3b, realizados anteriormente, apesar de apresentarem um ligeiro aumento na redução do sistema, permaneceram obtendo uma redução limitada, especialmente quanto ao número de geradores representados por seus modelos completos. Portanto, o teste T2_4 terá como objetivo reduzir o número de geradores representados com seus modelos completos e avaliar as possíveis perdas de precisão no sistema equivalente, se diferenciando do T2_3 nas seguintes definições de parâmetros: definição do valor de RETVLT (\%), modificado de 10 para $15 \%$, do valor de RETFLW (MW), modificado de 10 para $40 \%$, do valor de DEVMIN (pu), modificado de 0,2 para 0,1, do valor de EXDST (pu), modificado de 0,5 para 0,3 .

De modo a aprofundar a verificação dos impactos das modificações implementadas no Organon, foram realizados dois testes, o T2_4, na versão inicial, e o teste T2_4b, na versão modificada.

$\mathrm{Na}$ versão inicial do Organon, após o processamento dos parâmetros e opções, já descritas, a simulação da contingência no sistema reduzido foi instável, sendo considerada como uma perda de precisão inaceitável. Dessa forma, embora o programa tenha efetuado a redução da rede e disponibilizado seus resultados, estes não serão apresentados neste item. 
Para o teste $\mathrm{T} 2 \_4 \mathrm{~b}$, realizado na versão modificada, os resultados se mostraram bastante diferentes aos obtidos dos demais testes. Como se pode observar na Figura 4.42, a seguir, foi possível efetuar a redução geral de cerca de $66 \%$ da rede original, tendo obtido uma redução de cerca de $65 \%$, no número de barras, e de cerca de 59\%, no número de circuitos, obtendo-se uma diferença em relação às tensões pré e pós a redução da rede, de no máximo 1,6\% e na média de cerca de $0,5 \%$. Para o índice de estabilidade, as diferenças foram de cerca de 0,114 entre a rede completa e a reduzida.

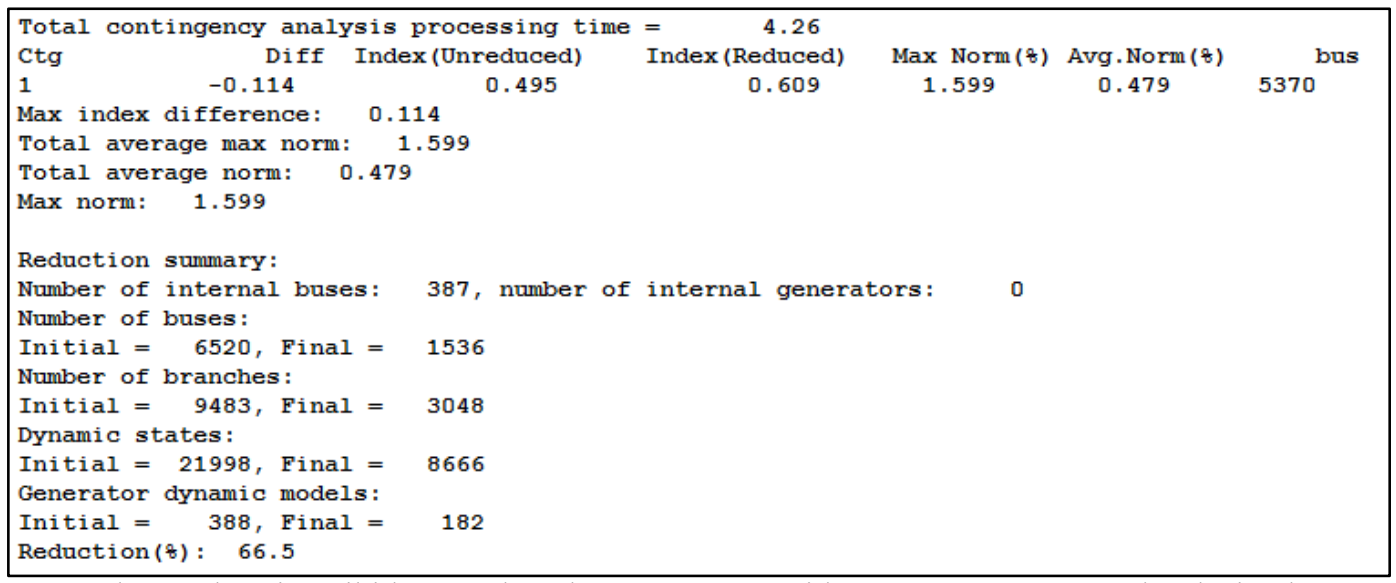

Obs.: Relatório exibido em tela pelo Organon, considera o “.” como separador decimal

Figura 4.42. Síntese da redução da rede e do teste de precisão para o teste T2_4b.

É importante notar que os valores de redução da rede foram bem superiores no teste T2_4b e vieram acompanhados por uma grande diminuição no número de estados dinâmicos, ou seja, o valor da redução total no teste T2_4b foi maior do que todos os demais testes, em termos relativos e absolutos.

Dessa forma, na Figura 4.43, na Figura 4.44, na Figura 4.45, na Figura 4.46, na Figura 4.47 e na Figura 4.48, a seguir, são mostradas as comparações entre os resultados da rede completa e reduzidas para as tensões nas SEs R. Éguas, S. Mesa e R. Gonçalves, da corrente na LT $500 \mathrm{kV}$ Miracema Colinas e da resistência aparente vista pelas PPS's instaladas nas LTs 500 kV R. Gonçalves Colinas e S. Mesa - Peixe 2, respectivamente. 


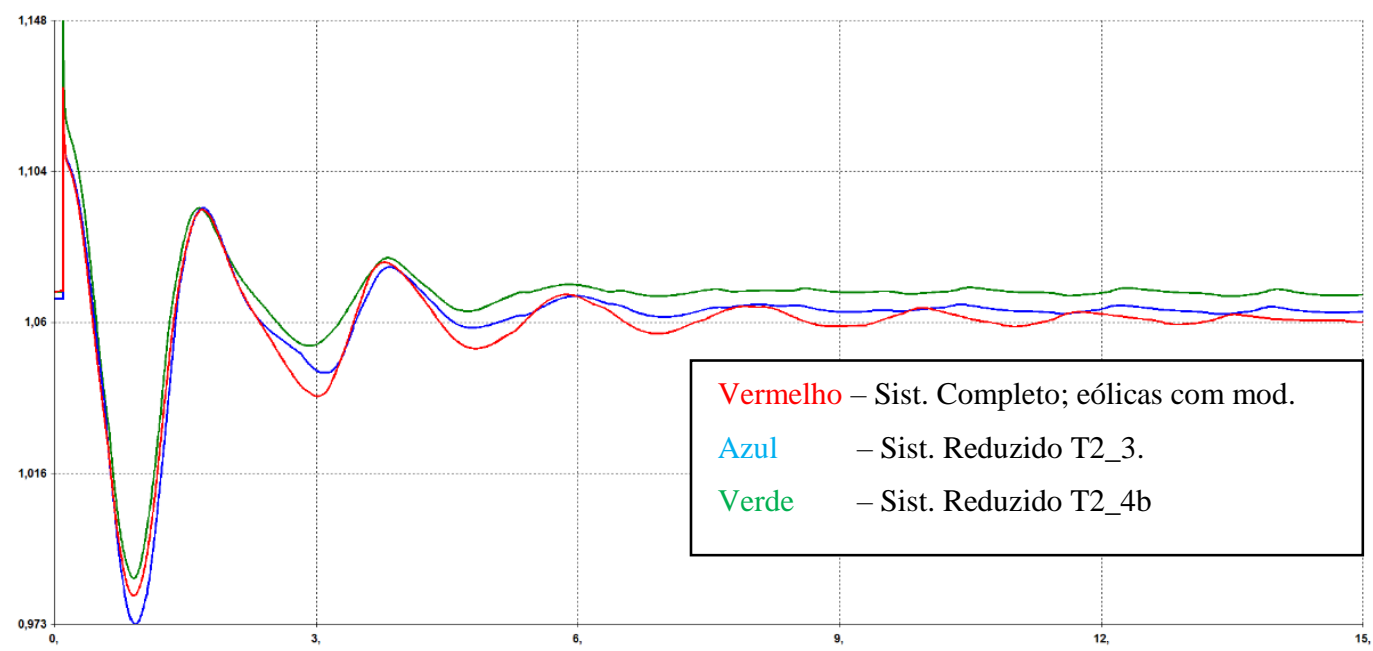

Figura 4.43. Comparação da tensão na barra de Rio das Éguas 500 kV.

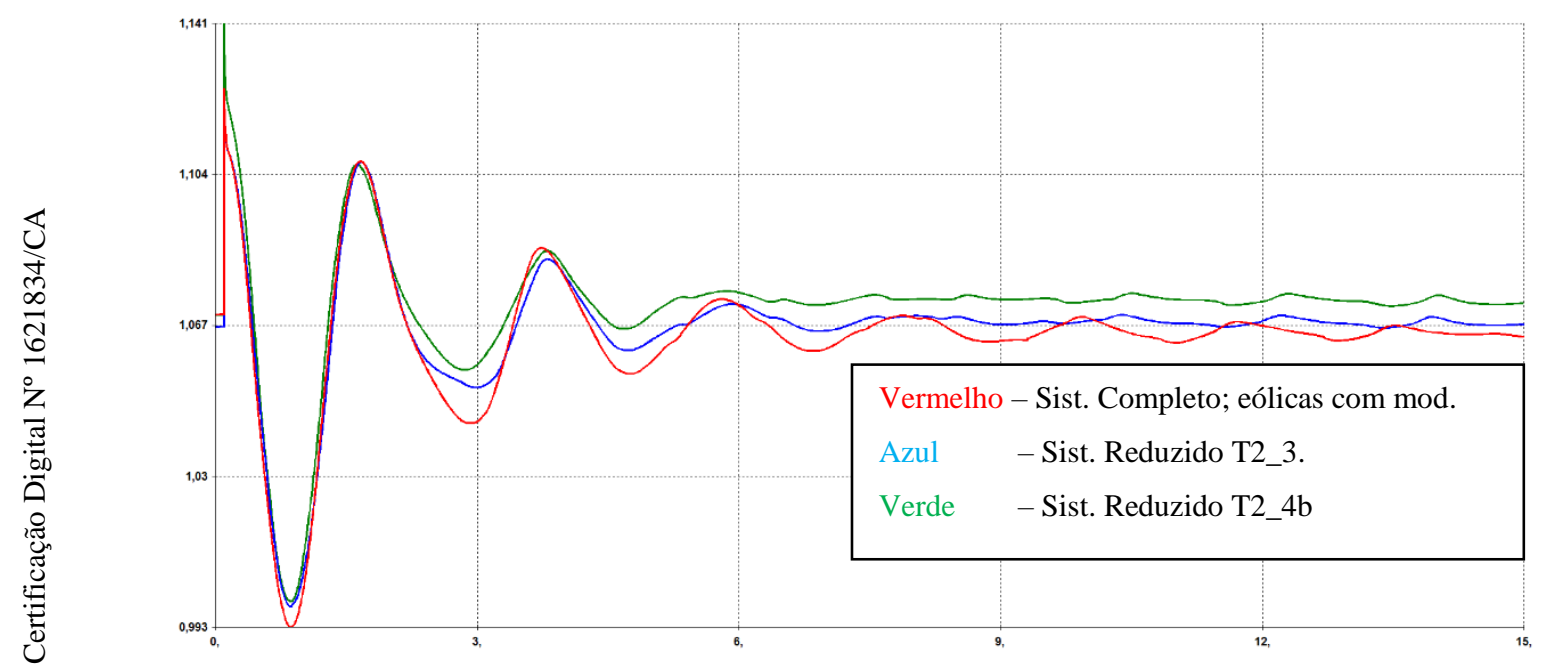

Figura 4.44. Comparação da tensão na barra de Serra da Mesa 500 kV.

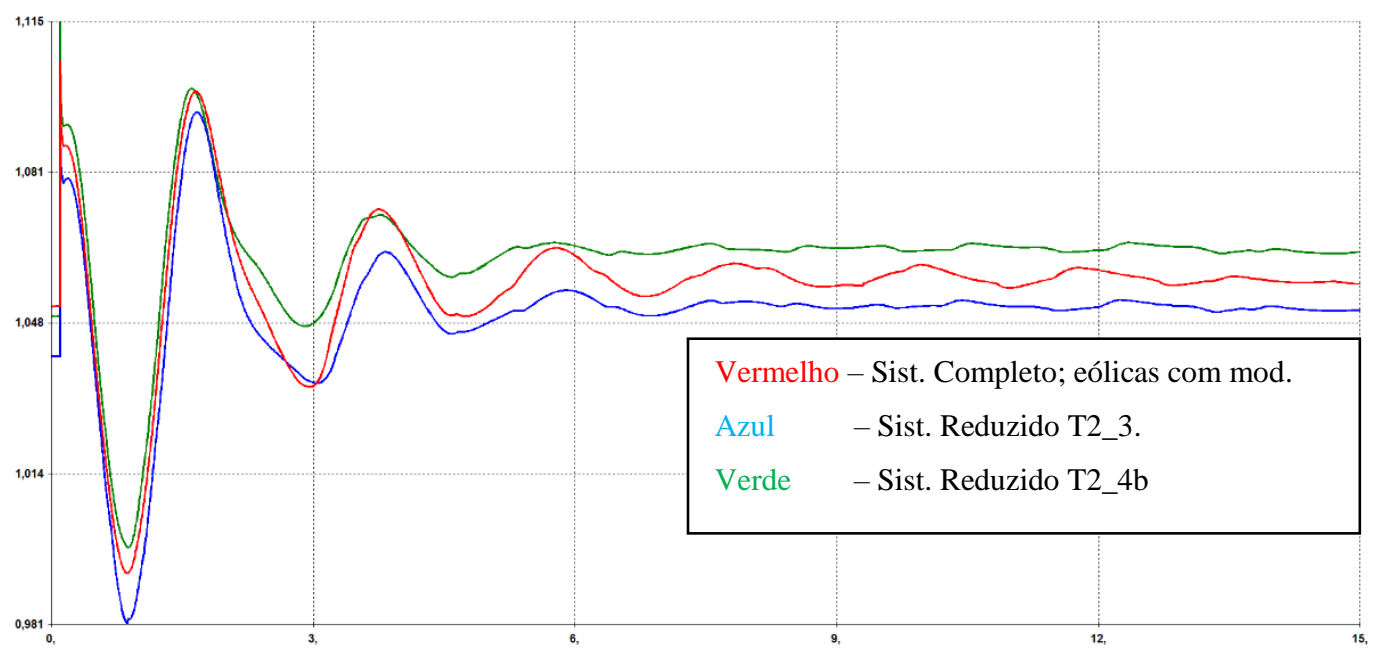

Figura 4.45. Comparação da tensão na barra de R. Gonçalves 500 kV. 


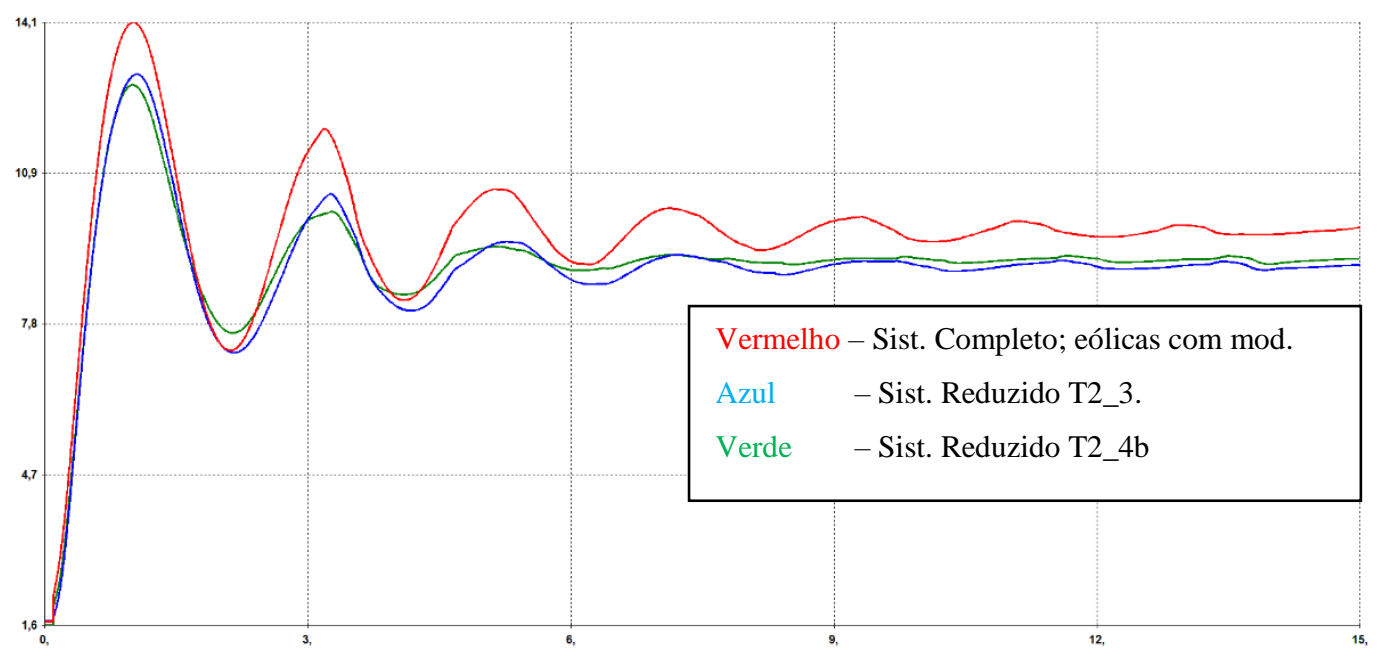

Figura 4.46. Comparação da corrente na LT 500 kV Miracema - Colinas.

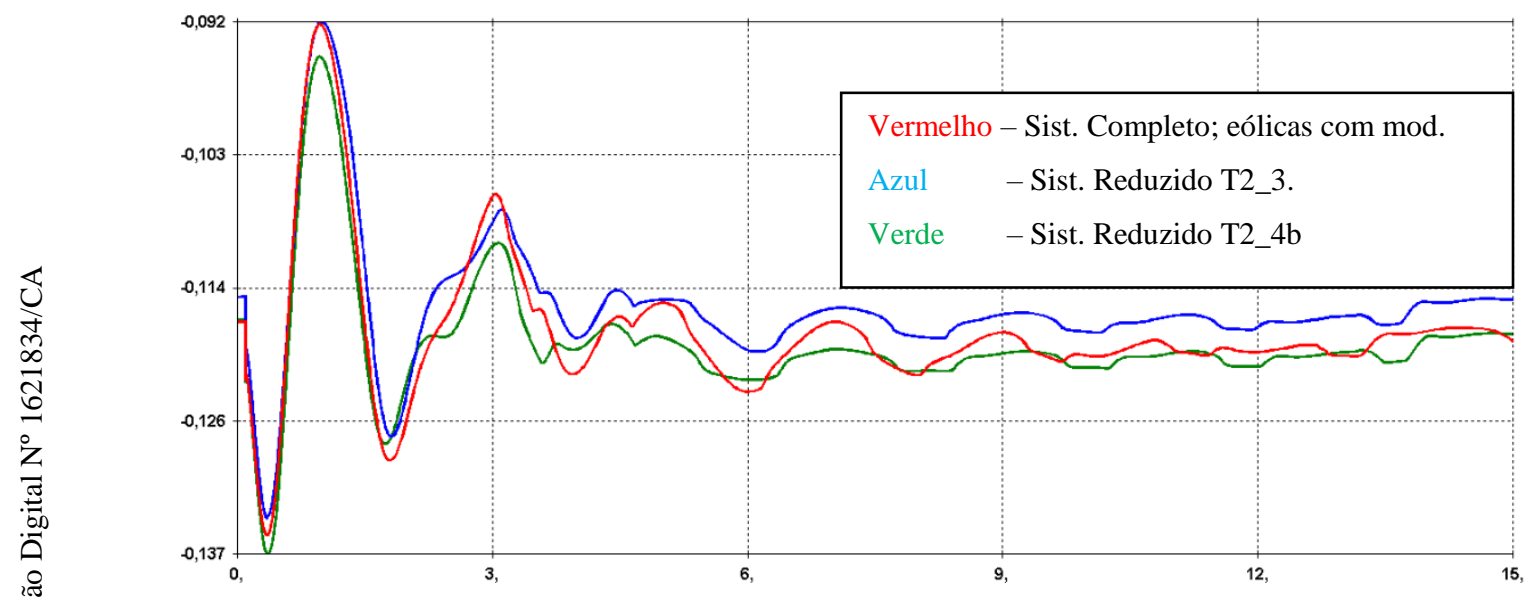

Figura 4.47. Comparação da resistência aparente na LT 500 kV R. Gonçalves Colinas.

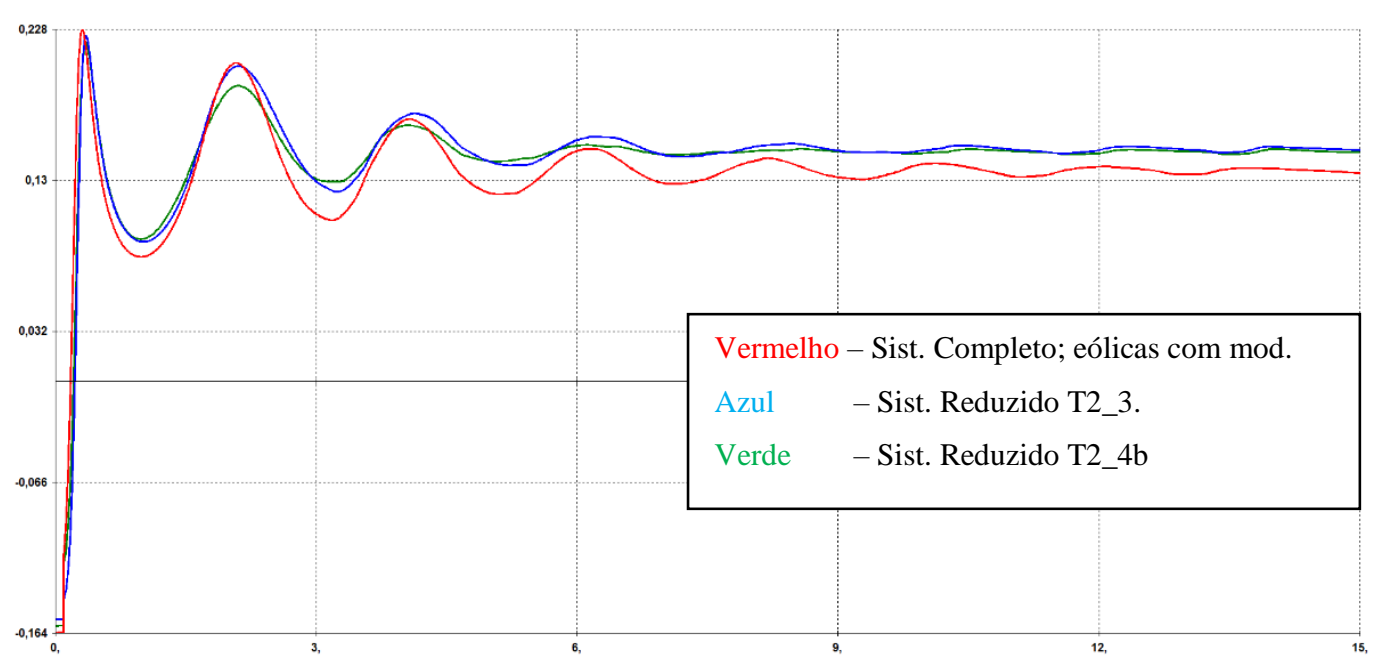

Figura 4.48. Comparação da resistência aparente na LT 500 kV S. Mesa Peixe 2. 


\subsection{8.}

\section{Conclusões dos Testes T2_1, T2_2, T2_3 e T2_4}

Como pode ser observado nas figuras anteriores, a simples desconsideração dos modelos dinâmicos dos geradores eólicos produz grandes diferenças entre as simulações com a rede completa. Embora, no futuro, a evolução do programa possa vir a permitir a criação de modelos dinâmicos equivalentes para esse tipo geração, no presente, as mesmas são mantidas quando possuem modelos completos associados e as barras às quais estão conectadas são retidas devido aos testes de sensibilidade de tensão. Uma vez que suas barras não sejam retidas, os parques eólicos são completamente excluídos da rede.

De modo geral, as barras com geradores conectados podem ser mantidas, desde que estejam com os seus modelos dinâmicos definidos no arquivo de modelos dinâmicos (.DYN), que a faixa de reativo [Qmin, Qmax] existente no caso base seja maior que o limite definido no parâmetro RETGENMVA (definido em p.u. da base 100 MVA) e que seja atingido o valor mínimo de alguma das sensibilidades de retenção.

Como mencionado anteriormente, no item 4.3.7, para a realização dos testes $\mathrm{T} 2 \_3 \mathrm{~b}$ e $\mathrm{T} 2 \_4 \mathrm{~b}$ foram implementadas modificações no Organon. A primeira delas, foi fruto da identificação de que barras de geração que estivessem controlando a tensão de barras remotas, eram retiradas das análises de sensibilidade, impedindo que estes geradores tivessem seus modelos completos mantidos e/ou participassem de agrupamentos de geradores, deteriorando os resultados da redução da rede.

Em relação à segunda modificação, como comentado anteriormente, no item 4.2.6, foi observado durante os testes que alguns valores de sensibilidade de tensão apresentavam alguns valores incoerentes. Após a verificação das rotinas utilizadas para o cálculo da sensibilidade de tensão, via interface do usuário e durante o processo de redução de rede, se identificou um descasamento de índices entre matrizes que podia levar à não associação dos valores de sensibilidades às suas respectivas barras. Cabe destacar que não foram identificados erros de cálculos nos fatores de sensibilidade, no entanto, como consequência, eram retidas barras cujas sensibilidades não estavam dentro dos parâmetros selecionados, enquanto barras desejadas eram retiradas. 
Ambas as modificações descritas anteriormente permitiram que houvesse um aumento significativo no nível de redução de rede, de 35,7\%, no T2_3 para 65,5\%, no T2_4b, com valores de erros máximos e médios inferiores aos obtidos nos testes anteriores.

Neste sentido, também foi identificado que existe a possibilidade de melhoria na forma como são calculadas as sensibilidades referentes à variação de fluxo em circuitos internos, devido à abertura de circuitos da região externa. Foi percebido que tal sensibilidade não leva em consideração o fluxo inicial desses circuitos. Ou seja, o circuito interno que, por exemplo, tenha seu fluxo variado de 5 MW para $10 \mathrm{MW}$, será identificado como um circuito com 5 MW de sensibilidade, o que poderia ser visto como insignificante. No entanto, caso o valor do fluxo no circuito interno fosse considerado, tal valor seria de $100 \%$ de sensibilidade, bem superior ao anterior. Por outro lado, uma outra alternativa para o cálculo da sensibilidade do mesmo circuito seria considerar o valor do fluxo no circuito externo, por exemplo, $1000 \mathrm{MW}$, então a sensibilidade do mesmo circuito interno seria calculada em $0,5 \%$. Outra alternativa, seria a consideração da capacidade dos próprios circuitos para efetuar a ponderação. Embora devam ser feitos testes para a identificação de qual seria a opção mais eficiente, parece claro que a utilização de alguma ponderação do fluxo inicial, seja do circuito interno ou externo, permitiria um ajuste mais preciso desta sensibilidade do que apenas o seu valor em MW, podendo aumentar a eficiência com a qual o Organon retém circuitos.

Outra dificuldade encontrada durante os testes foi relacionada ao tratamento de barras conectadas aos conversores. Ao se efetuar uma redução de rede, caso algumas das barras suprimidas durante o processo tenha um conversor conectado, sua injeção equivalente não é considerada em nenhuma das barras remanescentes, ficando a cargo da barra Swing a diferença. Em alguns casos, a mudança do ponto de operação era tão extensa que impedia a convergência do fluxo de potência do sistema reduzido. Dessa forma, foi necessária a definição da barra retificadora de Araraquara como parte da zona intermediária e/ou da região interna. Uma correção para tratar tal situação já se encontra implementada no Organon.

$\mathrm{Na}$ Tabela 4.4, a seguir, estão resumidos os principais resultados obtidos nos testes apresentados. Nela, é possível perceber que os três primeiros testes alcançaram excelentes níveis de precisão e que a redução global da rede atingiu 
valores de cerca de $30 \%$, porém com relação à utilização de agrupamentos de geradores equivalentes, os resultados foram mais modestos, apresentando uma redução de cerca de $2 \%$ no número de geradores e com a criação de apenas 4 agrupamentos de geradores equivalentes. No último teste, T2_4b, a redução do sistema foi levada ao extremo, com cerca de $66 \%$ de redução global, enquanto que, com relação à utilização de agrupamentos de geradores equivalentes, foram criados 33, permitindo uma redução de $77 \%$ no número de geradores representados com seus modelos completos.

Os resultados encontrados no teste $\mathrm{T} 2 \_4 \mathrm{~b}$ em relação ao aumento de redução do sistema, rede e modelos, vieram acompanhados com o aumento na precisão, expressa pelos índices de diferença normalizada, máxima e média, entre as curvas de tensão das barras de fronteira. Tomando como base os resultados do teste T2_3, segunda maior redução de rede entre os testes, e comparando com os resultados do teste T2_4b, observa-se que ocorreu uma pequena piora na diferença entre os índices de estabilidade, de 0,04 para 0,114. Essa diferença pode ser explicada pelo grande aumento do número de geradores agrupados. No entanto, em relação às curvas de tensão, houve uma grande melhora nos índices, saindo de 13,619 para 1,599, na máxima diferença normalizada, e de 1,942 para 0,479, na média das diferenças normalizadas.

Tais resultados, conjuntamente com a constatação de que os níveis de redução alcançados no teste T2_4b não puderam ser reproduzidos pela versão inicial do Organon, evidenciam que as modificações implementadas aumentaram a seletividade e eficiência com a qual o Organon conseguiu efetuar a redução da rede e a criação de agrupamentos, sendo capaz, inclusive, de manter um excelente nível de precisão no sistema reduzido testado. 
Tabela 4.4. Síntese dos resultados de redução do sistema

\begin{tabular}{|c|c|c|c|c|c|c|c|}
\hline \multicolumn{2}{|c|}{ Teste } & $\mathrm{T} 2 \_1$ & T2_2 & $\mathrm{T} 2 \_3$ & $\mathrm{~T} 2 \_3 \mathrm{~b}$ & $\mathrm{~T} 2 \_4$ & $\mathrm{~T} 2 \_4 \mathrm{~b}$ \\
\hline \multirow{3}{*}{$\begin{array}{l}\mathbf{N}^{\circ} \text { de } \\
\text { Barras }\end{array}$} & Inicial & 6520 & 6520 & 6520 & 6520 & 6520 & 6520 \\
\hline & Final & 3382 & 3382 & 2671 & 2670 & 2237 & 1536 \\
\hline & Redução & $48,1 \%$ & $48,1 \%$ & $59,0 \%$ & $59,0 \%$ & $65,7 \%$ & $76,4 \%$ \\
\hline \multirow{3}{*}{$\begin{array}{c}\mathbf{N}^{\circ} \text { de } \\
\text { Circuitos }\end{array}$} & Inicial & 9483 & 9483 & 9483 & 9483 & 9483 & 9483 \\
\hline & Final & 5524 & 5524 & 4509 & 4506 & 3912 & 3048 \\
\hline & Redução & $41,7 \%$ & $41,7 \%$ & $52,5 \%$ & $52,5 \%$ & $58,7 \%$ & $67,9 \%$ \\
\hline \multirow{3}{*}{$\begin{array}{l}\mathbf{N}^{\circ} \text { de Est. } \\
\text { Dinâmicos }\end{array}$} & Inicial & 16673 & 22678 & 22678 & 22678 & 22678 & 22678 \\
\hline & Final & 16209 & 18201 & 17627 & 16042 & 5324 & 8666 \\
\hline & Redução & $2,8 \%$ & $19,7 \%$ & $22,3 \%$ & $29,3 \%$ & $76,5 \%$ & $61,8 \%$ \\
\hline \multirow{3}{*}{$\begin{array}{c}\mathbf{N}^{\circ} \text { de } \\
\text { Geradores }\end{array}$} & Inicial & 395 & 395 & 395 & 395 & 395 & 395 \\
\hline & Final & 387 & 387 & 386 & 381 & 91 & 182 \\
\hline & Redução & $2,0 \%$ & $2,0 \%$ & $2,3 \%$ & $3,54 \%$ & $77,0 \%$ & $53,9 \%$ \\
\hline \multirow{3}{*}{$\begin{array}{c}\mathbf{N}^{\circ} \text { de } \\
\text { Geradores } \\
\text { Eólicos }\end{array}$} & Inicial & 65 & 65 & 65 & 65 & 65 & 65 \\
\hline & Final & 0 & 19 & 14 & 8 & 15 & 15 \\
\hline & Redução & $100,0 \%$ & $70,8 \%$ & $78,5 \%$ & $87,7 \%$ & $76,9 \%$ & $76,9 \%$ \\
\hline \multicolumn{2}{|c|}{ Número de Agrupamentos } & 4 & 4 & 4 & 1 & 33 & 33 \\
\hline \multicolumn{2}{|c|}{ Redução Global } & $22,7 \%$ & $30,1 \%$ & $35,7 \%$ & $40,1 \%$ & $69,5 \%$ & $66,5 \%$ \\
\hline \multirow{3}{*}{ Acurácia } & Index. Dif. & 0,05 & 0,021 & 0,04 & 0,029 & \multirow{3}{*}{ 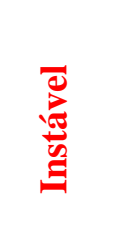 } & 0,114 \\
\hline & Max. Norm. & 5,61 & 6,583 & 13,619 & 1,036 & & 1,599 \\
\hline & Med. Norm. & 0,760 & 0,897 & 1,942 & 0,215 & & 0,479 \\
\hline
\end{tabular}




\section{5 \\ Conclusões}

A presente Dissertação de Mestrado apresentou e discutiu, primeiramente, as referências mais significativas para o entendimento de forma global, tanto dos equivalentes estáticos de rede, em especial o método Ward e suas derivações, quanto dos principais métodos de equivalentes dinâmicos.

Tendo o programa Organon como ferramenta de referência, foram apresentados os resultados de diversos testes. Os mesmos foram especialmente elaborados para que, de forma progressiva, as potencialidades e possíveis limitações dos modelos utilizados e suas implementações fossem devidamente investigadas. Dessa forma, os bons resultados atingidos permitem o vislumbre de novas possibilidades para a utilização dos equivalentes dinâmicos, tanto para o seu uso no planejamento, quanto em tempo real.

De um modo geral, os modelos e métodos implementados no Organon, se mostraram bem eficazes em identificar aqueles geradores passíveis de formar agrupamentos, enquanto o método de definição de um modelo de segunda ordem para esses agrupamentos, certamente permitiu um expressivo aumento de precisão, como demonstrado em vários testes. Cabe destacar que não foram observados problemas de inicialização desses modelos, bem como o seu comportamento dinâmico se provou bastante eficaz na reprodução do comportamento dinâmico global das máquinas com seus modelos completos que, posteriormente, constituíram agrupamentos.

Mais especificamente, a escolha do sistema Acre e Rondônia para o início dos testes se mostrou correta, uma vez que por ser uma rede de menor porte e radial, foi possível perceber os impactos do uso de diferentes parâmetros entre as simulações dinâmicas realizadas pelo usuário. Também foi possível identificar que o Organon não considera os equipamentos de controle de tensão de Compensadores Estáticos e Staticoms nos testes de sensibilidade de tensão, sendo desejável que o fizesse como demonstrado nos testes. Esta modificação será futuramente incorporada ao Organon. 
Para permitir que o usuário tivesse maior controle sobre as opções e parâmetros utilizados durante o processo do cálculo de acurácia, já se encontram implementadas algumas modificações, sendo agora possível:

- Utilizar o evento de curto circuito com tensão definida pelo usuário;

- Ligar ou desligar os controladores de velocidade de usinas durante as simulações para cálculo de acurácia;

- Determinar o tempo de simulação durante as simulações para cálculo de acurácia;

- Habilitar ou não a detecção automática de instabilidade durante as simulações para cálculo de precisão.

Para o sistema Acre e Rondônia os resultados encontrados foram muito bons, permitindo uma redução global de cerca de 90\%, mantendo valores de precisão significativos tanto na média como na máxima global entre todas as contingências simuladas.

Para o segundo cenário, reduzir o sistema interligado, frente à perda do bipolo com fluxo de Estreito para Xingu, permitiu observar o processo de redução de rede num sistema influenciado por inúmeros caminhos de fluxos e centenas de geradores.

Quanto aos geradores, percebeu-se ao estudar os relatórios de saída dos testes de sensibilidade que muitos dos valores apresentados eram tanto, diferentes do esperado, quanto dos valores obtidos quando o mesmo calculo era feito via a interface de usuário. Também se observou que algumas das usinas que se esperaria ter grande influência numa dada barra não apareciam nos resultados de sensibilidade. Em relação aos geradores não apresentados nos relatórios, percebeu-se que os mesmos eram retirados das análises de sensibilidade por estarem controlando barras remotas, dessa forma geradores importantes no sistema (e.g., UHEs Itaipu e S. da Mesa) não eram considerados nos testes de sensibilidade. Por outro lado, foi identificado que a retirada desses geradores provocava um descasamento entre matrizes internas do Organon, que levava não só à exibição de valores de sensibilidade em barras equivocadas, como também a sua retenção caso tal valor fosse superior ao limite determinado. 
Após a implementação dessas duas correções, quais sejam, consideração de todos os geradores do sistema nos testes de sensibilidade de tensão, mesmo se por venturas os mesmos estejam controlando barras remotas, e a correção da associação de valores de sensibilidade em barras equivocadas, o teste T2_4b mostrou uma grande evolução em relação aos testes anteriores, T2_1, T2_2 e T2_3. Como consequência, foi possível quase que dobrar a redução global do sistema e, ainda assim, se obter valores de precisão superiores aos testes com menor redução global. Também chama a atenção o grande aumento dos números de agrupamentos de geradores obtidos que passaram de 4, no teste T2_3, para 33, no teste T2_4b. O aumento da redução global do sistema se torna ainda mais significativo quando é obtido com excelentes níveis de acurácia, como é o caso.

Por fim, de forma resumida são exibidas abaixo as principais contribuições já implementadas durante esta dissertação:

- Permitir maior controle de usuário nas opções e parâmetros utilizados durante o processo do cálculo de acurácia;

- Tratamento diferenciado quando uma das barras da região interna possui um conversor conectado;

- Tratamento diferenciado quando uma das barras da região interna possui um transformador defasador conectado, estando este no modo de controle de potência;

- Permitir que todos os geradores do sistema participem dos testes de sensibilidade de tensão, estejam controlando barras remotas, ou não;

- Correção da associação de valores de sensibilidade a barras equivocadas.

Com base na experiência adquirida no desenvolvimento desta dissertação e nos estudos que foram realizados, é possível indicar as seguintes sugestões para trabalhos futuros:

- Avaliar formas alternativas de parametrização da sensibilidade de fluxo em circuitos internos para contingência em circuitos externos: e.g., implementar uma ponderação relativa da sensibilidade de acordo com a capacidade do circuito interno ou com o fluxo externo interrompido; 
- Inclusão de equipamentos de controle de tensão de Compensadores Estáticos e Staticoms nos testes de sensibilidade de tensão;

- Realização de novos testes, considerando contingências que possam submeter o sistema à sub/sobre frequência, analisando o impacto de tal fenômeno nos índices de precisão;

- Possibilidade de se utilizar o sistema equivalente como base para a determinação de regiões de segurança e apontar o enorme potencial de ganho de tempo de processamento;

- Realização de novos testes, considerando outras áreas elétricas para a montagem de regiões de segurança;

- Em sistemas com grande penetração de geração eólica e/ou solar, a implementação de modelos equivalentes para agrupamentos desses geradores poderá permitir resultados de precisão ainda melhores;

- Definição de uma metodologia que permita quantificar as diferenças de acurácia, considerando a adição ou remoção da representação de usinas ou de circuitos fora da rede de supervisão. Tal metodologia poderia permitir a mensuração dos ganhos de representatividade do sistema de uma dada região com a adição de instalações ou redes equivalentes ao sistema supervisório das salas de operação. 
6

\section{Referências bibliográficas}

1. MONTICELLI, A., et al. Real-time external equivalents for static security analysis. IEEE Transactions on Power Apparatus and Systems, v. PAS-98, n. 2, p. 498-508, 1979.

2. STOTT, B.; ALSAÇ, O.; MONTICELLI, A. Numerical testing of power system load flow equivalents. IEEE Trans. on Power Apparatus and Systems, v. PAS-99, n. 6, p. 2292-2300, 1980.

3. STOTT, B.; ALSAÇ, O., MONTICELLI, A. Studies on power system load flow equivalencing. IEEE Trans. on Power Apparatus and Systems, v. PAS-99, n. 6, p. 2301-2310, 1980.

4. TINNEY, W. F.; BRIGHT, J. M. Adaptive reductions for power flow equivalents. IEEE Transactions on Power Systems, v. 2, n. 2, p. 351-359, 1987.

5. MONTICELLI, A. Fluxo de carga em redes de energia elétrica. São Paulo: Editora Edgard Blücher LTDA., 1983.

6. PODMORE, R. Identification of coherent generators for dynamic equivalents. IEEE Trans. on Power Apparatus and Systems, v. PAS97, n. 4, p. 1344-1354, 1978.

7. GEEVES, S. Modal-Coherency Technique For Deriving Dynamic Equivalents. IEEE Transactions on Power Systems, v. 3, n. 1, p. 44$51,1988$.

8. LAWLER, J. S.; SCHLUETER, R. A. Computational Algorithms for Constructing Modal-Coherent Dynamic Equivalents. IEEE Power Engineering Review, v. PER-2, n. 5, p. 30-31, 1982.

9. RAMASWAMY, GANESH N., et al. Synchronic modal equivalencing (SME) for structure-preserving dynamic equivalents. IEEE Trans. on Power Systems, v. 11, n. 1, p. 19-29, 1996.

10.JARDIM, J. L.; LEITE DA SILVA, A. M. A methodology for computing robust dynamic equivalents of large power systems. Electric Power Systems Research, v. 143, p. 513-521, 2017. 
11.DE OLIVEIRA, S. E.M.; DE QUEIROZ, J.F. Modal dynamic equivalent for electric power systems Part I: Theory. IEEE Trans. on Power Systems, v. 3, n. 4, p. 1723-1730, 1988.

12.DE OLIVEIRA, S. E. M.; MASSAUD, A. G. Modal dynamic equivalent for electric power systems part II: Stability simulation tests. IEEE Trans. on Power Systems, v. 3, n. 4, p. 1731-1737, 1988.

13.PRICE, W. W., et al. Testing of the Modal Dynamic Equivalents Technique. IEEE Trans. on Power Apparatus and Systems, v. PAS97, n. 4, p. 1366-1372, 1978.

14.PIRES DE SOUZA, E. J. S.; LEITE DA SILVA, A. M.. An Efficient Methodology for Coherency-Based Dynamic Equivalents. IEE Proceedings C - Generation, Transmission and Distribution, v. 139, n. 5, p. 371-382, 1992.

15. CHOW, J. H. New Algorithms for Slow Coherency Aggregation of Large Power Systems. Systems and Control Theory for Power Systems, v. 64, p. 95-115, 1995.

16. MARINESCU, B.; MALLEM, B.; ROUCO, L. Large-scale power system dynamic equivalents based on standard and border synchrony. IEEE Trans. on Power Systems, v. 25, n. 4, p. 1873-1882, 2010.

17. HPPA. Manual do Usuário do Organon. Rio de Janeiro, 2018. 53 p. Disponível em <htpp://www.hppa.com.br>

18.Lima, L. R.; LEITA DA SILVA, A.M.; JARDIM, J.L.; CASTRO, A.M. SILVA, N.S.M. A Method to compute flexible static equivalents for very large power networks. Anais do VII Simpósio Brasileiro de Sistemas Elétricos (SBSE), 2018. 6p.

19. UNDRILL, J. M.; TURNER, A. E. Construction of power system electromechanical equivalents by modal analysis. IEEE Transactions on Power Apparatus and Systems, v. PAS-90, n. 5, p. 2049-2059, 1971.

20.NATH, R.; LAMBA, S. S.; RAO, K. S. P. Coherency based system decomposition into study and external areas using weak coupling. IEEE Trans. on Power Apparatus and Systems, v. PAS-104, n. 6, p. 1443-1449, 1985. 
21. LARSEN, E.; SWANN, D. Applying Power System Stabilizers: Part I-III. IEEE Transactions on Power Apparatus and Systems, v. PAS-100, n. 6, p. 3017-3046, 1981.

22. PINTELON, R. et al. Parametric Identification of Transfer Functions in the Frequency Domain: A Survey. IEEE Transactions on Automatic Control, v. 39, n. 11, p. 2245-2260, 1994. 